\title{
Recent Advances in Boundary Layer Ingestion Technology of Evolving Powertrain Systems
}

\author{
Dimitra Eirini Diamantidou ${ }^{1, *(\mathbb{D})}$, Md Lokman Hosain ${ }^{2}$ and Konstantinos G. Kyprianidis ${ }^{1}$ (D) \\ 1 School of Business, Society and Engineering, Mälardalen University, 72123 Västerås, Sweden; \\ konstantinos.kyprianidis@mdh.se \\ 2 Hitachi Energy, 72226 Västerås, Sweden; lokman.hosain@hitachienergy.com \\ * Correspondence: dimitra.eirini.diamantidou@mdh.se
}

check for updates

Citation: Diamantidou, D.E.; Hosain, M.L.; Kyprianidis, K.G. Recent Advances in Boundary Layer Ingestion Technology of Evolving Powertrain Systems. Sustainability 2022, 14, 1731. https://doi.org/ $10.3390 /$ su14031731

Academic Editor: Firoz Alam

Received: 6 December 2021

Accepted: 26 January 2022

Published: 2 February 2022

Publisher's Note: MDPI stays neutral with regard to jurisdictional claims in published maps and institutional affiliations.

Copyright: (c) 2022 by the authors Licensee MDPI, Basel, Switzerland. This article is an open access article distributed under the terms and conditions of the Creative Commons Attribution (CC BY) license (https:// creativecommons.org/licenses/by/ $4.0 /)$.

\begin{abstract}
The increasing environmental concern during the last years is driving the research community towards reducing aviation's environmental impact. Several strict goals set by various aviation organizations shifted the research focus towards more efficient and environmentally friendly aircraft concepts. Boundary Layer Ingestion (BLI) is currently investigated as a potential technology to achieve different design goals such as energy efficiency improvement and noise emission reductions in the next generation of commercial aircraft. The technology principle is to place the propulsive unit within the boundary layer generated by the airframe body. Although several studies showed its theoretical benefits, a multidisciplinary nature is introduced in the design phase. This imposes new challenges on the current design tools. An increasing number of publications are focusing on assessing this technology while taking into account interlinks between different disciplines. The goal of this work is to review the current state-of-the-art of BLI evaluation studies. Particular focus is given to the underlying assumptions of each work, the methodology employed, and the level of fidelity of the tools used. By organizing the available work in a comprehensive manner, the up-to-date results are interpreted. The current trends and trade-offs emerging from studies are presented. Through reviewing the ongoing published work, the next steps for further development of the methods that will assess this technology are derived.
\end{abstract}

Keywords: boundary layer ingestion (BLI); propulsion; aerodynamics; engine-airframe interaction; system level assessment

\section{Introduction}

\subsection{Motivation}

The development of industrial activity on an extensive scale over the years has a major impact on the environment. However, public and political awareness led to an increasing environmental concern over the last years. Governments and concerned environmental public groups started discussing on potential solutions. Eventually, measures were taken towards minimizing emissions from the consumption of nonrenewable fuels and noise. In parallel, the global economic growth led to a rapid increase in demand for aviation services. The aviation sector is recognized as one of the main contributors to climate change and noise emissions. Therefore, reducing aviation's environmental impact was one of the most important focus during the last years.

In 2010, the Advisory Council for Aircraft Innovation and Research in Europe (ACARE) set the "Flightpath 2050" vision for European aviation sector. It was envisioned that by year 2050 , advances in aviation technology will allow for a $75 \%$ reduction in $\mathrm{CO}_{2}$ emissions per passenger kilometer, a $90 \%$ reduction in $\mathrm{NO}_{X}$ emissions, and a $65 \%$ reduction in perceived noise compared to that of technology level in 2000 [1-3]. In parallel, NASA (National Aeronautics and Space Administration) identified the goals for three future time frames. The time frames are referred to as $\mathrm{N}+1, \mathrm{~N}+2$, and $\mathrm{N}+3$ goals, which represent the years 
2015,2020 , and 2030, respectively. The NASA N+3 time frame targets to a reduction of $50-60 \%$ in fuel burn, a $75 \%$ reduction in $\mathrm{NO}_{X}$ emissions and reduced noise emission by 42 decibels $(\mathrm{dB})$ compared to that of the year $2000[4,5]$.

To meet these environmental goals, either new aircraft configurations have to be developed or the existing ones have to be improved. The NEWAC (NEW Aero Engine Core concepts) project was carried out within European Union (EU) funding programme and focused on introducing new innovative core configurations to improve the thermal core efficiency [6]. On the other hand, the improvement of the propulsive efficiency was the main task of the VITAL (EnVIronmenTALly Friendly Aero Engine) and DREAM (valiDation of Radical Engine Architecture systeMs) projects; both projects were funded by EU programs. They introduced novel concepts with low specific thrust levels (VITAL project) [7] and open-rotor concepts to minimize the fuel consumption (DREAM project) [8] Research efforts to improve aircraft fuel efficiency often focus on technologies that are applicable to a single subsystem or discipline. However, the current trend in aviation technology is to focus towards radically more fuel efficient and quieter vehicles. The next generation of aircraft is envisioned to further explore the design space by considering not only the propulsion system, but also aspects of the airframe in parallel.

The introduction of alternative energy sources in propulsion systems, such as electric energy stored in batteries offers high potential in reducing environmental impact due to the high efficiency of electric components. Alternative powertrain architectures offer the possibility to disengage the power source from the propulsor, which creates the potential for distributing the propulsion units on different locations of the aircraft. This concept is referred as distributed propulsion and allows the realization of the optimal combination of thrust split between the propulsion units. Electrified propulsion introduces new synergetic propulsion architectures [9] or even new aircraft concepts. These new aircraft concepts take a step forward from the conventional tube and wing design $[10,11]$. Therefore, the introduction of alternative powertrain architectures gives the opportunity to explore novel airframe designs that can improve aerodynamic performance.

\subsection{Alternative Powertrain Architectures}

The classification of the alternative powertrain architectures proposed by Felder [12] arranges the electrified powertrain architectures in different categories. According to Figure 1, electric aircraft powertrain systems can be grouped under three main categories:

1. All-electric architecture: use of solely batteries to power the aircraft without having a thermal engine.

2. Hybrid-electric architecture:

(a) parallel hybrid electric: the propulsion unit is a combination of both batteries and thermal engines that are mechanically connected in a common shaft

(b) series hybrid electric: turboshaft engines and a battery provide the required power, while the thrust is provided by additional propulsors that are connected only to electric motors

(c) series/parallel partial hybrid: the thermal engines and battery provide power but the thrust is provided by both the thermal engines and propulsive units driven by motor

3. Turbo-electric architecture

(a) turbo electric: turboshaft engines provide power, while multiple propulsive units generate the required thrust

(b) partial turbo electric: similar to the turbo electric architecture with the difference of the main engine, which can provide part of the thrust 


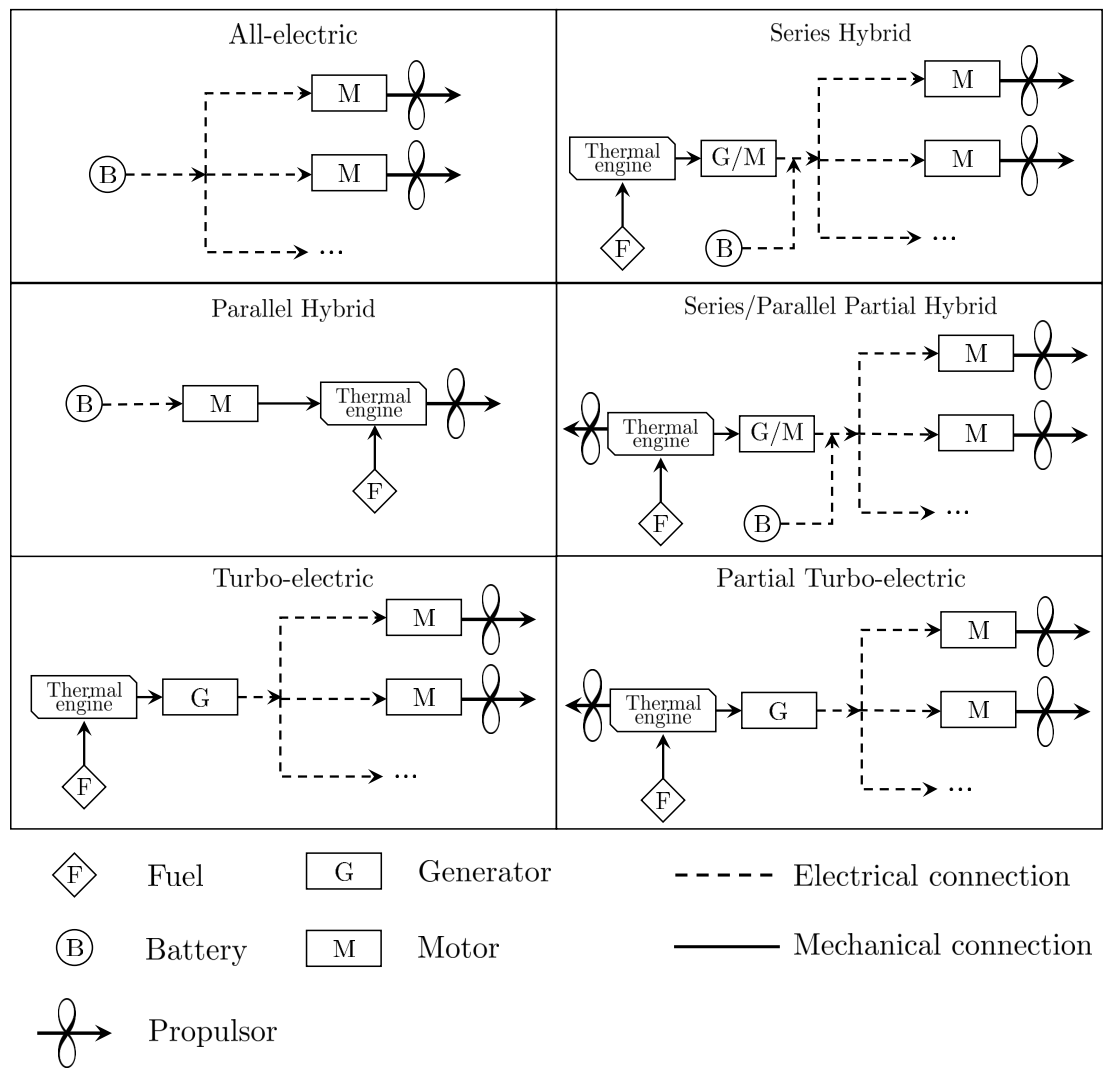

Figure 1. Alternative propulsion architectures definition (adapted from Felder [12]).

\subsection{Boundary Layer Ingestion}

"Boundary Layer Ingestion" (BLI) is a technology used with success in marine propulsion applications [13-15]. The initial BLI concept for aircraft application was presented in 1940s. Smith and Roberts [16] were the first to present a comparison between traditional and BLI propulsors. They introduced a concept that featured two turbojet engines buried in the main wing to be exposed to boundary layer inflow. The presented methodology was adapted later by Leroy Smith [17]. The author used actuator disk theory to calculate the BLI benefit. Then, Plas [18] presented a detailed study on embedded propulsion system employing BLI technologies for a wing aircraft. The study concluded that the benefits of this technology are highly sensitive to the inflow distortion, and hence, fan and duct losses. The authors highlighted that despite the distorted inflow, the technology is very promising in terms of fuel burned reduction.

Typical examples of aircraft concepts are shown in Figure 2. An example of an aircraft with pylon-mounted propulsor (or commonly known as podded propulsor) is presented in Figure 2a. A podded propulsor is considered as conventional installation option and is exposed to nondistorted and uniform flow similar to free-stream conditions. On the other hand, the aircraft concept illustrated in Figure $2 \mathrm{~b}$ is a concept employing the BLI technology. The BLI fan is encircling the aft-part of the fuselage and ingests the boundary layer formed at the fuselage surface forming the propulsive fuselage concept (PFC). The BLI propulsor is exposed to the nonuniform and highly distorted boundary layer flow as it will be further discussed in this work. 


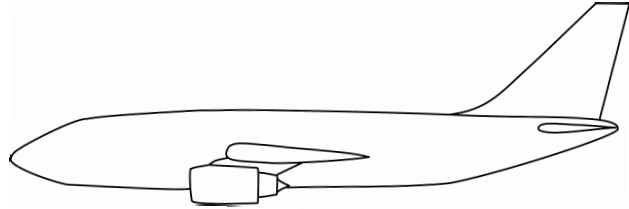

(a)

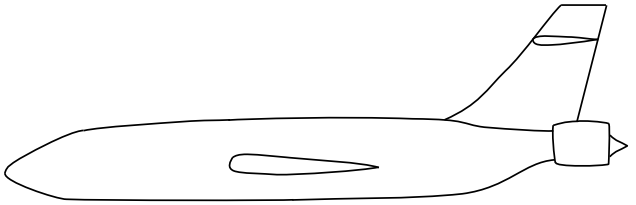

(b)

Figure 2. Typical examples of propulsion mounting options. (a) Aircraft concept with podded propulsor; (b) Aircraft concept with BLI propulsor.

\subsubsection{Benefits}

To present the overall concept aspects of this technology, examples of a BLI fan encircling the aircraft fuselage and a conventional aircraft are illustrated in Figure 3. This illustration was adapted from Rolt and Whurr [19]. The conventional aircraft is presented in Figure 3a. The MIDAP (Ministry-Industry Drag Analysis Panel) Study Group in 1979 [20] worked closely with various specialists on methods of thrust and drag measurements used for flight testing and engine calibration. A comprehensive discussion of the fundamental of thrust and drag forces accounting was presented. As expected, the velocity profile over the wing and fuselage areas presents a momentum deficit due to the airflow passing from the aircraft's body. The drag force, in subsonic flow conditions, comprises of two components: parasite drag and lift-induced drag. The first component includes the skin friction that is the integrated shear stress at the wall, as well as the pressure or form drag arising from the modification of the pressure distribution due to boundary layer growth and flow separation. The second component refers only to aircraft components that are responsible for the lift force generation, because it refers to the drag produced from bodies that redirect air to generate lift. Momentum deficit usually indicates drag force generation. The engine's propulsive jet presents excess momentum as shown in Figure 3a. Excess momentum is the main indication of thrust generation. Depending on the operation of the aircraft, thrust is used to match or overcome the drag force to keep the aircraft in motion.

A BLI concept is presented in Figure 3b. Instead of using the engine's jet excess momentum to compensate the momentum deficit, the BLI propulsor targets in ingesting part of the drag and "filling" the fuselage wake. The wasted kinetic energy is determined by the square of the velocity compared to free-stream conditions. The kinetic energy waste in the aircraft's wake for the BLI aircraft is reduced. Due to reduced wasted kinetic energy, a lower generated kinetic energy is expected for the same net axial force. As Rolt and Whunn stated in their work [19], the propulsion system efficiency is increased when the system must minimize the residual disturbance and kinetic energy in the aircraft's wake. Figure $3 b$ shows a concept in which the BLI propulsor does not fully counterbalance the fuselage momentum deficit. Depending on the selected power provided to the BLI propulsor, the momentum deficit could become excess momentum in some design scenarios.

The rest of the propulsive force required to keep the aircraft in motion is provided by the main engines mounted under the wings. The power split ratio is defined as the ratio between the propulsive power produced by the BLI propulsor and the total propulsive power required. For a higher power split, the power requirements from the main underwing podded engines are less than in the case of conventional aircraft. Hence, the wasted kinetic energy in the propulsive jet is reduced.

The size of main engines is selected based on the powertrain architecture. For a turbo-electric propulsion architecture, the main engines need to provide the power to the BLI propulsor. However, a detrimental effect is the efficiency loss due to the power conversions from mechanical to electrical and power transmission. On the other hand, for a parallel/series hybrid configuration, the power required by the BLI fan can be provided by a battery. Depending on the operational strategy selected, it is possible to downsize the main engines and hence the resulting nacelle and pylon drag. Alternatively, the diameter 
of the main engine can be kept constant and the specific thrust can be reduced resulting in better propulsive efficiency.

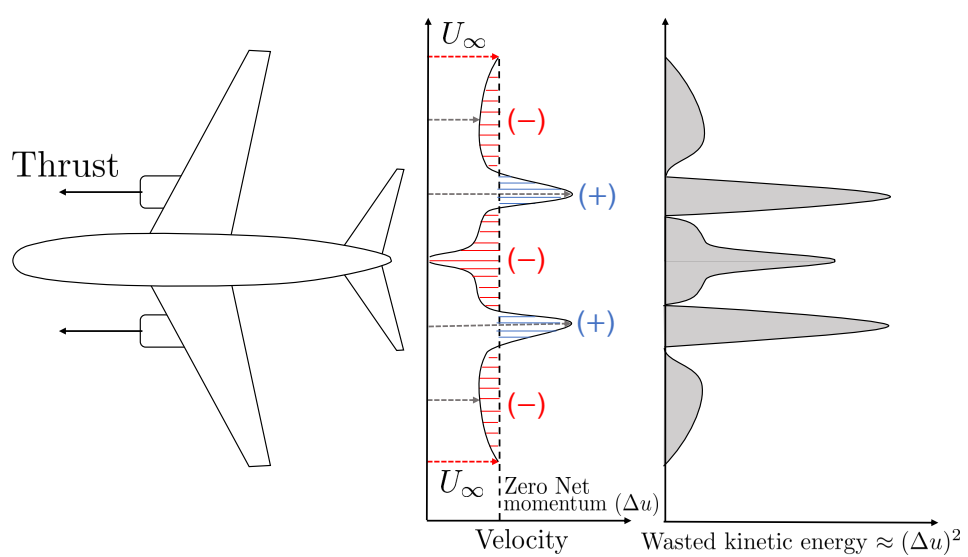

(a)

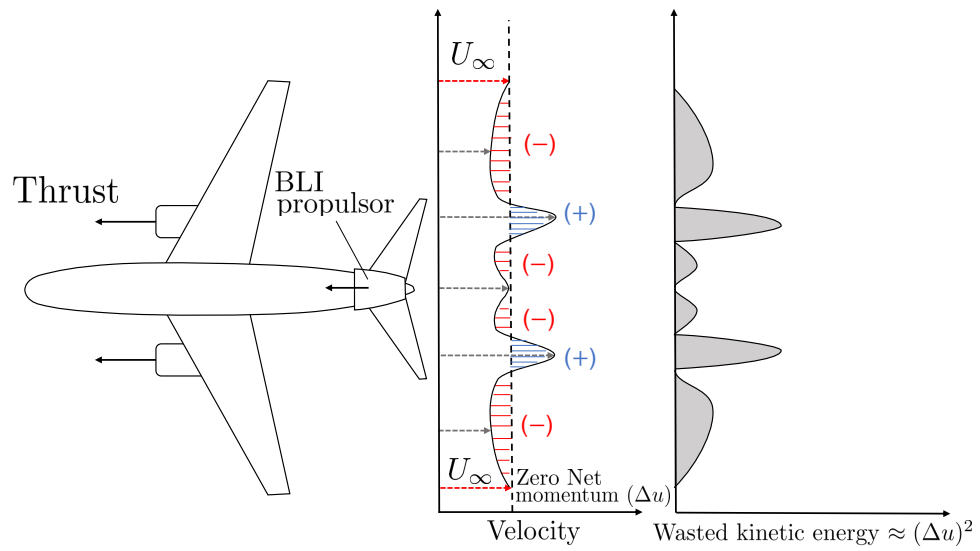

(b)

Figure 3. Qualitative illustration of velocity and wasted kinetic energy distributions for of conventional and boundary layer ingestion aircraft concepts (adapted from Rolt and Whunn [19]). (a) Conventional aircraft; (b) boundary layer ingestion (BLI) aircraft.

\subsubsection{Challenges}

BLI concepts introduce closely integrated airframe and propulsion systems. Therefore, a high level of coupling between airframe and propulsion system is required. When investigating an aft-mounted BLI propulsor, the fuselage aerodynamics and the performance of the BLI propulsor are closely coupled. A BLI design results in a tightly integrated propulsion system, in which the conventional definition of thrust and drag as separate forces will become invalid [21,22]. Placing the propulsor in the boundary layer generated on the fuselage alters the surface forces on the airframe. The drag of the isolated airframe cannot determine the engine thrust requirement anymore.

Furthermore, the ingested flow enters the propulsor at reduced momentum flux, relative to free stream conditions. The altered surface forces and the reduced momentum inflow flux modify the required added power by the propulsor to maintain a given thrust requirement. Therefore, there is a need for a "revised" force bookkeeping scheme to account for both effects to the required added power [21].

Another aspect is that the propulsor is placed in the boundary layer, and thus, there are nonuniform and unsteady inflow conditions. This may lead to circumferential and radial distortion at the fan face. The radial distortion could be managed by designing the 
fan for different conditions over the blade span. However, when circumferential distortion is induced, the fan blades are exposed to different conditions for one fan revolution. This could cause vibrations and part of the fan blades is always operating at "off-design" conditions with reduced efficiency [23]. This effect can cause degraded engine performance, and therefore counterbalance the potential benefits.

Finally, aspects such as the additional weight and drag resulting from the extra components must be carefully taken into consideration when assessing the whole aircraft system.

\subsubsection{Overall}

There are several contributions (positive and negative) when assessing BLI concepts. The designer's main challenge is to develop a "consistent" methodology that meets requirements from each discipline, while demonstrating that the BLI theoretical benefits can be practically realized. Although BLI concepts are investigated on a theoretical level since the 1940 s $[16,17]$, the design and analysis of BLI concepts is still a field of active research. An overview of the aforementioned benefits and challenges is presented in Figure 4. It is the designer's responsibility to account for all of the effects that are caused from the introduction of this technology and to eventually show that, despite the challenges imposed, there is a benefit.

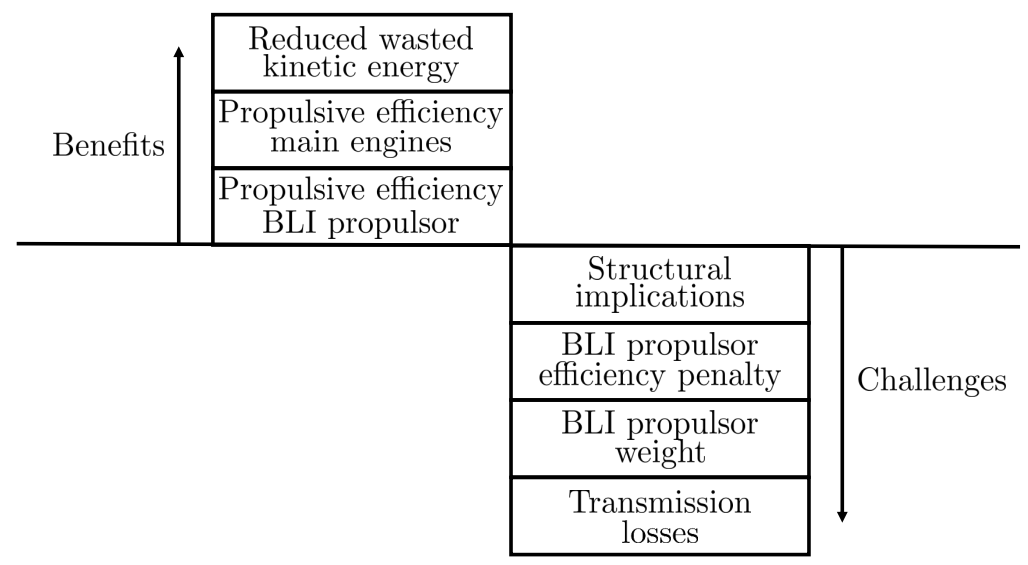

Figure 4. Qualitative stack-up of benefits and challenges for BLI concept.

\subsection{Modeling Approaches}

Various research efforts were focused on determining the conceptual design and quantifying BLI technology's potential benefits. The number of publications per year is shown in Figure 5, using data from the Web of Science [24] and Scopus [25] search engines. During the period of 1940-1990, several publications discussing this technology in marine applications were presented. The publications related to BLI in aerospace applications are increasing throughout the last decade. The modeling of a BLI propulsor requires modifications in existing methods. Each of the research efforts in the available literature is unique in terms of modeling and interaction between the different disciplines. Also, results and trends presented in each publication are relevant to the application investigated, assumptions taken, and level of fidelity of the used tools.

There were some efforts in the past to review the state-of-the-art of BLI modeling approaches. Ferrar and O'Brien [26] focused on reviewing the modeling efforts related to BLI embedded engines. They presented both benefits of embedded engines and BLI engines, while also giving information on the performance analysis and propulsion airframe integration aspects. Hendricks [27] reviewed the up-to-date modeling efforts from NASA projects related to BLI and tried to categorize them by the nature of the interaction between different disciplines: uncoupled, weakly coupled, and coupled methods. A more recent publication from Menegozzo and Benini [28] further investigates different modeling efforts from all research groups as an extension to Hendricks work. The categorization applied is 
based on three different concepts identified: propulsive fuselage concept, distributed fans concept, and rear engines concept. This work is a good example to understand the main trends of BLI modeling strategies adopted in each research group.

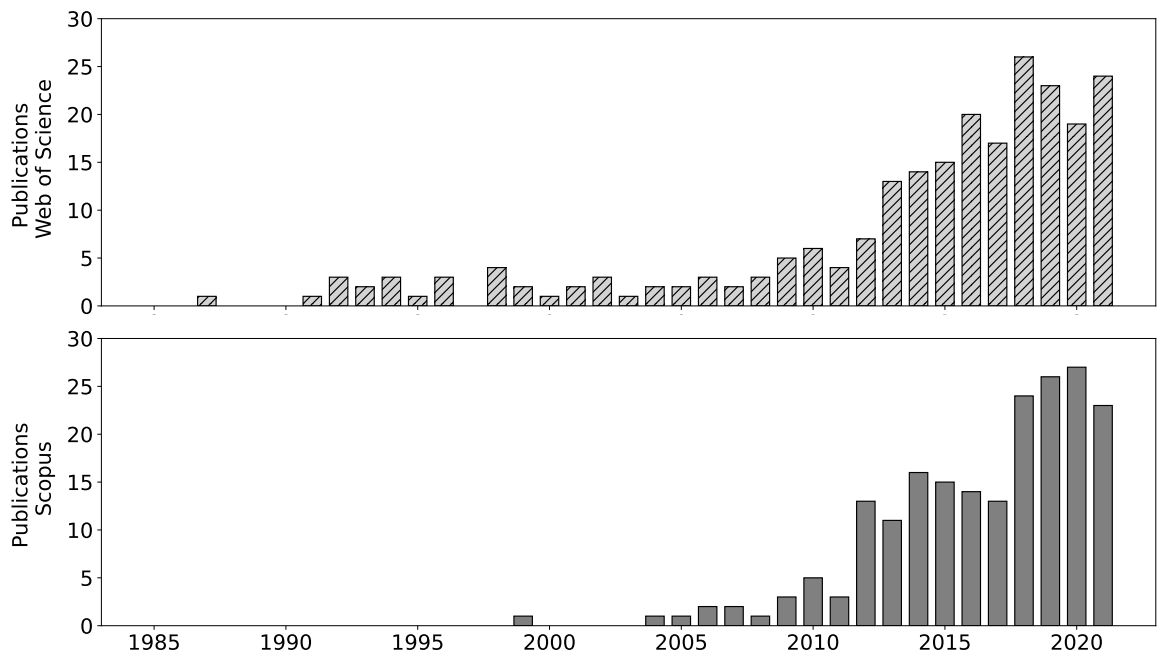

Figure 5. Number of publications related to boundary layer ingestion technology over years.

According to the authors' knowledge, there is no similar work that reviews in a critical manner the results and trade-offs presented in different BLI assessments at aircraft system level. The aim of this work is to review the current state-of-the-art of BLI concepts giving particular focus to the interpretation of the results presented, the underlying assumptions of each modeling effort, the level of fidelity of the tools and, lastly, the integrated methodology employed. By analyzing a large amount of existing studies, this in-depth review arrives to new conclusions and gives recommendations for best practices to be used in future conceptual design assessment efforts for BLI.

\subsection{Structure of the Review Paper}

This article is divided into six main sections. Section 1 presents the motivation of this work, a description of potential electrified powertrain systems, and an overview of the main benefits and challenges when employing BLI technologies. Section 2 gives an overview of the figures of merit used in the available literature to evaluate and compare the BLI concepts. Then, the remaining sections are organized per family of concepts presented in the open literature. The concept families adopted are similar to the ones presented by Menegozzo and Benini [28]. Section 3 presents studies focusing on hybrid wing body (HWB) concepts. Section 4 presents publications on the rear mounted engine(s) concept. These studies are based on conventional gas turbine engine(s) mounted in the aft-part of the fuselage to ingest the boundary layer. Section 5 focuses on the studies using the PFC. Finally, Section 6 summarizes the authors' main findings and a set of suggestions for future research are provided.

\section{Performance Metrics}

Due to the increased system complexity when using BLI technologies, it is important to predict the potential efficiency gains and to understand their physical origins. There are some typical metrics that are used to describe the aircraft performance. These include the specific fuel consumption (SFC), propulsive efficiency and block fuel burned. However, according to Hendricks [27] traditional metrics might be inadequate merit functions for BLI technologies. Therefore, the establishment of performance metrics that show the technology's benefits and can compare different concepts based on the potential gains is of 
primary importance. In this section, different performance metrics will be presented along with their basic mathematical derivations.

\subsection{Specific Fuel Consumption}

A common metric used widely in the open literature when assessing propulsion performance is the SFC. There are two definitions of the SFC depending on the output of the engine under investigation. The first definition is based on the thrust output and the metric is named thrust specific fuel consumption (TSFC). The TSFC metric is calculated by Equation (1) [29].

$$
\mathrm{TSFC}=\frac{\dot{m}_{\text {fuel }}}{F}
$$

where $\dot{m}_{f u e l}$ is the engine fuel flow and the $F$ is the thrust output. The TSFC expresses the fuel efficiency of an engine with respect to thrust output. Its units are fuel consumption per unit of thrust. The SFC can be also calculated with respect to the power output forming the power specific fuel consumption (PSFC) and the definition is given in Equation (2) [29].

$$
\text { PSFC }=\frac{\dot{m}_{f u e l}}{P}
$$

In Equation (2), $P$ is the power output. PSFC units can be expressed fuel consumption per unit of power. Both metrics can be related since power of an engine equals the thrust times the flight velocity $\left(P=T \cdot V_{\infty}\right)$. Their relationship is shown in Equation (3).

$$
\mathrm{TSFC}=\mathrm{PSFC} \times V_{\infty}
$$

SFC is one of the most important metrics used in aviation because it can be directly linked to the overall efficiency of the engine. This metric is showing how efficient a engine design converts chemical to mechanical energy. It is directly affected by the engine design as well as the engine operating conditions. Therefore, for flight velocity and altitude of different engine families, SFC presents different levels. However, when performing parametric or sensitivity studies varying the engine design, the SFC provides a clear indication of how efficient this design is. Therefore, it is widely used during the conceptual design of new engine concepts.

However, this metric gives information only about the engine performance and the fuel efficiency. Therefore, it does not take into account installation effects such as additional drag and weight when increasing the engine size. Also, for hybrid-electric concepts, only the fuel chemical energy is taken into account, whereas the electrical energy is not considered. Alternative definitions were introduced in the open literature. To account for the installation effects, the installed TSFC can be estimated by using the net propulsive force (NPF) that considers all installation effects. Regarding hybrid-electric concepts, the thrust specific power consumption by Seitz et al. [30] as defined in Equation (4).

$$
\mathrm{TSFC}=\frac{P_{\text {supply }}}{T}=\frac{V_{\infty}}{\eta_{o v}}
$$

In this metric, $P_{\text {supply }}$ refers both to the electrical and chemical power provided by the propulsion architecture. Additionally, $\eta_{o v}$ includes both the efficiency of the thermal engine as well as the efficiency chain from the electrical power system.

\subsection{Propulsive Efficiency}

Propulsive efficiency is one of the metrics that distributed propulsion concepts often rely on to demonstrate their potentials. BLI technologies are considered within the same category of concepts, and therefore, several studies tried to use the same efficiency definition. Smith [17] and Plas [18] evaluated BLI benefits using the propulsive efficiency definition, which is given by Equation (5). 


$$
\eta_{\text {prop }}=\frac{F V_{\infty}}{\left[\left(\dot{m}_{\text {exit }}\right) V_{\text {exit }}^{2}-\dot{m}_{\text {inlet }} V_{\text {inlet }}^{2}\right] / 2} \approx \frac{2 V_{\infty} / V_{\text {exit }}}{1+V_{\text {inlet }} / V_{\text {exit }}}
$$

In Equation (5), $F$ is the thrust produced, $V_{\infty}$ is the freestream velocity, $V_{\text {inlet }}$ is the propulsor inlet velocity, $V_{\text {exit }}$ is the propulsor exit velocity, $\dot{m}_{\text {inlet }}$ is the propulsor inlet mass flow and finally, $\dot{m}_{\text {exit }}$ is the propulsor exit mass flow. However, this definition remains controversial when applied to BLI concepts. Although the propulsive efficiency is increased because $V_{\text {inlet }}<V_{\infty}$, both authors acknowledged that the result could exceed unity, which leads to the application of the term propulsive coefficient instead.

However, Bevilaqua and Yam [31] presented a different approach based on a physicsbased analysis to investigate the BLI effect on the propulsive power and propulsive efficiency. They investigated a concept in which a propeller accelerated the wake of a blunt body back to the freestream velocity and derived that the useful thrust power by the propeller $\left(P_{\text {out }}\right)$ is the thrust $(T)$ times the inflow velocity of the slipstream $\left(V_{w}\right)$ as shown in Equation (6).

$$
P_{\text {out }}=F \times V_{w}
$$

while the kinetic energy added by the propeller to the air is derived by Equation (7).

$$
\Delta K E_{i n}=(1 / 2) \dot{m}_{\text {inlet }}\left(V_{\infty}^{2}-V_{w}^{2}\right)
$$

Finally, the propulsive efficiency can be calculated as per Equation (8).

$$
\eta_{\text {prop }}=\frac{F \times V_{w}}{(1 / 2) \dot{m}_{\text {inlet }}\left(V_{\infty}^{2}-V_{w}^{2}\right)}=\frac{2}{1+\left(V_{\infty} / V_{w}\right)}
$$

\subsection{Brèguet-Coffin Range Equation}

Another important analytical estimation of the mission range is based on the Brèguet equation [32] or also known as Brèguet-Coffin [33] equation. For the interested reader, a discussion on the origin of the equation was presented by Cavcar [34]. For the BLI technology, it was used by Bevilaqua and Yam [31] as well as Seitz et al. [35]. An adapted definition of the Brèguet-Coffin equation was presented for the cruise portion since this mission phase is dominant in the majority of long haul aircraft families. The used form of the Brèguet-Coffin equation is shown in Equation (9).

$$
R=V_{\infty} \frac{F}{(1 / 2) \dot{m}_{\text {inlet }}\left(V_{\infty}^{2}-V_{w}^{2}\right)} \eta_{f u e l} \frac{h}{g} \frac{L}{D} \ln \frac{W_{\text {start }}}{W_{\text {end }}}
$$

According to the authors, $R$ is the mission range, $\eta_{f u e l}$ is the efficiency with which the engine converts the chemical energy of the fuel into the kinetic energy of the jet, $g$ is the gravitational constant, $h$ is the energy density of the fuel, $L / D$ is the lift to drag ratio, and $W_{\text {start }}$ and $W_{\text {end }}$ are the weight of the aircraft at the start and end of the cruise mission phase, respectively.

\subsection{Power Saving Coefficient}

As mentioned before, the interactions between airframe and propulsion components within BLI concept made it impossible to assess their benefits by using the conventional drag and thrust force bookkeeping scheme. Smith [17] was the first to introduce a new performance metric trying to tackle the aforementioned challenge. This metric is very popular among the research community and is called power saving coefficient (PSC). Its mathematical formula is presented in Equation (10).

$$
\text { PSC }=\frac{P_{\text {shaft }_{B L I}}-P_{\text {shaft }}}{P_{\text {shaft }_{B L I}}}
$$


$P_{\text {shaft }}$ iLI is the power required from the BLI propulsor and $P_{\text {shaft }}$ is the power required from a conventional propulsor to achieve the same net force $\left(F_{n e t}\right)$. The main concept behind PSC is to show the lower power requirement in the case of BLI concept without using the ill-define forces of drag and thrust. The PSC can be used to evaluate the performance of the BLI concept in different operating conditions, depending the value of $F_{n e t}$. For cruise condition, $F_{n e t}$ must be equal to zero. On the other hand, $F_{n e t}$ can be positive or negative indicating deceleration or acceleration respectively. Therefore, it is important that the PSC is computed for the same $F_{n e t}$ level in both BLI and conventional propulsor to consistently compare the shaft power required in each case. Smith [17] performed a series of studies for different wakes by varying parameters affecting the wake shape and presented the computed PSC. The results showed that BLI concepts can theoretically save up to 50\% power compared to that of conventional propulsors.

For system level analysis, it would be interesting to take into account the propulsive power from the main conventional engines when calculating the PSC. A similar approach was followed by Hiebl et al. [36] where the propulsive power of the main propellers was included in the PSC metric along with the BLI propeller. The total propulsive power needed for a conventional and BLI aircraft could be calculated and give insights on the BLI benefit. However, PSC does not give any insight on the additional weight needed to realize this concept and its impact to the overall aircraft performance. Therefore, it should be treated carefully when making conclusions about the potential BLI benefit.

An alternative approach was proposed by Blumenthal et al. [37]. They presented a study that examines the potential benefits in the propulsion and aerodynamic systems in BLI configurations. In the computational fluid dynamic (CFD) studies conducted, an axial force coefficient and a net propulsor coefficient were calculated. The BLI and non-BLI cases were compared based on the net power coefficient, which is calculated from Equation (11).

$$
C_{P_{K}}=\frac{P_{K}}{q_{\infty} V_{\infty} S_{r e f}}
$$

$P_{K}$ is the net mechanical power, $q_{\infty}$ is the freestream dynamic pressure, $V_{\infty}$ is the freestream velocity, and $S_{r e f}$ is a geometry reference area. The authors use a metric similar to the PSC to evaluate the BLI benefit:

$$
\text { BLI benefit }=\frac{\left(C_{P_{K}}\right)_{n o n-B L I}-\left(C_{P_{K}}\right)_{B L I}}{\left(C_{P_{K}}\right)_{n o n-B L I}}
$$

where $\left(C_{P_{K}}\right)_{n o n-B L I}$ is the axial force coefficient for non-BLI configuration, and $\left(C_{P_{K}}\right)_{B L I}$ is the axial force coefficient for BLI configuration.

\subsection{Net Propulsive Force}

The NPF and net propulsive coefficient $\left(C_{F}\right)$ are two metrics used instead of the traditional thrust and drag forces or coefficients to evaluate the forces acting on a BLI integrated propulsor and airframe. These metrics were used widely in coupled aeropropulsive modeling efforts in which an interface between the aerodynamic and propulsion models had to be established. Depending on the methodology used to model the BLI propulsor, the mathematical derivation of the NPF should be modified. This metric is the most common in PFC, since it gives a clear indication of the BLI propulsor size and the rest thrust required by the main under-wing engines. Gray et al. [38] proposed a mathematical formula for the NPF calculation using a body-force zone method to model the BLI propulsor, which is shown in Equation (13).

$$
\mathrm{NPF}=\iint_{S}\left(\left(\left(p-p_{\infty}\right) \hat{n}+\vec{f}_{\text {visc }}\right)\right) d S+\left(\vec{F}_{B L I} \times \hat{n}_{B L I}\right)
$$

where $p$ is the static pressure, $p_{\infty}$ is the freestream static pressure, $\hat{n}$ is the normal vector, $\vec{f}_{\text {visc }}$ is the local viscous force on an infinitesimal surface element and $F_{B L I}$ is the BLI force contribution acting on the BLI zone selected within the model. Each force component 
is integrated along the surface of the fuselage and BLI nacelle, based on the geometry considered in the aerodynamic model. Similarly, the NPF coefficient can be derived using the traditional formula in Equation (14).

$$
C_{F}=\frac{2}{\rho_{\infty} V_{\infty}^{2} S_{r e f}}\left[\iint_{S}\left(\left(\left(p-p_{\infty}\right) \hat{n}+\vec{f}_{\text {visc }}\right)\right) d S+\left(\vec{F}_{B L I} \times \hat{n}_{B L I}\right)\right]
$$

where, $\rho_{\infty}$ is the freestream air density, $V_{\infty}$ is the freestream velocity and $S_{r e f}$ is a geometry reference area. Another approach that can be used is to model the BLI fan as a black box as presented by Gray et al. [39]. Appropriate boundary conditions are selected on the fan face and fan exit. The term $\left(\vec{F}_{B L I} \times \hat{n}_{B L I}\right)$ is modified to the boundary conditions exchanged between the propulsion and aerodynamic model. The mathematical derivation is shown in Equation (15).

$$
\begin{aligned}
\mathrm{NPF}= & \underbrace{\iint_{S_{1}}\left(p \hat{n}+\vec{f}_{\text {visc }}\right) \cdot \hat{x} d S}_{F_{\text {fuselage }}}+ \\
& \underbrace{\iint_{S_{2}}\left(p \hat{n}+\vec{f}_{\text {visc }}\right) \cdot \hat{x} d S-\iint_{S_{3}} \rho_{3} u_{3}^{2} d S+\iint_{S_{4}} \rho_{4} u_{4}^{2} d S}_{F_{\text {propulsor }}}
\end{aligned}
$$

where $S_{1}$ corresponds to the fuselage surface, $S_{2}$ corresponds to the BLI aft propulsor surfaces and $S_{3}, S_{4}$ correspond to the fan face and exit respectively. The total force decomposed into two contributors the $F_{\text {fuselage }}$ and the $F_{\text {propulsor }}$ to get intuitive indications in the calculated results. However, these two forces cannot by directly related to terms such as fuselage drag, nacelle drag, and thrust separated.

\subsection{Bare Propulsive Fuselage Efficiency Factor}

After conducting an evaluation assessment for all applicable figures of merit [22], Seitz et al. [35] presented a new efficiency factor for their PFC. This new efficiency definition can be used either to compare different BLI propulsor geometries or as an objective in an optimization study and it is given by Equation (16).

$$
f_{n, P F C, \text { bare }}=\frac{N P F_{P F C, \text { bare }} \times V_{\infty}}{P_{\text {disc }, F F}}
$$

where the $N P F_{P F C \text {,bare }}$ is the NPF calculated from CFD simulations, $V_{\infty}$ is the flight velocity and $P_{d i s c, F F}$ is a positive value and represents the ideal power added by the Fuselage Fan (FF). This metric can take both positive and negative values depending on the NPF calculation.

\subsection{Exchange Rates}

Exchange rates are used widely when a first-order estimation of the fuel burned is calculated [40-42]. The propulsion system performance exchange rates show the effect of parameters emerging from new engine design concepts on the typical fuel burned over an aircraft mission. The effect on the mission fuel burned is calculated in Equation (17).

$$
\Delta F B \%=\sum_{i=1}^{k} \frac{\partial F B_{X_{i}}}{\partial X_{i}} \times \Delta X_{i} \%
$$

In Equation (17), $\triangle F B \%$ represents the percentage difference of the fuel burned compared to that of a reference aircraft, $k$ is the number of parameters $X_{i}$ considered, $\partial F B_{X_{i}} / \partial X_{i}$ is the exchange rate and finally $\Delta X_{i} \%$ is the percentage difference of the parameter $X_{i}$ compared to that of a reference aircraft. Typically, the parameters taken into consideration are the TSFC at various operating points, additional weight and additional drag. The exchange 
rate is usually calculated by imposing a $1 \%$ variation of the parameter considered, and then estimating the effect on the fuel burned.

This approach is considered useful when a first estimation of the fuel burned of several different design alternatives is needed, which is typical for initial aircraft conceptual design. This is because it considers both performance and installation effects.

However, for later stages of design mission-level analysis including the aircraft envelope at a business case range is required. An accurate estimation of the fuel burned and total fuel burned can be calculated accounting for both the performance benefits from the BLI concept as well as potential weight penalty and conversion or transmission losses when introducing electric power system components.

\section{Hybrid Wing Body (HWB) Concepts}

NASA initiated several studies as a part of the Ultra Efficient Engine Technology Program Propulsion Airframe Integration [43]. These studies were focused on the implementation of HWB concept, also commonly known as the blended-wing body (BWB) concept. Kim [10] published an overview on distributed propulsion systems as a part of the work conducted in NASA to develop new concepts and technologies. He mentioned in his work that to achieve the goals, the research focus should be shifted towards concepts that utilize airframe and propulsion interaction. Furthermore, the author highlighted that such effects must be taken into consideration from the early stages of conceptual design to achieve maximum benefits.

Boeing initiated an iterative design process to achieve low noise levels and reduced fuel burn. Through this design work [44,45], they created a concept aircraft SAX-40 (silent aircraft experimental) that formed the basis for numerous studies. Boeing further developed this aircraft concept into the N2A-EXTE [46]. This concept was based on a BWB design with podded engines to avoid ingesting boundary layer. Later, several studies from NASA focused on a concept called N2B [47] with multiple number of conventional high-bypass turbofan engines that takes advantage of the boundary layer ingestion technology by embedding the engines within the hybrid fuselage. When embedding the main engines, the main goal is to expose the fan in the boundary layer. For the core, it should be avoided to ingest the boundary layer. This concept was targeting to meet the N+2 NASA goals.

\subsection{N2B Concept}

Tong et al. [48] compared a podded engine and an embedded BLI engine for a HWB cargo freighter of $6000 \mathrm{~nm}$ range based on the N2A and N2B concepts. The NPSS (Numerical Propulsion System Simulation) [49] performance simulation tool was used and the podded engine was modeled for a range of 1.4 to 1.7 fan pressure ratio (FPR). Also, engine mechanical design was conducted for different cases. The podded-engine system included two engines in the HWB aircraft, while the embedded one included a three-engine configuration with a total of nine fans. The WATE (Weight Analysis of Gas Turbine Engines) software tool developed by NASA [50] was used to estimate the engine weight while assuming the use of advance materials in each component. The authors were able to make estimations on the fuel burn benefits for the two concepts by conducting mission and sizing analyzes. The results showed that N2A had a $29 \%$ fuel burn reduction and N2B had a $25 \%$ fuel burn reduction when compared to the current cargo freighters. Unfortunately, these numbers cannot clarify the actual benefit of the BLI concept. Finally, noise estimations were conducted that showed that the N2B concept can achieve lower noise emissions.

Kim et al. [47] conducted detailed CFD calculations for NASA's N2B concept coupled with a turbofan engine model. The total pressure recovery at the engine fan face was calculated by CFD and it was provided to the engine model. The engine boundary conditions at the engine fan face and exit were required for the CFD calculations and they were obtained from the engine model. The authors used the NPSS engine tool [49]. For the CFD simulations, a finite-volume Navier-Stokes solver was used. For the initial CFD boundary conditions, the density and velocity were extrapolated to impose a static back 
pressure at the engine exit that will match the target mass flow rate. The authors noted that a direct coupling of the inlet and full annulus fan blades would give more accurate and realistic results, but the computational cost required for this simulation was considerably large. The authors also used parametric geometry to perform sensitivity and optimization studies to minimize the distortion of the inlet flow. The results of this study showed that when comparing the clean wing with the N2B concept the coefficient of lift $\left(C_{L}\right)$ for the BLI aircraft was increased for a constant angle of attack (AoA). Furthermore, when comparing the boundary layer profile of the clean with the N2B concept, it was observed that the N2B concept has a higher boundary layer thickness near the inlet. Finally, the results showed that shock waves and flow separations occurred on the upper area of the engine nacelle. Therefore, the authors concluded that this concept results in strong engine-airframe interactions that were impossible to estimate a priori and that the simulations showed considerable differences from the clean wing concept.

Hardin et al. [40] study was based on the N2B aircraft concept and developed an analytical engine thermodynamic model in NPSS [49]. They included a new BLI module within the model to be able to capture important trends while accounting for the engine-airframe interaction. They proposed a new method to handle inlet and outlet conditions within the engine model. The boundary conditions for the inlet and outlet should be applied directly from the properties calculated from the flow field of the airframe. The ingested drag was calculated using data available from Kawai et al. [46]. Using the 1D theory developed by Smith [17], the authors were able to calculate the propulsive efficiency benefit for several architectures with different number of engines and inlet aspect ratio. The benefit in propulsive efficiency and TSFC was cross-compared with the corresponding baseline architecture (podded engines) and it was converted in mission fuel burn benefit using aircraft trade factors of all aspects such as BLI, nacelle weight, nacelle drag, etc. The overall benefit achieved was $4.5 \%$ for five engines and $3 \%$ for three engines. The authors concluded that a distortion tolerant fan design is important to gain more realistic assessments. Finally, another important factor in their studies is the consistent accounting for the impact of inlet and engine on the airframe design.

\subsection{N3-X Concept}

While N2B concept studies showed useful insights, to meet the N+3 goals, drastic changes in the propulsion system were necessary. The initial conventional propulsion system was replaced with a row of fans driven by superconducting electric motors [51]. The power to drive the electric motors was provided from two wing-tip mounted superconducting generators driven by gas turbines. This component distribution was selected in such a way to keep the fans embedded in the upper surface of the fuselage and place the conventional gas turbines near the wing tip and exposed to undistributed air flow. The N3-X concept is design for 7500nm and entry into service (EIS) 2050. The propulsion system can be identified as a turbo-electric architecture according to the definition presented in Section 1.

Felder et al. [51], introduced a common nacelle for all electrically driven fans. This concept was thoroughly investigated by a number of different publications, it is known as N3-X and it is presented in Figure 6. The single box nacelle was selected to minimize the interference drag between nacelle and fuselage. The number of fans was directly related to the selection of FPR. The authors recognized that the vehicle concept under examination could greatly benefit from better propulsion system integration. Therefore, an estimation of the boundary layer profile was obtained using simple flat plate equivalent of the upper airframe surface. They concluded that using the freestream velocity will overestimate the ram drag by $1.8 \%$ of the net thrust. The authors stated that the importance of this investigation was to show the highly coupled nature of airframe and propulsion system within this concept and not the actual differences. Therefore, they recognize that the uninstalled performance of such propulsion system will lead to inaccurate results. Furthermore, the use of multiple BLI fans across the upper aircraft surface gives the 
possibility to fill the wake across the entire span of the aircraft. However, some of the potential disadvantages identified were the higher component weight that comes with the use of turbo-electric architecture, higher complexity and, lastly, possible nonlinear aircraft control laws due to interactions with external aerodynamics and propulsion system.

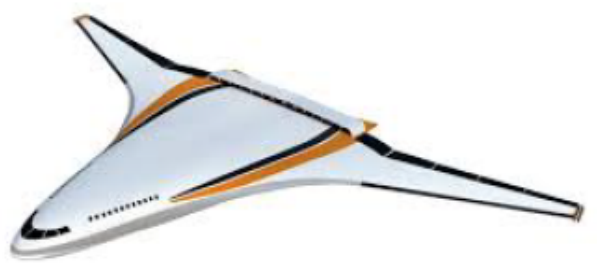

Figure 6. N3-X concept's artistic impression, as presented in [52] and described by Felder [51].

The N3-X configuration was further investigated by Felder et al. [53], with respect to different design FPR. The boundary layer estimation was based on a 3D CFD study performed on the previous N2A-EXTE concept by Boeing. The CFD results were converted to mass-averaged total pressure and Mach number profiles for each chord length. These profiles were further normalized with respect to freestream Mach number and total pressure to be used in similar flight conditions. Taking into account the anticipated technology trends and the loss of efficiency due to boundary layer distorted flow, the efficiency penalty of the examined fans was assumed to be $1 \%$. The authors highlighted that the design process must be done in such a way to account for the installed performance of the propulsion system when using boundary layer technologies. They also noted that the calculation of the boundary layer for different Mach numbers and AoA was significant.

A whole system level study of the HWB concept was performed firstly by Gladin et al. [54]. Since there were no available data for a HWB aircraft, the authors built a "baseline" HWB aircraft using the Boeing N2A HWB aircraft. The HWB 300 passenger aircraft model with BLI technologies was selected to exist within the N+2 timeframe. Furthermore, the engine selected was represented by an ultra-high bypass turbofan model. Different operating points were taken into account during the simulations. The HWB flow field and boundary layer profile were obtained by a previous study performed by NASA [47]. The boundary layer thickness was computed in different flight conditions by scaling the original cruise profile. For the rest flight conditions, the authors applied the similarity assumption to obtain the boundary layer profile. The authors assumed that the installation drag was $50 \%$ of the ram drag for this study. For the thermodynamic cycle calculations, the authors selected to perform two different studies assuming $1 \%$ and $3 \%$ fan efficiency penalty. The results of this study showed that the actual trade-off was between the increase in the propulsive efficiency and the thermal efficiency penalty due to the lower pressure recoveries. Depending on the FPR levels, the BLI case resulted in an $2.4-6 \%$ improvement in TSFC. Finally, by performing sensitivity studies with two sets of possible engine penalties, the authors showed that the engine design was greatly affected by the assumed negative impact. Therefore, they highlighted the importance of estimating the imposed penalties due to BLI.

Liu et al. [55] used the N3-X HWB aircraft as a baseline for their study. They developed a BLI model based on computational simulations for different inlet conditions. They employed a weight estimation and thermal cycle model to assess the weight and performance of the propulsion system. The authors were able to show fuel burn benefits assuming superconducting system and distortion tolerant fan. They highlight that these assumptions are challenging and need to be carefully selected to examine these concepts. They also stated that the investigation of the number of fans and related design choices are important variables in the conceptual design. The authors published a new study later [56] and focused on developing a method to estimate the impact of inlet flow distortion. The 
fuel consumption benefit was lower and the authors concluded that new novel fan blade designs must be investigated for such concepts.

Valencia et al. [57] presented a methodology that enables the assessment BLI concepts while optimizing the system to be less affected by distortion and intake pressure losses. The baseline aircraft used was the N3-X, and the optimum thrust split between different propulsors was investigated for maximum benefits. The study focused on the performance analysis while sizing and aircraft performance were not investigated. The authors recognized that the important parameters affecting the system are the thrust split, height of the capture sheet, number of propulsors and propulsor pressure ratio. In a latter stage of this work, Valencia et al. [58] developed a model using the parallel compressor approach to estimate the distortion and the detrimental effect of intake pressure losses. The parallel compressor theory splits the propulsor inflow into two zones: a low velocity zone and a relatively high velocity zone. This way more accurate performance estimations were acquired. However, this approach neglects circumferential distortion and total temperature distortion while the exit static pressure was uniform. The authors were able to make more accurate estimations on the fan power needed when the inflow distortion changes. Therefore, new results on the optimum thrust split ratio and number of propulsors were found.

A method to calculate the system performance of BLI concept was presented by Ochs [59]. This method was based on isentropically expanding CFD results to freestream conditions. The method was applied on the N3-X aircraft concept and the results showed good agreement with Massachusetts Institute of Technology (MIT) wind-tunnel experiments [60]. The propulsive efficiency benefit calculated was $4.2 \%$ for the BLI concept compared to a conventional propulsion system. The authors highlighted the importance of an aero-mechanics model that will enable more detailed assessments.

Cousins et al. [61] presented a work focusing on the design of a distortion tolerant BLI fan. The authors recognized the importance of development of design methods of turbomachinery elements to ensure efficiency operation under highly-distorted inflow. Distortion-tolerant fan designs ensured the positive impact of BLI technology on the system-level analysis. The authors investigated the integrated inlet/rotor behavior using a designed inlet by Florea et al. [62,63]. Two aspects highlighted by the authors were the mechanical excitation due to the rotor blades exposed to circumferential distortion leading to mechanical failure and high incidence angle causing stall. The inlet design was refined to minimize the distortion levels to enable the mechanical design as well as improve the fan operability. As a first step, a reference blade from a conventional podded propulsor was examined under BLI inflow conditions. The authors examined the Goodman and Campbell diagrams and concluded that this design was inadequate for BLI inflow. The main requirement for BLI design was structural integrity while keeping good performance levels. The authors used the blade thickness as a design parameter while reshaping the leading and trailing edges of the blade to be able to perform under varying incidence angle and Mach number. The new distortion-tolerant blade design showed good performance both in mechanical analysis and when it was tested in the NASA Glenn Wind Tunnel [64-66].

Goldberg et al. [67] presented a work flow to estimate BLI system performance for both design and off-design conditions. The authors developed a framework that uses boundary layer theory with an 1D propulsion performance tool. They presented a thrust and drag bookkeeping scheme that was based on the definition of NPF. The off-design simulations were based on performance maps created within the propulsion performance tool. Because the authors took into account the captured boundary layer for off-design operating points, a matching process was developed to match the mass flow of the propulsor inflow to the mass flow required by the propulsion system. The methodology was applied on the N3-X that was used for demonstration. The authors selected to size all propulsors for the same NPF at one design point. However, the performance for each propulsor was different depending on the operating point because of different inflow characteristics in different locations. 


\subsection{Other Relevant Research}

Mantič-Lugo et al. [68] investigated the aerodynamics of a transonic HWB concept featuring a BLI propulsion system. The authors used a 2D CFD model of a RAE 2822 airfoil in cruise conditions to assess the BLI benefit and highlight the complexities arising from such configurations. The authors presented a preliminary parametric analysis while varying the mass flow ratio (MFR), Mach number, AoA, and various geometrical parameters related to the engine nacelle. They used the definition of propulsive efficiency derived from Felder et al. [53] to estimate the benefit in TSFC. The authors highlighted the strong coupling between engine and airframe when varying the MFR. AoA and Mach number affects the thickness of boundary layer and therefore the ingested drag. Finally, the authors concluded that the design process of such a concept requires a multiobjective optimization to find an optimal between aircraft aerodynamics and propulsion system performance.

Budziszewski and Friedrichs [69] identified the need for a fast computing tool that can conduct performance analysis of a single BLI propulsor decoupled from the aircraft design process. The authors employed the parallel compressor approach to model the BLI propulsor. There were two concepts under investigation; one featuring a propulsive fuselage and one using a HWB concept. The boundary layer data were obtained from the XFOIL analysis tool [70] for 2D subsonic airfoils. The authors used the PSC as a figure of merit. The results showed a PSC of $1-4 \%$ at the BLI propulsor level depending on the thrust and altitude levels. Furthermore, PSC was lower for higher altitudes because of higher exit velocity to compensate for the decreased density.

Gao and Smith [71] presented a multidisciplinary aircraft design and analysis environment called GENUS in their work and demonstrated its capabilities by assessing a BLI HWB aircraft. Within this environment the geometry definition and mission profile were included. Furthermore, propulsion system specifications and mass breakdown were based on empirical approaches. The aerodynamic analysis was conducted by using panel methods. To assess the BLI concept, the power balance method presented by Drela [21] was used and a parallel compressor approach was employed for the performance calculations. The authors stated that this environment has the possibility to combine tools with different levels of fidelity, which makes it more appropriate for novel aircraft concept assessments.

\section{Rear Mounted Engine(s) Concept}

This section reviews all studies related to the rear mounted engine(s) concept. This concept involves the placing of a number of turbofan or turboprop engines in the aft-part of the fuselage. The engines ingest part of the boundary layer flow leading to an improved system performance. The following studies mainly focus on conventional propulsion system, but they are considered as the stepping stone for other research groups to take a step forward and introduce electrified powertrain systems. Therefore, the work done in the studies mentioned in this section is very important for the interested reader.

\subsection{D8 Concept}

The D8 jet transport configuration was initially presented by Drela [72]. The concept adopted a wide "double-bubble" fuselage with two rear-mounted engines that ingest the boundary layer flow as shown in Figure 7. The D8 aircraft targets for EIS 2035 and it is designed to accommodate 180 passengers (PAX) for a distance of $3000 \mathrm{~nm}$. The distinguishing aircraft geometry presents benefits in aerodynamic characteristics and is accompanied with a twin "pi-tail" configuration to accommodate the rear-engine installation. 


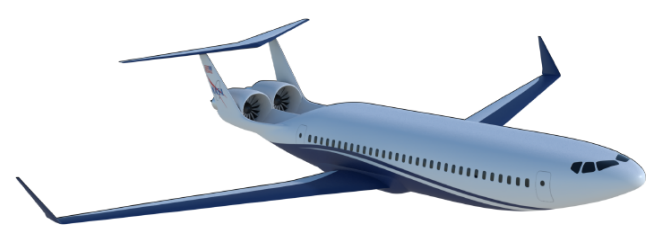

Figure 7. D8 concept's artistic impression, as presented by Drela [72] and Pandya et al. [73]

The power balance method approach first presented by Drela [21] is important to mention. In an effort to overcome the thrust and drag invalid definitions in airframe/engine integrated systems, Drela proposed a different approach that was based on the power balance of the system. The basic power balance equation is given in Equation (18).

$$
P_{K}+P_{V}+P_{S}=\dot{\mathcal{E}}+\Phi
$$

where $P_{K}$ is the net propulsor mechanical energy flow, $P_{V}$ is the net pressure-volume power that is assumed to be negligible, $P_{S}$ is the net propulsor shaft power, $\dot{\mathcal{E}}$ is the total energy rate and $\Phi$ is the power lost due to viscous dissipation. The interested reader can find the detailed explanation for all terms in the publication presented by Drela [21]. The main concept here is that the BLI benefit comes from reducing $\Phi$. The term $\Phi$ represents viscous dissipation from different sources such as friction drag, shock losses, jet dissipation, etc. When introducing a BLI concept, a part of the airframe wake is ingested by the BLI propulsion and re-energized. Therefore, the entropy generation related to the wake mixing is minimized and $\Phi$ will be reduced in BLI concepts. According to the energy conservation, the power provided by the propulsor $\left(P_{K}\right)$ shall also be reduced.

Drela [72] presented different variants of the $\mathrm{D} 8$ concept while evaluating them using a multi-disciplinary optimization (MDO) framework, which included structural information, engine performance, and aerodynamics prediction based on empirical correlations. All configurations were evaluated using the fuel burn estimated by the Brèguet-Coffin equation for the cruise portion. The results showed that this concept can achieve up to $33 \%$ fuel burn reduction compared to that of a conventional aircraft using the same set of assumptions. In a later stage of this work, Pandya and Uranga [73] presented a study to assess the benefits of this configuration. Several CFD Reynolds-averaged Navier-Stoke (RANS) simulations were conducted using the bare fuselage geometry at the cruise condition. The CFD results were validated against data from wind tunnel experiments. The validation showed good agreement between the CFD and experimental data. Therefore, the authors used a 1:11 scaled D8 geometry to match the geometry tested in the NASA Langley wind tunnel. The authors presented a comparison between the podded and integrated (BLI) configurations. The propulsors were modeled using an actuator disk zone placed in the approximate fan position. The authors noted that the actuator disk in both the BLI and podded configurations were set at the same static pressure rise. Since, the actuator disk does not affect the fluid velocity, the total pressure rise was also the same. The BLI configuration showed $9 \%$ less mechanical flow power when compared to the podded configuration for zero net axial force (cruise operating point). The authors investigated the simulation results at various cut planes along the airframe geometry. They concluded that the $9 \%$ reduction in required mechanical energy for the BLI configuration comes from the $6 \%$ reduction in overall dissipation compared to the podded configuration. This reduction was driven by lower jet and wake mixing despite the losses because of flow separation in the BLI configuration. Finally, the authors highlight the need of extending this work on a range of different flight Mach and Reynolds numbers of a full-scale geometry.

Uranga et al. [60] studied both podded and BLI configurations of the 1:11 scaled D8 in a subsonic wind tunnel. The authors showed that the BLI configuration leads to roughly $6 \%$ less electrical power delivered to the propulsor during testing. The comparison between the podded and BLI configuration was conducted for the same net axial force, which was set to zero and AoA at $2^{\circ}$ to simulate the cruise operating point. Additionally, 
the authors estimated total savings up to $15 \%$ for a full-size D8 aircraft including secondary drag and weight benefits that were a result of the location of the engines in the BLI configuration. A later stage of this work was published by Uranga et al. [74]. The authors used the mechanical flow power as a metric to compare BLI from conventional concepts. This power was estimated by measuring the provided electrical power and multiplying with the fan and motor efficiency. This way, both aerodynamic and propulsive benefit can be included in the comparison. The results showed reduction of $8.6 \%$ in mechanical flow power for the BLI concept.

The modeling approach presented by Drela [21] was further analyzed by Hall et al. [75]. The main sources of benefit in BLI concept were identified for the D8 aircraft; reduced jet dissipation due to decreased jet kinetic energy and reduced airframe dissipation due to reduced wetted area and re-energized airframe wake. The integrated nacelle can also result in lower associated weight. Uranga et al. [76] also presented analytic expressions for the input mechanical flow power, net axial force and dissipation sources. The authors recognized the main parameters that affect the benefit: the dissipation ingested, propulsor jet velocity, and the BLI installation concept, which affects the surface dissipation. Therefore, a benefit breakdown was conducted using wind tunnel models for both BLI and podded concepts.

Marien et al. [77] used the D8 concept to assess the benefit of the BLI technology. The power balance method was used along with the assumption that there was a $3.5 \%$ penalty in the fan efficiency due to operation in distorted flow field. FLOPS (Flight Optimization System) [78] along with other tools were used to calculate the aerodynamic performance, weight and wetted areas. The engine performance and weight were estimated using the NPPS [49] and WATE [50] tools respectively. The engine was simulated for an inlet kinetic energy defect due to the boundary layer inflow. The authors were able to show vehicle-level assessments and they compared a podded and a BLI D8 aircraft to understand only the BLI technology impact. Their results showed that the aeropropulsive benefit was greater than the detrimental effects of inlet total pressure loss and fan efficiency penalty. Therefore, the BLI case led to $2.8 \%$ decrease in fuel burn.

The conceptual design of the D8 aircraft including structural and aerodynamic aspects was presented by Yutko et al. [79]. The authors developed an MDO framework called TASOPT (Transport Aircraft System OPTimization), which uses low fidelity models to evaluate the performance of new aircraft concepts. The authors conducted investigations on the aircraft layout, structural analysis and aerodynamic analysis. The aerodynamic performance was estimated using 3D CFD models for different fuselage, nose, and tail geometries. They highlighted that the main requirement with respect to aft-end design was to minimize dissipation while achieving the design Mach number at the fan face. Two areas of interested were identified: the space between the two nacelles and connection of nacelle and vertical tail plane. According to the authors, the main design drivers were related to effects found in cruise, start of descent, and take-off operating conditions. Furthermore, the one engine inoperative (OEI) and crosswind take-off conditions are crucial to achieve good yaw control. The TASOPT framework was used to design a D8 aircraft for EIS 2016 and compare it with an $737-800$ aircraft. The block fuel was reduced by $25 \%$ for the D8 aircraft.

Finally, Clark et al. [80,81] published two studies focused on the noise assessment of the D8 concept. In both studies, the authors used the NASA's ANOPP-Research (Aircraft NOise Prediction Program) tool [82] to predict noise for each component and finally build a noise emission estimation for the aircraft. The reduced thrust requirements at cruise for the D8 aircraft led to reduced climb performance at take-off compared to the reference aircraft. The authors tried to break down each of the physical phenomenon and study each acoustic effect using available data from similar studies. The authors focused on on two physical phenomena-turbulence ingestion and variation of fan blade incidence angle for each fan revolution. The results showed that the BLI has 15 EPNdB (Effective Perceived Noise in deciBels) noise penalty on cumulative certification noise. The authors highlighted that the benefit from shielding resulted due to the BLI engine placement was counterbalanced by the unshielded aft-radiated fan noise. In the second study, the authors presented a noise 
reduction road-map for aircraft accommodating 160-180 PAX. They considered both the D8 and a conventional tube and wing aircraft by applying different technologies and assessing the noise effect. The results showed that BLI leads to noise penalty and when considering other aspects such as lack of shielding and significant reflection of aft-noise, the far term goal set might be very challenging to meet.

\subsection{ONERA}

ONERA (Office National d'Etudes et de Recherches Aérospatiales) performed a series of investigations in aircraft concepts utilizing BLI technologies. These concepts are based on the aircraft design of having rear-mounted engines. Two concepts will be presented in this section: the NOVA (Nextgen Onera Versatile Aircraft) concept with conventional powertrain architecture shown in Figure 8a and the DRAGON (Distributed fans and Research Aircraft with electric Generators) concept with turbo-electric powertrain architecture shown in Figure 8b.

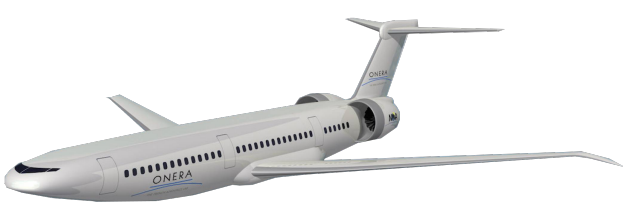

(a) NOVA concept

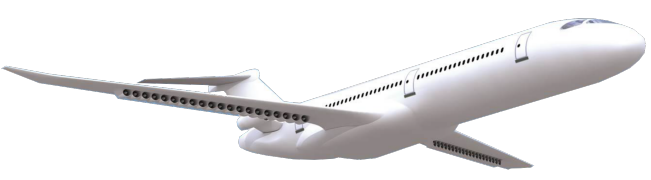

(b) DRAGON concept

Figure 8. Office National d'Etudes et de Recherches Aérospatiales (ONERA) concepts' artistic impression, as presented in [83,84] and described by Wiart et al. [85] and Schmollgruber et al. [86].

Arntz [87] developed an exergy balance method to evaluate BLI technologies. As Habermann et al. [22] described in their work, the methodology was based on momentum balance and second law of thermodynamics. The methodology is similar to the power balance method presented by Drela [21], since it describes the exergy as supplied by the propulsor while there is partial destruction within the control volume by different sources. Studies including the aero-thermo-propulsive performance are feasible since the exergy balance can take into account both mechanical and thermal energy. The methodology was applied in both unpowered aircraft concept [88] and a 2D HWB model with BLI [89,90]. The benefit of BLI technologies was found to come from the smaller propulsive exergy requirements to counter-balance the exergy losses.

\subsubsection{NOVA Concept}

The NOVA concept is an aircraft for EIS 2025 year with design range of $3000 \mathrm{~nm}$ featuring two rear-mounted gas turbine engines that ingest boundary layer flow. Wiart et al. [85] focused their efforts on the engine/airframe integration opportunities. The authors used 3D CFD studies while modeling the BLI fan as an actuator disk. They employed the exergy-based calculation [87] to evaluate their results. They were able to show that the BLI configuration leads to lower aircraft wake creating a better thrust-drag balance compared to the other configurations. In a latter stage of their work, Wiart et al. [91] compared podded and semiburied, rear-mounted engines using 3D CFD simulations. The results showed that a PSC of $5 \%$ was achieved using BLI technologies in cruise conditions.

Furthermore, several studies focused on the aeroacoustic aspect of the BLI concept. Mincu et al. [92] and later Lorteau [93] presented methodologies using CAA (Computational Aero-Acoustic) solvers with 3D CFD simulations to assess the noise emission of the aircraft. Further aeroacoustics studies were presented by Romani et al. [94,95] by conducting CFD/CAA simulations. The results showed that for the NOVA BLI configuration, the ingestion of turbulence and distorted inflow can lead to higher levels of noise emissions. The two works by Romani et al. [94,95] provide more information on the noise sources related to BLI. 


\subsubsection{DRAGON Concept}

The second concept, DRAGON, is based on the principle of distributed electric architecture. The DRAGON concept has EIS in 2035, accommodates 150 PAX. It features two rear-mounted turboshaft engines that power an array of BLI electric ducted fans ingesting across the wingspan of the aircraft. In this concept, the electric ducted fans ingest the boundary layer formed on the wing surface. Schmollgruber et al. [86] was the first to present this concept. The authors used a multidisciplinary framework tool accounting for turboshaft performance, 3D aircraft aerodynamics, wing structural considerations and electric powertrain performance to assess the concept. The authors were able to show that the DRAGON configuration can achieve up to $7 \%$ fuel burn reduction compared to a conventional aircraft with the same technology assumptions.

\subsection{Other Relevant Studies}

After investigating the NOVA configuration, Wiart and Negulescu [96] explored the Nautilius concept, which was based on the same principle as that of NOVA. The aircraft geometry was modified to place the engines at the aft-part of the fuselage in a similar way to the D8 aircraft. In contrast to the NOVA concept, the engines were not buried in the fuselage. They were located in a downstream position similar to the propulsive fuselage concept. The authors conducted 2D axisymmetric studies of two different design iterations and compared the results to a similar podded configuration. The authors used the exergy balance method and performed a component breakdown to investigate which terms were reduced in the BLI concept. The authors showed lower propulsive power requirements for the BLI concepts for the second design iteration. Finally, they highlighted the need for further concept redesign, as well as, investigation of other operating points in the flight envelope.

Mennicken et al. [97] introduced a through-flow based design methodology for BLI fans. The authors highlighted the BLI flow physics principles that were taken into consideration for high bypass turbo-fan engines exposed to boundary layer. The main principles consist of reduced expected axial velocity, swirl due to the pressure gradients cause by the circumferential distortion, and stream-tube contraction. The authors focused in developing a design methodology that considered the main BLI flow features to predict the velocity triangles and provided an estimation of the BLI performance with lower numerical effort. An in-house streamline curvature (SLC) approach was used based on the work presented by Schnoes et al. [98]. The main flow aspects were modeled and the proposed methodology was calibrated using the results of high-fidelity 3D CFD simulations of 12 individual designed fans. These fan designs were exposed to a generic boundary layer profile similar to the fully turbulent flat-plate boundary layer profile [99]. The results from the SLC approach and the 3D CFD simulations presented a good agreement. Then, an exploration study with varying international standard atmosphere corrected rotor tip speed and meridional Mach number was presented. The authors highlighted the existence of different optimal points inside the design space depending on the metric considered.

Silberhorn et al. [100] presented a study where a current Airbus A320neo was calibrated to accommodate the two boundary layer ingesting geared-turbofan engines at the back of the fuselage. The concept under investigation had an EIS 2035 and a set of different models were employed to estimate the propulsion performance, weight of components, aircraft conceptual sizing and finally mission analysis. In particular, the aircraft aerodynamics were estimated from 3D CFD simulations presented by Mennicken et al. [97]. The authors presented several intermediate phases of the aircraft design and the block fuel change for each phase compared to the reference aircraft. The final BLI aircraft concept resulted in $1.1 \%$ block fuel reduction compared to the A320neo reference aircraft with EIS 2035. The authors highlighted that the new BLI concept will possibly result in higher cabin noise because of the distorted fan inflow and lack of defined path for the body sound transmission. Furthermore, the authors discussed potential challenges in maintenance and 
disc burst scenario. The aforementioned challenges arose from the mounting location of the engines.

The previous concept was further explored by Mennicken et al. [101]. The performance of an ultra-high bypass fan was investigated. As a first step, the authors performed 3D CFD simulations of a reference fan under homogeneous inflow conditions for different operating points to derive the fan performance maps. The authors proceeded with imposing different total pressure distribution as inlet boundary conditions. These distributions were taken from 3D CFD aircraft simulations [102]. The authors kept the same static pressure at the fan exit as the reference fan. They noted a decreased corrected mass flow for the BLI fan while the total pressure ratio increases and the fan efficiency drops. The authors noted that the flight operating condition affects the levels of distortion. In particular, low altitude and low speed resulted in a more uniform distortion pattern compared to the other operating conditions. For the interested reader, a detailed comparison of the flow characteristics between the conventional and BLI fan was presented. Additionally, to provide a predesign of the fan for the BLI concept, the SLC approach described by Mennicken et al. [97] was employed. The inlet boundary conditions were taken from fully turbulent flat-plate boundary layer profile [99] and the rotor tip diameter was kept the same with the previous studies. The authors highlighted the effect of tip speed and blade thickness to the fan efficiency. Finally, the importance of a nonaxisymmetric stator was discussed to reduce losses near the tip area of the blade.

Ahuja and Mavris [103] recently published a work focusing on the development of a methodology based on the isolated BLI impact on the vehicle performance that can be employed in aircraft conceptual design estimations. This work was a part of Ahuja's $\mathrm{PhD}$ thesis [104]. The authors initially presented different modeling procedures found in literature. They followed the schemes by Hendricks [27] and discussed on the applicability of different procedures on the conceptual design of novel BLI aircraft. They highlighted the importance of coupled aeropropulsive approaches as a decoupled approach might incorrectly estimate the BLI impacts. However, they commented that most of the coupled approaches available were suitable for post conceptual design phases where the aircraft was already sized. Therefore, they investigated in their study the difference between using a coupled or decoupled approach. Their proposed methodology was based on Drela's power balance approach [21]. An initial aircraft sizing was estimated using the conventional tube-and-wing geometry for a set of key performance requirements and constrains. The sensitivity of the aerodynamic performance to the BLI effects was explored through CFD simulations when varying different design parameters. The sensitivity studies were a result of another publication of Ahuja and Mavris [105] where the key airframe and propulsor parameters were identified. Using the CFD simulation results, the authors trained surrogate models to capture the behavior of the system. The surrogate models were integrated within the engine design analysis to update parameters resulting in correcting the engine performance estimations. Also, fuselage and nacelle wetted areas changes were taken into consideration. A coupled approach with the airframe, engine and BLI effects through the surrogate models was developed. Then, a decoupled approach with the same models but not parameter updates for each algorithm iteration was also presented. The method was tested on the D8 and NOVA concepts mentioned above using a current 737-8 aircraft as a starting point for a full flight envelope. By performing parameter sweeps and optimization, they showed that for both concepts, the BLI concept block fuel estimation was lower than the conventional aircraft for both approaches. However, for all studies conducted the block fuel requirements of the BLI decoupled variants were higher than the corresponding BLI coupled variables. The authors highlighted the importance of uncertainty quantification when assessing the results, since the whole method estimates were based on the surrogate models' accuracy. Therefore, they showed that for the coupled approach the BLI fuel savings were ranging between 1 to $6 \%$, whereas for the decoupled approach this range was 3 to $8 \%$ while using the non-BLI concept as the reference aircraft. 


\section{Propulsive Fuselage Concepts}

In this section, the studies featuring a propulsive fuselage concept (PFC) are presented. The PFC geometry is based on the idea that the fuselage viscous drag is one of the largest portions compared to the aircraft viscous drag and therefore the BLI propulsion unit is placed to encircle the aft-part of the fuselage. This way the boundary layer generated on the fuselage is ingested by the BLI propulsor. Several studies were published using this geometry.

\subsection{DISPURSAL Concept}

The DISPURSAL (Distributed Propulsion and Ultra-high By-Pass Rotor Study at Aircraft Level) project was an EU-funded collaborative project organized by Bauhaus Luftfahrt. The project had as a goal to propose novel aircraft systems integration and investigate possible multidisciplinary interactions. The final outcome was to produce a roadmap for future research efforts on novel aircraft configurations. This project, as presented by Isikveren et al. [11] investigated two different concepts featuring distributed propulsion for EIS 2035. A PFC using a third gas turbine at the aft-part of the fuselage and a HWB configuration. The results presented in this section focuses on the PFC. Steiner et al. [106] conducted a study to down-select the configurations investigated within the project. Different configurations were assessed in terms of PSC and the concept was found to achieve the maximum power savings.

Seitz and Gologan [107] presented an analytical approach to assess efficiency benefits for the PFC. The approach was based on modified system efficiencies by breaking down drag components while taking into consideration the level of ingested drag from the BLI propulsor. The authors used this approach to evaluate results from a series of parametric studies using both gas turbine performance and axisymmetric CFD simulations [106]. Significant power savings were presented by calculating both the PSC and energy-specific air range (ESAR).

Bijewitz et al. $[108,109]$ further developed the aforementioned methodology by introducing the aircraft sizing aspect. The authors recognized the intake area, fan pressure ratio and intake pressure ratio recovery as the main design drivers. They also concluded that fan efficiency and additional BLI engine weight are of major importance when assessing aircraft level parameters such as block fuel and maximum take-off weight (MTOW). Finally, Bijewitz et al. [110] introduced the thrust split ratio as a very important parameter when investigating the system performance. By varying this parameter, the authors were able to find a balanced design point using the block fuel as metric. The block fuel reduction was $12.1 \%$ compared to that of a conventional aircraft with same technological assumptions. However, the study's results were based on turbulent boundary layer flow data for the BL profile. In terms of aircraft weight, operating empty weight (OEW) increased by $4.6 \%$, while MTOW remained in similar levels.

\subsection{STARC-ABL Concept}

The STARC-ABL (Single-aisle Turboelectric Aircraft with Aft Boundary Layer propulsion) concept initially proposed by NASA is a single-aisle commercial transport concept that uses an electric fan embedded in the aft-part of the fuselage. The STARC-ABL is a partial turbo-electric concept meaning that its' turbofan main engines generate part of the axial force necessary to move the aircraft and the rest of the axial force is generated by the BLI aft fan as shown in Figure 9. Welstead and Felder [111] highlighted that the Turbo electric powertrain architecture may lead to system efficiency losses due to the conversion of power and transmission losses imposed by the additional components needed. However, they highlight that these losses can be overcomed by the use of distributed propulsion concepts that are enabled in this case. The STARC-ABL concept is based on an 150 PAX class commercial transport with a traditional "tube-and-wing" shape, and it is an excellent example of retrofitting a novel technology into an existing aircraft with EIS in 2035. However, a T-tail empennage was placed upstream of the BLI fan due to its position. The 
application has its origins in a relevant tube and wing concept developed by Boeing, the SUGAR (Subsonic ultra Green Aircraft Research) concept [112].

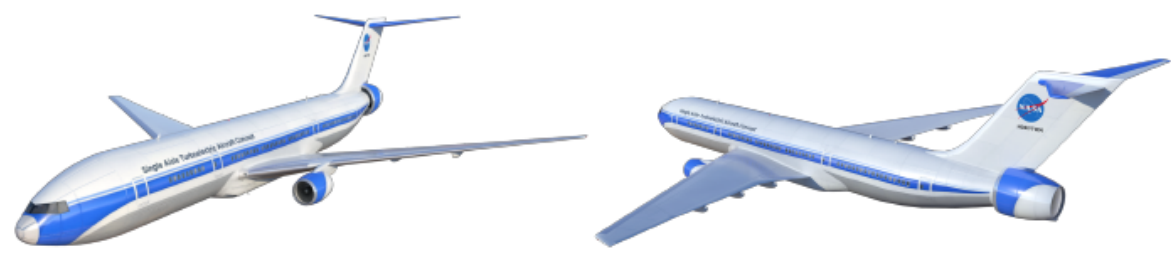

Figure 9. STARC-ABL concept's artistic impression as presented in [113] and described by Welstead and Felder [111].

Welstead and Felder [111] were the first to investigate the STARC-ABL concept. They assumed a constant aft-fan power of $3500 \mathrm{hp}$. To calculate the boundary layer shape, they used CFD results provided by Boeing for the SUGAR concept bare fuselage. The authors converted the mass-averaged total pressure and Mach number results in normalized representation. The normalized profile was used in the NPSS [49] propulsion simulation tool for different flight conditions. Taking into consideration a selected FPR and maximum power delivered to the BLI fan, the authors were able to select the size of the fan and, therefore, estimate the boundary layer captured. The rest of required thrust was provided by the main turbofan engines. Since the main engine thrust requirement was lower compared to the baseline case, the engine nacelle decreased, keeping similar levels of specific thrust. Their calculations resulted in a 15\% improvement of TSFC in cruise conditions, which was translated into $7 \%$ and $12 \%$ fuel burned saving for the economic and design range missions. They also highlighted the possibility of downsizing the main engines due to more efficient electrical system for different flight conditions. However, this work's analysis was based on the boundary layer of a bare fuselage and it was uncoupled with the propulsion model. Therefore, they did not account for the additional drag generated on the BLI fan as well as possible design modifications at the aft-part of the fuselage that will potentially change the boundary layer shape.

Gray et al. $[39,114,115]$ conducted more detailed studies of the same concept to validate the results presented by Welstead and Felder [111]. They presented a new approach that included a 2D CFD simulation of the BLI fuselage coupled with a simple 1D propulsion model. The propulsion model included a single compressor representing the BLI fan. The power to the BLI fan was kept constant as per the assumption of Welstead and Felder. The adiabatic efficiency of the fan was selected as a function of FPR. Depending on the FPR selection, the BLI fan diameter was adjusted using free-form deformation (FFD) approach. The propulsion model and CFD simulation exchanged boundary conditions for the inflow and outflow of the fan as presented in Section 2.5. By integrating the pressure and viscous forces in all surfaces as well as the pressure and momentum flux on the fan face and exit, they were able to compute a net propulsive force. The coupling between the two models was realized within the OpenMDAO framework [116]. The authors compared the results from the BLI concept to a podded engine baseline configuration for varying FPR. The authors highlighted that both aerodynamic and propulsion effect contributed to the overall BLI benefit, and therefore coupled simulations are very important.

In a latter stage of this work, Gray and Martins [117] were able to set up an optimization problem using a detailed CFD model. They used FFD to modify the surface mesh in the aft taper section of the fuselage, BLI nacelle and plug. The CFD model was coupled with the above mentioned propulsion model. The optimization objective was to minimize the power required at the BLI shaft and therefore, the PSC. They performed a series of optimizations with different constrains on the axial net force coefficients for both BLI and baseline configurations. The results showed that a PSC of $20.2 \%$ was achieved for the smallest BLI fan design. However, the authors highlighted that this metric was only giving an insight on one part of the propulsion system, since the rest required thrust would come from the 
main engines. Therefore, to find the best overall design they accounted for the effect of the transmission efficiency and performance of main engines to calculate the PSC. The results showed that the transmission efficiency highly affects the PSC. Finally, they concluded that the aero-propulsive analysis and the electrical system analysis cannot be conducted separately since the redesign of the main engine and BLI propulsors simultaneously could lead to different results.

Lee and Liou [118] published a preliminary design for the low FPR fan and outlet guide vanes (OGV) of a BLI propulsor. The BLI fan was simulated using 3D RANS solver for turbomachinery components. The inflow conditions were obtained by a propulsor/airframe integrated model using a body-force zone. The author's goal was to maximize fan and OGV efficiency while accounting for the severe inlet radial distortion. The fan and OGV designs were obtained by employing optimization studies with several design variables that affect the geometry of the blades. Their results show that a $13 \%$ of fuel burn savings can be achieved in this preliminary fan design study. However, the authors highlighted that in this study an axisymmetric distortion was assumed and, therefore, a study including the wing and tail geometry was expected to impose a higher fan efficiency penalty.

Kenway and Kiris [119] performed aerodynamic shape optimization studies on the STARC-ABL BLI aft-propulsor concept to minimize inlet distortion. By selecting the ARP1420 distortion metric [120] and setting it as a minimization objective at the fan face, they were able to create optimal shapes for two different configurations: a configuration with simplified fuselage body and aft-propulsor (body-duct) and a more detailed configuration including the wing geometry as well (wing-body-duct). The BLI aft propulsor was modeled as an actuator zone where uniform thrust was applied. The authors did not have detailed information about the blade geometry, and therefore swirl components were neglected. The design variables were related to the aft-part geometry of the fuselage. For each configuration, two optimizations were conducted: one single point optimization using a nominal point and AoA of $2^{\circ}$ and one multi-point optimization taking into account three points in cruise condition with different angles of attack and two off-design points. The two off-design points represented the Climb and Take-off conditions. Each design point was weighted equally within the optimization study. The results of this work showed that the wing-body-duct configuration shows differences with the simplified configuration due to the effect of the wing's downwash. The authors were able to show that the wing's wake was ingested by the aft-fan, and therefore it affects the distortion imposed on the fan-face. Therefore, the optimal designs presented significant differences between the two geometry configurations. The authors explained that since in the wing-body-duct configuration the main distortion driver was the wing downwash, the design variables related to the aft-part of the fuselage geometry were unable to control and minimize the distortion. The authors concluded that the full aircraft geometry was very important to be included in the simulations for these concepts.

In a later stage of this work, Gray et al. [38] performed CFD studies at cruise operational point including the vertical tail-plane geometry. The authors selected to model the BLI propulsor as a body-force zone developed by Hall et al. [121]. They used a total force coefficient by integrating all forces across the computational domain boundaries and they accounted for the force acting in the body-force zone as presented in Section 2.5. A propulsion model in pyCycle [122,123] was employed within this study. The authors stated that the transition from CFD model to the propulsion model was critical because of the net force accounting inconsistencies that may arise between the two models. Therefore, the inflow conditions to the propulsion model were selected in such a way to match the averaged static pressure and mass average velocity on the interface plane between the two models. Within the propulsion model, an adiabatic fan efficiency and transmission efficiency were accounted to calculate the generator power required to drive the BLI fan. This required power is extracted from the low speed spool of the under-wing main engines. The authors performed aeropropulsive optimization studies to find the optimal thrust split between the main engine and the BLI fan. The authors performed optimization studies 
for three different propulsor sizes that were directly driven from the net force imposed. The optimization objective was to minimize the power requirement of the BLI fan. Several geometrical constrains were imposed. Furthermore, the ARP140 distortion metric [120] was calculated using the methodology described in [119] and was monitored throughout the optimization process. The results showed that the lower the net force constraint in the optimization, the higher the BLI shaft requirement and the lower the required thrust from the under-wing engines. Furthermore, the nozzle plug geometry directly affects the performance of the BLI fan in terms of overall thrust and to avoid flow separation phenomena. The authors also highlighted that the total pressure field at the fan face indicates one-per-revolution excitation due to different total pressure levels on the top and bottom parts of the fan. Therefore, they highlight that the structural design of the BLI fan must account these effects. This study was also part of Gray's PhD thesis [115], where the whole methodology and optimization problem setup was thoroughly described.

Building upon the methodology developed by Gray [115], Yildirim et al. [124] performed optimization studies using the STARC-ABL configuration for a series of NPF coefficient $\left(C_{F}\right)$ and FPR values while minimizing the shaft power required for the BLI fan. The STARC-ABL geometry included all important components (wing-body-tail-BLI fan) of the aircraft geometry as it was highlighted in the previous studies. The authors used a parameterized geometry where the aft-part of the fuselage and the BLI propulsor could be modified by the optimizer. Within the aerodynamic model, the BLI propulsor was modeled as an actuator zone. The results showed that increasing FPR will also increase the required shaft power for the BLI fan. Similarly, the shaft power and nacelle diameter were increasing for constant FPR when the net force coefficient was set to a lower values. This was because lower net force coefficient value means that a larger portion of total thrust must be produced by the BLI fan and hence the BLI fan diameter increases. For the FPR variation, the authors highlighted that although the shaft power was more sensitive to $C_{F}$, the flow uniformity at the nozzle exit was increased with increased FPR. Therefore, the authors conclude that since lower FPR led to more uniform wake and less energy lost, lower FPR are more suitable for BLI fans. However, this guideline must be taken carefully under consideration since low FPR might cause fan operability issues in other aircraft operating points.

Gray et al. [125] published a work where the coupled aero-propulsive studies are further developed to take into account inlet distortion constraints. A comparison between optimization studies with and without inlet distortion constraint activated was presented to show the importance of this aspect. The authors highlight that designs with increased inlet distortion will present an effect in the inlet pressure recovery and reduced fan efficiency as well. Therefore, it was of paramount importance to take this aspect into consideration during the conceptual design phase. The results showed that the distortion constraint reduces the effectiveness of the BLI propulsor in terms of more required shaft power. However, this power penalty depends on the size of the propulsor. The power penalty ranged between $0.1 \%$ and $1.2 \%$ for the smallest and largest propulsor size respectively. The lower the net force coefficient $\left(C_{F}\right)$, the smaller the penalty. The authors highlight that some of the ingested flow for the largest propulsor was free-stream flow that contributes significantly in the nonuniformity of the flow. The authors stated that the increased power requirement for the optimized geometry that has the distortion constraint activated might be counterbalanced by the improved fan efficiency in reality. Finally, the authors highlight that by keeping the distortion to low levels, a lightweight fan design can be achieved but at the cost of larger shaft power requirements. On the other hand, a high distortion level might lead to heavier fan blades due to excessive vibrations and fan efficiency penalty. Therefore, a trade-off arises between the distortion constraint, fan efficiency and whole system design. However, this must be examined closely to calculate an optimal value, which also depends on the aircraft configuration selected. The authors conclude that there is room for improvement in aero-propulsive studies: a promising idea would be to consider 
multiple mission points within the optimization studies, as well as to account for effects in fan efficiency and structural impacts on the whole system performance.

Building upon the experience and the models developed in the previous studies mentioned, Yildirim et al. [126] recently published a work focusing on the aero-propulsive approach across the entire mission profile. The authors based their work on the previous CFD models presented by Yildirim et al. [124] and performed a series of geometry optimization studies where the power delivered to the fan was used as an optimization objective while the NPF coefficient $\left(C_{F}\right)$ and FPR were used as constrains. The fan was modeled using an actuator disk approach within the CFD simulations. The authors noted that even if a smaller BLI fan with higher $C_{F}$ will lead to higher PSC value, this means that small BLI fans are benefited from BLI effect when comparing to a podded propulsor. However, in a system-level analysis this may be not true. Therefore, they continued their work with off-design analysis to consider other operating points. They assumed that the electrical system was sized for the cruise operating point and a constant hybridization schedule. Therefore the shaft power that can be provided to the electrical BLI fan for all operating points was defined. Also, both podded and BLI configurations were selected to operate in similar thrust levels to have a direct comparison and be able to estimate the PSC. They explored operating points with different altitude levels, Mach number and AoA. The results showed that the PSC levels were significantly lower for the take-off operating points compared to cruise for all design FPR considered. The authors highlighted that the effect of Mach number at $1000 \mathrm{ft}$ altitude was higher for fans with higher design FPR. On the other hand, a higher AoA leads to higher PSC for all design FPR. Finally, they identified a mild altitude effect on the PSC compared to the rest parameters. The authors concluded that the sensitivity of PSC to AoA creates a complicated interaction of wing lift and integrated performance.

Hall et al. [127] developed a signomial programming optimization framework to analyze the performance of an aircraft conceptual design. The aircraft concept selected was the STARC-ABL and several components were taken into account. The airframe and propulsion weight breakdown and drag estimation was estimated using statistical methods. In the case of the aft BLI propulsor, the airframe/propulsor integration was accounted using an empirical formula to calculate the ingested drag. The whole powertrain system such as main engines, electrical powertrain system and thermal management system are taken into consideration. Furthermore, the authors introduced a cruise power balance equation instead of the traditional thrust and drag forces. Initially the framework was used to build a conventional Tube-and-Wing baseline model based on the SUGAR concept to calibrate their model. Finally, the STARC-ABL model was developed within this framework and was compared to the conventional configuration. After conducting optimization studies for the propulsion system for both aircraft, they presented that the optimized BLI aircraft consumes $0.5 \%$ more fuel burn than the conventional one. However, the authors stated that since there was no high fidelity models to assess the airframe/engine interaction, no general conclusions should be drawn for the STARC-ABL. However, they highlight the importance of a modular optimization framework in these studies since the accuracy will be improved by improving the fidelity of the models involved.

\subsection{CENTRELINE Concept}

CENTRELINE (ConcEpt validatioN sTudy foR fusElage wake-filLIng propulsioN intEgration) project is an European Union-Funded collaborative project that targets in exploring a promising BLI aircraft design by adopting the PFC [128]. The concept features a partial turbo-electric powertrain system. The project's target is to demonstrate the PFC benefits while designing for EIS 2035. Seitz et al. [129] gave an overview of the project's goal and initial results. The authors mention that the project's goals are also based on a previous project ran by Bauhaus Luftfahrt, the DISPURSAL project, which was presented in Section 5.1. The aircraft concept is based on a wide body, long-range application scenario as shown in Figure 10. The design case range selected was $6500 \mathrm{~nm}$ and the aircraft can 
carry 340 PAX. In this subsection, published studies that use the CENTRELINE aircraft will be thoroughly described.
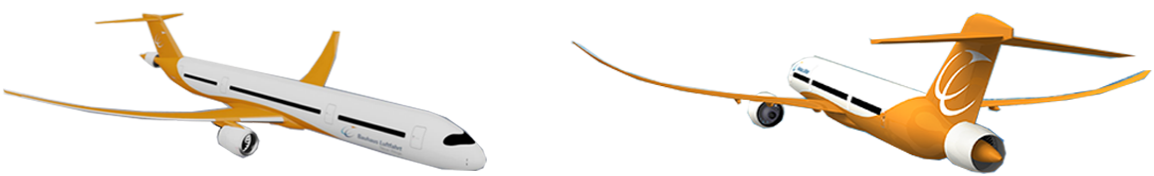

Figure 10. ConcEpt validatioN sTudy foR fusElage wake-filLIng propulsioN intEgration (CENTRELINE) concept's artistic impression, as presented in [130] and described firstly by Seitz et al. [129].

Initial investigations of the PFC concept used in the project are presented by Bijewitz et al. [131]. Since a turbo electric powertrain architecture was investigated, the two main gas turbine engines located under the wing provide the electrical power. This was simulated as a power off-take from both high pressure (HP) and low pressure (LP) spools to investigate the whole design space and possible operatibility issues. The authors use the PSFC instead of the more conventional TSFC to account for the effect of the power off-take to the fuel consumption. First, a reference configuration engine was established. Then, several parametric studies are presented for different power off-take levels in the LP and HP shafts. Finally, the authors conducted parametric studies varying the design FPR and inlet total pressure recovery ratio of the BLI fan while taking into account a possible fan efficiency penalty and lower fan axial Mach number from previous investigations. The authors highlight the importance of these two parameters to overall system design and performance. However, they stated that an integrated assessment including both aircraft and powertrain model was essential to quantify the true impact in the system performance.

To enable for more detailed airframe/engine integrated studies, Habermann et al. [22] presented a new forces bookkeeping matching scheme. The authors surveyed several bookkeeping schemes and figures of merit used in the available literature. The authors stated that most of existing bookkeeping schemes are application-specific that makes their use in a variety of different applications unfeasible. Furthermore, they highlight that in a multidisciplinary conceptual design process, the use of several tools of different level of fidelity was necessary to account for important interactions. They also provided a detailed assessment of the current figures of merit by evaluating them using a set of different criteria. The assessment was based on the authors' engineering judgment, and the criteria were divided into two main categories: degree of universality and application to conceptual design phase. Therefore, the authors proposed a unified bookkeeping approach that can be used in multidisciplinary analysis and it was used within the CENTRELINE project. This modeling scheme was based on integral momentum approach and was demonstrated for a 2D axisymmetric PFC. The authors divide the initial computational domain into five control volumes. This way the propulsion system was accounting the forces acting within the streamtube control volume, which follows the fuselage shape while the BLI propulsor was simulated as a body force zone. On the other hand, forces acting outside of the selected streamtube are accounted in the nacelle force term. This bookkeeping scheme had the capability to be applied in different phases of conceptual design. This makes it suitable for conceptual design as the selected underlying assumptions as well as level of fidelity in the aerodynamic simulation tools can be included.

Castillo Pardo and Hall [23] presented an initial fan design that can operate in a PFC concept. They initially developed a design for a fan exposed to uniform inflow. Then the authors tested their design in clean and BLI inflow conditions to understand the effect of radial BLI distortion to the fan aerodynamics. The authors, re-optimized their design for the BLI conditions and tested it within the same rig. They compared the two fan designs and concluded that it was possible to design a fan that can handle BLI distortion inflow. But, at the same time, they estimated that there was a $0.5-1 \%$ penalty in the fan isentropic efficiency. 
A series of parametric and sensitivity studies were presented by Troelsch et al. [132] to demonstrate the main trends and effects at the propulsion/airframe integrated performance. The authors described the project's main challenges related to the assessment of a PFC concept. These include:

- capturing and understanding aerodynamic effects related to propulsion and airframe integration

- $\quad$ structural design of the BLI propulsor considering aerodynamic effects

- design and selection of power management strategy for the partial turbo-electric powertrain components

- development of a multidisciplinary integrated framework that can perform optimization studies

The authors stated that a fully-coupled multidisciplinary approach was considered as impractical to overcome the challenges mentioned above. On the contrary, the project partners tried to tackle this by using a decomposed analysis, where individual optimization studies were performed at the component-level using objectives that can be directly related to the aircraft top-level requirements. To integrate component-level studies to the main framework, the authors used surrogate modeling techniques that were considered fast and accurate enough for the purposes of this study. To establish consistent interfaces between different disciplines, the authors use the NPF figure of merit presented in Section 2. The authors produced performance maps using surrogate models on samples generated by 2D axisymmetric CFD simulations. These maps included information about off-design performance of the BLI fan within the aircraft envelope. The aircraft sizing model employed within this study gave important information on the mission point ambient conditions to the optimization framework. Then, by using the performance map mentioned above, the model was able to calculate the thrust required by the main engines and important inputs to the BLI fan performance model. The BLI fan model used the fan efficiency penalty calculated by Castillo Pardo and Hall [23]. This model calculated the shaft power required for the BLI propulsion and fed it to a electrical system model. The electrical system model was able to estimate the required power off-take from the main engines. Therefore, the engines were sized based on the thrust requirement and power off-take requirement. Finally, the fuel flow was calculated and was set as minimization objective with the FPR schedule as design variable. Using this framework, the authors were able to vary different parameters within all components involved to demonstrate the trade-offs created for the block fuel, with OEW and MTOW calculated as well. Finally, the authors explained that they planned to refine the presented results by using a more analytical structure model, 3D CFD calculations and designs such as variable nozzle area or variable pitch BLI fan to improve BLI fan efficiency and operating range.

A more recent work published by Seitz et al. [35] was based on an analytical PSC derivation and Brèguet-Coffin equation. The PSC was applied on the CENTRELINE PFC concept to determine the optimal power saving strategies used. These include parameters that can be considered as technology demonstrators: powertrain efficiency, systems weight, and ratio of fuselage to overall drag in cruise conditions. The authors recognized that the power split between main engines and BLI propulsor was one of the most important design drivers within these concepts. The forces bookkeeping scheme employed was based on the unified one described by Habermann et al. [22]. To calculate the PSC, the authors made some important assumptions. The drag calculated within this study was based on 2D CFD axisymmetric simulations and therefore drag generated by other components were not included. The effect of aerodynamic interference between the fuselage and other airframe components as well as wing and tail ingested wake were not accounted for. Also, the authors assumed a $1 \%$ penalty on the fan polytropic efficiency. The authors stated that this work was based on steady-level flight at cruise conditions with AoA set to zero. To analyze the aircraft power savings, the authors used all aerodynamic data available from DISPURSAL and CENTRELINE projects and calculated the $f_{n, P F C \text {, bare }}$ metric. The $f_{n, P F C \text {, bare }}$ metric was illustrated against the BLI shaft power. Two different powertrain efficiency 
levels $(100 \%$ and $90 \%)$ were used and the PSC against the BLI fan relative power was evaluated. The BLI fan relative power was the ratio of the required shaft power to the total

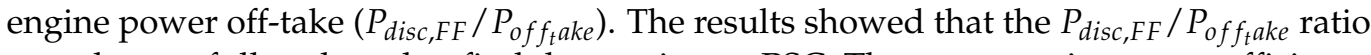
must by carefully selected to find the maximum PSC. The power-train system efficiency affects both the maximum PSC and optimal $P_{\text {disc,FF }} / P_{o f f_{t} a k e}$. However, since the PSC does not account for effect of changes in the aircraft component weight, the authors performed sensitivity studies to show how the fuel burn was affected. The results confirmed that the shape optimization of the PFC, an efficient powertrain system and minimum weight penalty were required to be able to achieve fuel burn reduction. Therefore, the authors concluded that a 3D shaping study along with overall technology studies that can identify synergy effects were essential to achieve better results for the PFC concept.

Habermann et al. [133] published a work focusing on parametric studies for different geometrical parameters and BLI FPR. As the authors stated, this work can be used as a tool to evaluate the aerodynamic performance of the PFC concept for overall system assessment. The authors used a set of design variables that were employed as input to the parameterized geometry. The design variables include the FPR, axial position of the BLI fan, fuselage length, BLI fan hub height, altitude, and Mach number. Some of them were used in sensitivity studies where each parameter was varied independently around their nominal value. Furthermore, the $f_{n, P F C, \text { bare }}$ NPF and shaft power were calculated. The results showed that the FPR has the greatest impact to the required shaft power; a 10\% reduction in FPR leads to $36 \%$ reduction in shaft power. The authors indicated that this trend was opposite to the one presented by Gray et al. [39] but justified the deviations on the different study objectives. While Gray et al. kept constant levels of BLI fan power, in this study the BLI fan inlet area was fixed. Therefore, in the former study, an increasing FPR led to a fan deeply embedded in the boundary layer whereas in the later study an increasing FPR led to increasing nacelle force. The authors performed design space exploration studies using four design variables described above: FPR, axial fan position, fuselage length, and a parameter related to the fan height. The authors used the Latin Hypercube sampling method to create the design of experiment samples and performed 2D CFD simulations for all samples. Then, they used a surrogate model technique, Kriging, to capture the nonlinear effects on the NPF, shaft power and inlet pressure recovery. The inlet pressure recovery was mostly affected by the fuselage length and fan axial position. This indicates that the relative fan axial position must be carefully selected since it affected the height and shape of boundary layer ingested. Furthermore, the BLI fan hub height showed an impact on the NPF as the boundary layer shape and height upstream to the BLI fan were affected by this parameter. The authors compared the best and worst $f_{n, P F C, \text { bare }}$ designs and performed optimization studies to maximize the $f_{n, P F C \text {, bare }}$ metric using the Kriging model. They concluded that all included design parameters affect the concept's performance and therefore holistic optimization to find an optimal design was essential. Finally, they concluded that a 3D geometry was required to reveal other trade-offs while calculating for other operating points to show the BLI concept's operability range.

A study focusing on the performance analysis of the concept under investigation was presented by Samuelsson et al. [134]. The methodology targeted on assessing the system-level performance including different disciplines of partial turbo-electric powertrain architecture at the cruise operating point. The authors aimed in conducting optimization studies including the BLI aft-fan and the main underwing engines to explore their interaction. Furthermore, the BLI fan diameter was varied to assess the impact of the fan size with varying size to the system performance. The fuselage drag and boundary layer profile were estimated based on semiempirical aerodynamic correlations. The authors highlighted the importance of conducting system-level assessment studies as a break-down of the effect and trends to different components can be conducted. From this analysis, the authors noted the similar impact of installation drag and installed weight to the system performance. These also presented a weak dependence with varying fan diameter. This was explained when considering the inversely proportional behavior of propulsion weight with electrical system 
weight. Therefore, the results were dominated by the amount of ingested boundary layer and installation losses. An optimal fan diameter of $1.9 \mathrm{~m}$ was selected and exchange rates to estimate the mission-level fuel burned were employed. The analysis showed that for a $0.6 \%$ fuel burn benefit for $30 \%$ captured boundary layer was achieved for current technology. Furthermore, the authors examined the case of superconducting technology in which the fuel burn benefit was increased to $3.6 \%$ when capturing $57 \%$ of the boundary layer.

Habermann et al. [135] published a study investigating effects of the fuselage upsweep geometry to the estimated BLI benefit. The authors developed 3D RANS CFD models at the cruise operating point for both an axisymmetric geometry and a geometry with fuselage upsweep angle to explore the effects on the aerodynamic performance. The BLI ducted fan was simulated as a "black box" using computational boundary conditions at the fan inlet and fan outlet where the flow parameters were estimated from simple thermodynamic calculations. The authors commented that when an upsweep angle was introduced, the BLI fan was exposed in both radial and circumferential distortion due to different flow conditions on the top and bottom side of the fuselage. A distortion coefficient was estimated. The distortion coefficient presented a 19\% increase for when comparing geometries with upsweep angles of $3.5^{\circ}$ and $4.5^{\circ}$. The distortion coefficient level was in agreement with the results presented by Gray et al. [125]. Furthermore, the BLI efficiency parameter presented in Section 2 was used. For an increasing upsweep angle, the authors highlighted a drop in BLI efficiency. However, the 3D geometry used for this study was designed based on engineering judgment and it was, hence, not optimized. Additionally, the circumferential distortion levels could be affected by the addition of the wing and tail-plane geometries that were not included in this study. The authors tried to address the first challenge by conducting a study varying the thickness-to-chord ratio of the top and bottom part of the propulsor nacelle. The CFD results showed that the variation of the bottom nacelle geometry had a bigger impact on the BLI efficiency. By testing different thickness-to-chord ratio variations, the authors managed to recover part of the BLI efficiency level. There was also a positive effect on the circumferential distortion coefficient. Since large 3D CFD models were used, the boundary layer was selected to be modeled using wall functions to minimize the mesh size and computational time. However, this assumption resulted in a decrease in the simulation accuracy, and therefore uncertainty in the results. Another uncertainty arises from the BLI fan simulation method, as an estimation of the FPR and fan polytropic efficiency was given in the start of each simulation. Finally, the authors commented that the BLI fan operation should be investigated on other important operating points within the mission profile to able to draw meaningful conclusions about the effect of BLI technology on the block fuel.

Della Corte et al. [136] conducted low-speed wind tunnel experiments on a simplified axisymmetric PFC model to investigate the complex interaction between airframe and propulsor. The key aerodynamic phenomena were explored using particle image velocimetry techniques (PIV). Additionally, aerodynamic forces analysis based on power balance method [21] was conducted. The simplified PFC model geometry was based on the study performed by Della Corte et al. [137] that focused on the optimization of the PFC fuselage and its structure support within the wind tunnel facility. The BLI propulsor was sized to ensure aerodynamic similarity with the CENTRELINE full-scale fan developed by Castillo Pardo and Hall [23]. The authors performed experimental studies and extracted data for both a PFC and a bare fuselage geometry. They compared parameters such the axial kinetic energy, total pressure and turbulent kinetic energy at a wake plane for both cases highlighting the flow main differences. After analysing the flow-fields at the symmetry fuselage plane for both cases, they highlighted that the BLI propulsor affects both the upstream and downstream flow-field. The axial momentum deficit or excess, which is linked to the configuration drag or thrust forces, was increased by $10 \%$ upstream of the BLI fan due to interaction of the flow with the fan operation. Furthermore, the authors highlighted the increased tangential kinetic energy flux as a results of the tangential momentum caused by the fan blades. Finally, the authors conducted tests for different axial force coefficient to 
understand the BLI fan performance at different operating settings. The BLI fan upstream flow presented to be influenced by the axial force coefficient because of the significant differences shown at the lower part of the boundary layer profile. For the model under investigation, it was shown that an increasing axial force coefficient can diverge from a "wake-filling" scenario.

The most recent available publication considering this concept was presented by Seitz et al. [130]. This publication summarized the research efforts conducted within the CENTRELINE project and presented the project's key results. The authors highlighted the importance of top level aircraft requirements based on the selected EIS timeframe and anticipated transport requirements when assessing novel aircraft concepts. This work was directly linked with the publications reviewed within this section. The performance bookkeeping scheme presented by Habermann et al. [22] and several 2D CFD studies with actuator disk approach were conducted to investigate the airframe/propulsor aerodynamic interaction [138]. It was found that the parameters affecting the integrated aerodynamic performance were the BLI fan duct height, hub-to-tip ratio, relative axial position of the fuselage and the nozzle exit to fan face area ratio. As a next step, the authors conducted 3D CFD studies while successively adding airframe components to the geometry under investigation such as wings, tail and belly fairing. A half-PFC geometry without including the underwing mounted engines was aerodynamically investigated. The fan face total pressure levels presented and compared against the different geometries. The authors highlighted the effect of the wing downwash to the lower half of the fan face where a zone with high total pressure appears. Similar effect was noted with the addition of the tail for the upper half of the fan face. Furthermore, the fuselage upsweep to avoid increasing the landing gear length contributes as a penalty to the overall airframe force. However, as mentioned by the authors, design improvements could reduce these aerodynamic penalties. The authors used the nonuniform profiles extracted from the CFD studies as an input to 3D CFD models for the fan internal aerodynamics. Two fan designs were tested: one designed for clean uniform inflow at the aerodynamic design point and one with nonuniform BLI inflow. The second design was aligned to match the flow angles for up to $75 \%$ span. Above $75 \%$ span, the sections were re-staggered to operate at a negative incidence angle. The authors presented the fan map for both designs and highlighted the improved stability margin for the second design. Along with the experimental results from the work of Della Corte et al. [136], a experimental work including a 3D PFC model was presented. The authors investigated the total pressure field at the fan face for different aircraft incidence angle. The results showed good agreement with the CFD simulations for zero incidence conditions. For an incidence angle of $12^{\circ}$, which corresponds to the take-off condition, strong total pressure gradient were found.

Furthermore, the authors [130] performed conceptual design for the aft-BLI fan employing FEM (finite element method) structural analysis $[139,140]$ for a number of different design solutions based on the requirements from the CS-25 regulations [141]. Their main goal was to keep the nacelle mechanical complexity and mass to a minimum level. Using a flow path sizing based on the methods described by Seitz [142], the BLI fan main components weight was estimated. Additionally, the main underwing mounted engines integration options were explored. As mentioned above, the PFC of the CENTRELINE project featured a partial turbo-electric powertrain architecture and the integration of an electrical motor in the main engine was investigated. Two options were explored: one with low pressure turbine power off-take, and one with a free turbine power off take. Performance and weight estimations penalties led to a favorable extraction of power from the low pressure turbine. As described by Troelsch et al. [132], a common framework using surrogate models to integrate design tools of different levels of fidelity was employed for a system-level analysis. The analysis showed a $4.7 \%$ reduction in mission fuel burn when employing the 2D optimized design against an similar aircraft without BLI concept. The fuel burn estimation was 3.2\% when employing a preliminary 3D PFC geometry. Finally, an estimation of the $\mathrm{NO}_{X}$ emission based on the standard ICAO (International Civil Aviation 
Organization) landing and take-off (LTO) cycle and a lean direct injection technology was assumed for the combustor. The analysis showed a potential $64 \%$ reduction in $\mathrm{NO}_{X}$ relative to a reference aircraft of EIS 2000. A noise estimation analysis was conducted based on the methods described in [143] from aircraft and engine components at the ICAO certification points. The results showed a cumulative noise reduction of $12 \mathrm{EPNdb}$ compared to that of the reference 2000 aircraft. The main aspects driving the noise reduction were the smaller wing size, lower FPR and specific thrust of the main engine fans. Finally, an initial assessment of the cash operating cost (COC) was conducted based on the methods described in $[144,145]$. An increase of $9.5 \%$ in direct maintenance cost (DMC) was observed for the PFC concept due to additional BLI fan and powertrain components when compared to that of a conventional 2035 aircraft. The fuel burned and $\mathrm{NO}_{X}$ emissions reduction contributes in a reduction in the COC. A parametric study varying the fuel price showed lower COC for the PFC concept compared to the baseline aircraft for a price below US\$ 1.5 per gallon.

\subsection{Further Relevant Research}

In this subsection, a number of relevant studies will be presented. These studies employ the PFC geometry as it was described in the previous subsections. However, they do not belong into the concepts mentioned above, and therefore they are presented separately.

Bevilaqua and Yam [31] performed a control volume analysis for the cruise operating condition with a 1D flow employing an actuator disk to simulate a propeller that accelerates the wake of a body until the jet velocity reaches the freestream velocity. The authors used the propulsive efficiency derivations shown in Section 2 and found a reduction in propulsive efficiency when employing wake ingestion. This effect was explained by a reduction in kinetic energy available for generating a required thrust when wake ingestion was employed. Finally, the authors used the Brèguet-Coffin range equation as shown in Equation (9) and showed that the range of a BLI aircraft could be increased due to lower power necessary to produce similar levels of thrust. However, this work was a first-order analysis that is based on simple analytic equation derivations, and therefore first-order effects could be investigated.

A study implementing an all-electric propulsive fuselage was presented by Stuckl et al. [146]. After performing DSE studies on electric aircraft, the authors designed the Voltair concept. The Voltair concept was characterized by its' shorter fuselage to provide greater clearance during take-off rotation, lower slenderness ratio for easier positioning of high-volume components such as the battery and a BLI ducted aft-propeller. The author calculated a potential $25 \%$ benefit in energy efficiency due to aerodynamic benefits to be counterbalanced by the weight penalty effects using the all-electric powertrain architecture.

Elmiligui et al. [147], investigated different BLI configurations. In the first steps of this study, the results from numerical investigations of the XZS2G-1 Airship with no boundary layer ingestion [21], the Boundary Layer Control Cerreta Airship [21] and the Goldschmied propulsor $[21,148]$ were validated against wind tunnel data and previous numerical results. All airships were axisymmetric bodies of revolution. The meshes created were $5^{\circ}$ slices in the circumferential direction. Then, the Boeing 737-800 fuselage was selected as a reference geometry to mount a BLI propulsor. The authors used 2D RANS equations to evaluate the concept's benefits. The suction slots were modeled using a sink boundary condition. The authors ran several simulations with different flight Mach numbers and several variants of the baseline geometry and showed that power savings of $81-85 \%$ can be achieved. However, the authors highlight these power saving results were based on the product of the jet thrust and jet velocity. The power required to operate the BLI propulsor is not calculated in this study. Also, the ram drag of the BLI propulsor was not taken into consideration.

Atinault et al. [149] presented a study using both numerical and experimental approaches to validate the used methodology to assess BLI technologies. Their work was part of the RAPRO1 project organized by ONERA. The authors developed and manufactured a test rig to be tested within the ONERA low speed wind tunnel. The purpose of the experiment was to validate the results created by 3D CFD calculations that model the BLI 
fan as a actuator disk. The numerical and experimental results showed good agreement, and furthermore, there were positive effects for BLI technologies since the required power was reduced for a range of net axial force tested.

Mikic et al. [150] investigated the concept of the thin haul commuter propulsive fuselage using energy efficiency as a performance metric. They tried to address two different questions that arise when employing this concept. First, they looked at the challenges related to the interaction between flow around the fuselage and flow ingested in the BLI device. Second, they investigated the selection of the distribution of power between different propulsive units to find the optimal system efficiency. By employing a mathematical analysis using an actuator model, they were able to derive a theoretical propulsive efficiency for individual stream-tubes. By trying to minimize the power for constant thrust level, they were able to relate optimal efficiency to a number of variables related to wake structure, fraction of wake captured, and thrust level. From the derived mathematical analysis, they examined different cases of thrust level, actuation area and velocity deficit. The results show that the most important parameter affecting the theoretical propulsive efficiency was the velocity deficit parameter. Furthermore, they proposed that a comprehensive metric to assess such concept is the overall energy efficiency since it can be uniquely defined for different configurations and then compared directly with others.

Thauvin et al. [151] presented a review of potential technologies that can be applied in regional aircraft. The reference aircraft used was a conventional twin-turbo propeller aircraft for EIS 2035. They evaluated different technologies including use of hybrid-electric propulsion system, distributed propulsion and boundary layer ingestion. The BLI technology implemented included the use of a BLI propeller after the fuselage and it was exposed to the fuselage wake. The boundary layer profile was estimated by using the $1 / 7$ th power law for turbulent boundary layer. The authors performed studies for different thrust splits and rear propeller loading. The effect of the power consumption was calculated using actuator disk theory assuming ideal efficiency and was normalized for the corresponding value of the reference aircraft. The authors concluded that the BLI technology presented negligible benefits. However, since the studies in BLI technologies applied in regional aircraft are limited, more detailed studies using CFD simulations and detail propulsion models must be conducted to draw safe conclusions.

Antcliff and Capristan [152] presented a study for the PEGASUS (Parallel Electric-Gas Architecture with Synergistic Utilization Scheme) concept, which is a regional hybrid electric aircraft utilizing wingtip propulsors and an aft-BLI propeller. The authors stated that due to high weight penalty of the additional electrical components and battery necessary, the range of the aircraft must be carefully selected to increase the number of the airports covered. The PEGASUS concept was designed with EIS 2030 and the BLI propeller along with the wingtip propulsors were used to size the main engines.

An optimization to minimize the distortion on the fan was presented by Ordaz et al. [153]. This was achieved by employing an adjoint-based design tool that can adapt its meshing process to effectively calculate the distortion. The fan distortion was calculated on the aerodynamic interface plane and was based on mass-averaged properties. The authors selected to present three different case studies and were able to show that the minimization of the distortion did not have a negative effect on the propulsive or aerodynamic benefit.The authors concluded that cases where the vertical tail-plane is causing severe distortion effects must be also evaluated in the future. At the same time, different operating points must be considered within the optimization process.

A BLI regional aircraft was presented by Brown et al. [154] and Schwartz et al. [155]. The first work focused on the aerodynamic calculations while the second work focused on aeroacoustic performance. The concept adapted within the studies was a short haul all-electric regional commuter aircraft, TailWind developed by Ampaire. It was based on a baseline 9 PAX Turboprop aircraft broadly similar to the Cessna 208 Caravan. The first work included RANS CFD studies on the duct shape. The aircraft was simulated as an axisymmetric geometry with an actuator disk that represented the BLI fan. TailWind utilized 
only one propulsive device, the BLI aft-fan. The net force was calculated using integral methods on the computational domain. Then, fan blade and stator vane design tools were employed to calculate components geometries. A parametric analysis of the duct shape was performed and showed a potential interaction between the duct and fuselage. The results from the fan design showed only a small impact on BLI performance from inlet distortion. The authors evaluated different BLI configurations and showed that the power savings ranged between 3.4 to $4.9 \%$ compared to that of an isolated conventional propulsor. The aeroacoustic analysis presented in the second work involved the development of aeroacoustic analysis tools for tonal ducted fan noise sources. The tools accuracy was estimated using a validation case. The results presented a $20 \mathrm{~dB}$ noise reduction when comparing the TailWind aircraft with a 3 blade propeller from the reference aircraft mentioned above. This improvement was dominated by the rotor-alone noise source, which included a higher blade number (7), lower rotational speed, and smaller diameter.

An overall assessment analysis for a partial turbo-electric propulsive fuselage aircraft was presented by Giannakakis et al. [156]. The analysis included the forces bookkeeping scheme proposed by Ochs [59] and was based on the isentropic velocity concept. The authors assumed three levels of thrust generated by the BLI propulsor at max-climb thrust; $10 \%, 50 \%$ and $80 \%$ and compared the designs. CFD simulations were executed for the three different designs. The flow pattern on the fan-face showed the effect of the wing wake, wing and fuselage junction and T-tail arrangement to the BLI propulsor inflow distortion. However, the authors provide minimal information on the assumptions taken for the aerodynamic calculations. Furthermore, minimal design work along the fuselage shape was carried out to employ a BLI propulsor at the aft-part of the fuselage. The main engine performance was calculated using the PROOSIS (Propulsion Object Oriented Simulation Software) environment [157]. The bypass ratio and engine diameter were varied to match the rest required thrust. The authors performed an initial fuel burn estimation based on the whole system performance using three operating points: take-off, max-climb, and mid-cruise. The authors stated that they considered the weight penalty of additional components as well as lighter underwing main engines without providing information about the weight estimation approach. The results showed that the aircraft fuel burn was increased by $2.8 \%$. It is important to note that this fuel burned estimation was based on power density of $1.9 \mathrm{hp} / \mathrm{lb}$ and total efficiency of $96.5 \%$ of the electric transmission system. These levels remained constant for all operating points under consideration. After performing optimization studies using the BLI FPR and BLI fan take-off power as variables and fuel burn as a minimization objective, the authors stated a $1.7 \%$ fuel burn increase. They performed an uncertainty analysis that led to $1.7 \pm 1 \%$ fuel burn savings. The authors finally presented the impact on the main engine performance due to the considered power off-take to power the BLI propulsor. They concluded that there might be operability issues in the fan and booster components and that it is very important to redesign the main engines based on the BLI concept requirements.

A different approach focusing on design space exploration of partial turbo-electric BLI aircraft concepts was presented by Giannakakis et al. [42]. The authors highlighted the variance found in the results available at the open-literature and conducted this study to provide useful insights on the parameters affecting the fuel burned estimation for BLI concepts. The methodology used was based on the power balance method presented by Drela [21] and was adapted for a PFC similar to the work of Hall et al. [127]. The authors introduced several ratios to transform the power balance method equations. This transformation provided an analytical method to calculate the PSC. The authors also included calculations on the rest of the propulsion system components. The fuel burn was estimated by employing exchange rates as it was described in Section 2 including three main factors: TSFC, underwing turbofan diameter and propulsion system mass. The authors highlighted the high impact of the assumptions taken for the main underwing engines and the BLI fan mass to the fuel burned estimation. Similar levels of impact were observed for the electrical system efficiency assumption. Finally, after examining a series of differ- 
ent aircraft families they concluded that regional jet and short- to medium-range aircraft can be benefited the most by the technology. The authors notes that the analytical ratios were estimated by in-house models and the work presented by Isikveren et al. [158] and Fefermann et al. [159]. However, no additional information is given on the level of fidelity and underlying assumptions of the aforementioned models.

The work of Rainer et al. [41] focused on coupling a propulsion performance model with an enhanced SLC [98] method to provide more accurate estimations of the whole system performance. The aircraft used in this study was a single-aisle, medium-range configuration accommodating 150 PAX. The technology assumptions within the models were based on EIS 2035 year and the powertrain architecture selected was the partial turboelectric. The methodology employed was to model the main operating points within the mission selected and focus on the cruise operating point to make estimations on the fuel burned changes. This estimation was based on employing exchange rates to convert cruise SFC, weight and drag changes into a respective fuel burned change. The boundary layer profile was estimated using the $1 / 7$ th power law for turbulent flat plate theory for a given set of flight conditions. The authors used the input from the boundary layer estimation to perform engine performance calculations and aerodynamic design. Additionally, the authors presented the framework of equations used within this study in an analytical way. The authors updated the efficiency equations to account for effects imposed by the BLI aft-fan and the powertrain architecture selected. Initially, a sensitivity study was presented including the variation of the power delivered to the BLI-fan and the BLI FPR selected against the ingested momentum deficit. The authors split the aft-fan performance into transfer and propulsive efficiency and highlighted that the location of the optimum FPR for maximum TSFC benefit was a trade-off between these two efficiencies. By looking into both the main engine and aft-fan efficiencies, the authors were able to explain that the overall system efficiency and TSFC benefit trends are driven from opposite sensitivities in different components. The authors concluded that the overall system efficiency improvement was mainly driven by the aft-fan. The maximum overall TSFC benefit was achievable for high thrust split ratio towards the aft-fan side. Furthermore, by employing the exchange rates mentioned above the SFC benefit was translated into mission fuel burn reduction, which was calculated to $2.2 \%$. The authors presented that a number of other factors such as additional weight and drag from the BLI aft-fan could compromise the SFC benefit.

A regional aircraft utilizing a partial turbo-electric propulsion system and an additional BLI aft-fan was studied by Secchi et al. $[160,161]$. The reference aircraft used was the Embraer E175 aircraft with $2200 \mathrm{~nm}$ range while having the capacity to carry 80 to 86 PAX. The framework employed was based on detailed models that can account for effects in aircraft performance, aerodynamics as well as engine and partial turbo-electric powertrain system efficiency and additional weight. The boundary layer profile was estimated using empirical equations of a turbulent boundary layer on a flat plate and the climb rate was kept equal between the different configurations to allow for fair comparisons. Design space exploration studies were conducted with variation of the thrust split ratio and BLI FPR. The results showed that the thrust split ratio affects the size of the fan because of increased required mass flow rate. At the same time, more boundary layer is ingested resulting in greater benefits for the propulsion system. However, the authors highlighted that a greater fan diameter might lead to higher distortion and therefore efficiency penalty. The authors showed a similar analysis for different levels of FPR. They highlighted that to take into consideration all aforementioned effects, the specific range is a better metric to give a clear picture of the optimum design choice. The authors presented that the studied concept can achieve specific air range improvement of $4-7 \%$. Their recommendation for future work was to include economical aspects into the analysis to calculate the actual economical benefit for airline companies when using this concept.

Ahuja et al. [162] presented a sensitivity study to investigate the BLI effects with respect to the airframe design. The concepts under investigation included conventional tube-and-wing geometries. The reference aircraft used was the Boeing 737-8, which has the 
capability to carry 150-180 PAX. The authors used 3D CFD models and compared different geometries to the baseline aircraft. The selected cases under investigation included the following scenarios such as different AoA, nose and fuselage shapes, fuselage aft-section design, presence of belly fairing, wing and empennage designs. For all aforementioned cases, the BLI effect was calculated using the most important terms in the power balance method proposed by Drela [21]. The results of this study showed that several parameters present important effects on the BLI design depending on the concept selected and propulsor location. Therefore, the authors highlighted that this study could be used as a base when assessing different BLI concept designs. The results could be incorporated within an aeropropulsive coupled framework by using surrogate models.

Fernadez and Smith [163] developed a new simulation technique to investigate a partial turbo-electric aircraft similar to Airbus A320 featuring two main underwing engines and a BLI aft-fan. The authors presented two cases: one studying the electric fan and airframe separately and one including both in an integrated analysis. For both cases 3D transient CFD simulations of the bare fuselage and electric fan were conducted using a sliding mesh to model the rotating fan blades. The results showed that the integrated cases led to $34 \%$ drag reduction due to different airflow along the fuselage surface imposed by the presence of an aft-mounted BLI fan. The produced thrust from the BLI fan was increased by $33 \%$. The authors highlighted large deviations in moment coefficients for the two cases. Therefore, future work should focus on optimizing the fuselage geometry while minimizing the induced moments. The authors stated that the moment variations must be assessed for the whole detailed aircraft geometry, while taking into account other operating points and coupled aero-propulsive performance to be able to assess these effects.

Sanders et al. [164] introduced a novel forces decomposition method using the mechanical energy conservation. The authors identified that the use of alternative forces bookkeeping schemes that followed a convenient separation of thrust and drag cannot provide meaningful information on how thrust is translated to useful work. The authors built their method on the concept presented by Drela [21] using the mechanical energy conservation. They presented two reference frames used to derive equations; a relative reference frame (RRF) where the aircraft is stationary and the air is moving and an absolute reference frame (ARF) for the contrary situation. The energy balance analysis of Drela was converted from RRF to ARF to create more intuitive representation of term contributions and how the kinetic energy passed to the flow is used by the propulsion system. The bookkeeping scheme format allowed for explicit calculation of the remaining force requirement that allowed for isolated studies of the airframe propulsion assembly. The proposed methodology was applied to a unpowered axisymmetric large business jet fuselage and then a BLI propulsor was fitted to the geometry. The authors used 2D RANS CFD simulations and conducted parametric studies varying the thrust split ratio, portion of ingested boundary layer and FPR. They compared their results based on the net axial force calculated and power consumption metric that compared the product of net axial force with aircraft speed to the power input. The results showed that BLI performance was better for small FPR and ingested boundary layer due to the logarithmic shape of the boundary layer profile. The thrust split was identified as very important parameter because of the reduced jet plume wake from the main engines when the BLI propulsor contribution to the overall thrust is increased.

A recent work presented by Hiebl et al. [36] investigated the potential power saving on a partial turbo-electric 19-passenger commuter aircraft featuring an aft BLI propeller. The authors employed the blade element theory to simulate the propeller using the XROTOR tool developed by Drela and Youngren. They used the Beechcraft 1900D as a reference aircraft for the assumed thrust levels and to calculate the power saving coefficient. For the BLI propeller upstream flow, the authors used the XFOIL tool developed by Drela, in which they employed the fuselage geometry to get an estimation of the boundary layer profile. Since the XFOIL tool is based on potential flow data, to derive a more realistic boundary layer profile representation, the authors used Prandtl's power law for turbulent boundary 
layer for the viscous layer and interpolated the results between the two tools. The authors estimated the PSC for a baseline BLI propeller and the results was $24 \%$ lower power requirements. However, the authors performed a second analysis where the PSC calculation was based on the system power requirements. For the non-BLI configuration, a reference configuration of two propellers operating at freestream conditions and with thrust output of $5 \mathrm{kN}$ each were simulated. The BLI configuration power requirement featured two propellers exposed to freestream flow and a BLI propeller for a total thrust requirement of $10 \mathrm{kN}$. For the partial turbo-electric powertrain system, different levels of system efficiency were tested. The results showed reduction in the system-based PSC, which ranged from $1.5 \%$ to $5 \%$ depending on the powertrain system efficiency. The authors highlighted the benefit of larger BLI propellers to the system based PSC but also recognized weight and size limitations. These were not a part of this study but were highlighted by the authors. Finally, the authors also recognized the importance of powertrain system efficiency to the system based PSC results.

\section{Conclusions}

Due to the increasing environmental concern, novel concepts related to the boundary layer ingestion technology are gaining attention in recent years. The numerous publications related to the topic present a variety of different aircraft geometries, powertrain architectures and methodologies to assess the benefits. A comprehensive literature review is presented in this work focused on the modeling approaches, main design drivers, and interpretation of the results. In the next two subsections, the main findings from the existing literature and the authors' projected vision are presented.

\subsection{Main Findings}

The publications focusing on the hybrid wing body concept reviewed within this work are presented in Table 1. One of the most important aspects identified by the initial research efforts is the strong engine-airframe interactions when introducing this concept. The need for airframe/engine coupled approaches emerges from:

- considerable differences in system performance estimation when integrated airframe/engine and clean geometries are investigated

- different inlet flow characteristics for each individual propulsor depending on the mounting location on the aircraft

- $\quad$ high circumferential and radial distortion due to the boundary layer ingestion propulsor upstream flow characteristics 
Table 1. Summary of reviewed publications focusing on HWB concepts.

\begin{tabular}{|c|c|c|c|c|c|}
\hline Concept & Refs. & Propulsion Architecture & Baseline Aircraft & Modeling Approach & Main Conclusions \\
\hline \multirow{3}{*}{$\mathrm{N} 2 \mathrm{~B}$} & [48] & $\begin{array}{l}\text { three embedded turbofan } \\
\text { engines }\end{array}$ & state-of-the-art cargo freighters & engine cycle model; engine sizing model & $25 \%$ fuel burn reduction \\
\hline & [47] & $\begin{array}{l}\text { three embedded turbofan } \\
\text { engines }\end{array}$ & HWB (clean wing) & coupled CFD and engine cycle model & presence of complex flow characteristics \\
\hline & [40] & $\begin{array}{l}\text { three or five embedded } \\
\text { turbofan engines }\end{array}$ & $\begin{array}{l}\text { baseline HWB with } \\
\text { podded engines }\end{array}$ & $\begin{array}{l}\text { tabular data for inlet and outlet field conditions; } \\
\text { engine cycle model; exchange rates }\end{array}$ & $\begin{array}{l}3-5 \% \text { fuel burn reduction; } \\
\text { require distortion tolerant fan design }\end{array}$ \\
\hline \multirow{8}{*}{ N3-X } & [51] & turbo-electric & Boeing N2 HWB & $\begin{array}{l}\text { flat-plate assumption for boundary layer; } \\
\text { engine cycle model }\end{array}$ & high coupling of aircraft and propulsion systems \\
\hline & [54] & $\begin{array}{l}\text { UHBP embedded } \\
\text { turbofan engine }\end{array}$ & Boeing N2A HWB & $\begin{array}{l}\text { CFD results from previous study; engine cycle model } \\
\text { with } 1 \% \text { and } 3 \% \text { fan efficiency penalty }\end{array}$ & $\begin{array}{c}\text { 2.4-6\% TSFC improvement; } \\
\text { fan efficiency penalty important }\end{array}$ \\
\hline & {$[55,56]$} & turbo-electric & N3-X results from [51] & $\begin{array}{l}\text { analytical calculations for BL profile; } \\
\text { engine cycle and weight model }\end{array}$ & $\begin{array}{l}\text { fuel burn benefits assuming superconducting system } \\
\text { and distortion tolerant fan }\end{array}$ \\
\hline & [57] & turbo-electric & $\begin{array}{l}\text { configuration with } \\
\text { free-stream inflow }\end{array}$ & $\begin{array}{l}\text { boundary layer profiles from [51]; } \\
\text { engine cycle model; }\end{array}$ & $\begin{array}{l}\text { thrust split, number of propulsors, propulsor } \\
\text { pressure ratio and height the capture sheet importan }\end{array}$ \\
\hline & [58] & turbo-electric & results from [51] & parallel compressor approach & $\begin{array}{l}\text { estimations on fan required power; new optimal } \\
\text { thrust split ratio and number of propulsors }\end{array}$ \\
\hline & [59] & turbo-electric & $\begin{array}{l}\text { configuration with } \\
\text { free-stream inflow }\end{array}$ & isentropic expansion of CFD results & $\begin{array}{l}4.2 \% \text { propulsive efficiency benefit; importance of an } \\
\text { aero-mechanics model noted }\end{array}$ \\
\hline & [61] & embedded turbofan engine & on-wing blade design & investigation of Campbell and Goodman diagrams & importance of reshaping reference blade \\
\hline & [67] & turbo-electric & $\begin{array}{l}\text { configuration with } \\
\text { free-stream inflow }\end{array}$ & $\begin{array}{l}\text { 1D BL theory model; engine cycle model; } \\
\text { use of net propulsive force }\end{array}$ & $\begin{array}{l}\text { sizing of all propulsors at design point; different } \\
\text { sizing due to different inflow conditions }\end{array}$ \\
\hline \multirow{3}{*}{$\begin{array}{l}\text { Other } \\
\text { studies }\end{array}$} & [68] & $\begin{array}{l}\text { embedded engines with } \\
\text { common nacelle }\end{array}$ & no & 2D CFD model & strong airframe/propulsor coupling effects \\
\hline & [69] & series of embedded fans & $\begin{array}{l}\text { configuration with } \\
\text { free-stream inflow }\end{array}$ & parallel compressor approach; potential flow solver & $1-4 \%$ of PSC \\
\hline & [71] & series of embedded fans & $\begin{array}{l}\text { configuration with } \\
\text { free-stream inflow }\end{array}$ & $\begin{array}{c}\text { parallel compressor approach; mission analysis; } \\
\text { engine cycle model }\end{array}$ & $\begin{array}{c}\text { need for a framework that can combine different leve } \\
\text { of fidelity tools }\end{array}$ \\
\hline
\end{tabular}


A summary of the reviewed publications focusing on rear mounted engine(s) concepts is presented in Table 2. The research efforts employing this concept focused on:

- $\quad$ use of the power balance method; a reduced jet dissipation due to lower propulsor kinetic energy and reduced wake dissipation due to the re-energized wake are the main drivers of the boundary layer ingestion benefit

- due to the energy conservation, the mechanical flow power is expected to be lower

- $\quad$ the estimated mechanical flow power is used as the metric to compare boundary layer ingestion and conventional concepts

- $\quad$ use of a propulsor efficiency penalty as a modeling assumption

- $\quad$ initial experimental studies are conducted that confirm simulation results of the D8 concept aircraft

- $\quad$ initial noise emission assessments showed higher noise levels with the aft-radiated fan noise dominating the overall system noise.

The research efforts focusing on the propulsive fuselage concept are summarized in Tables 3 and 4. The research groups employing NASA's STARC-ABL concepts focuses on:

- $\quad$ identify the need of tightly coupled airframe/propulsor approaches

- the transition from the CFD model to the propulsion model is carefully investigated due to possible force inconsistencies

- $\quad$ highlight the importance of including the wing and tail geometry in the CFD studies because of potential ingestion of wing and tail downwash by the boundary layer ingestion propulsor

- $\quad$ include aspects from the rest of the powertrain system in the studies as the aeropropulsive analysis is affected by the efficiency of the powertrain system

- $\quad$ highlight the importance of boundary layer ingestion propulsor inflow distortion due to different total pressure levels on the top and bottom parts of the fuselage

- $\quad$ identify the effect of flow distortion to propulsor efficiency and weight

- $\quad$ perform optimization studies to minimize the inflow distortion, while highlighting a trade-off between the accepted propulsor distortion levels and resulting boundary layer ingestion propulsor power requirements

Studies within the CENTRELINE and DISPURSAL projects presented other important aspects:

- $\quad$ as fully coupled multidisciplinary optimization are impractical and time consuming, individual optimizations per component using objectives directly translated to toplevel aircraft requirements are a good first step

- $\quad$ use of reduced order models to integrate each component to a main framework to produce fast solutions while the main trends of the system are captured

- $\quad$ present a unified force bookkeeping scheme that has the possibility to include tools from different level of fidelity while the conceptual design is progressing

- $\quad$ noise assessments showed lower noise levels due to different overall aircraft geometry and design of the main underwing mounted engines 
Table 2. Summary of reviewed publications focusing on rear engine(s) mounted concepts.

\begin{tabular}{|c|c|c|c|c|c|}
\hline Concept & Refs. & Propulsion Architecture & Baseline Aircraft & Modeling Approach & Main Conclusions \\
\hline \multirow{8}{*}{ D8 } & {$[21]$} & embedded propulsor & podded configuration & power balance method & $\begin{array}{l}\text { analysis of different power } \\
\text { sources; identify BLI benefit }\end{array}$ \\
\hline & [72] & two embedded turbofan engines & Boeing 737-800 & $\begin{array}{c}\text { MDO framework with empirical correlations; } \\
\text { Brèguet-Coffin equation }\end{array}$ & $33 \%$ fuel burn reduction \\
\hline & [73] & two embedded turbofan engines & $\begin{array}{l}\text { unpowered and } \\
\text { podded configuration }\end{array}$ & $\begin{array}{l}\text { 3D CFD analysis of 1:11 scaled } \\
\text { D8 geometry; actuator disk }\end{array}$ & $\begin{array}{l}9 \% \text { reduction in mechanical flow due to } 6 \% \text { reduction } \\
\text { in overall dissipation }\end{array}$ \\
\hline & {$[60,74]$} & two embedded turbofan engines & $\begin{array}{c}\text { unpowered and } \\
\text { podded configuration }\end{array}$ & experimental test of 1:11 scaled D8 geometry & $\begin{array}{l}6 \% \text { reduction in electrical power; } 8.6 \% \text { reduction in } \\
\text { mechanical flow power }\end{array}$ \\
\hline & [76] & two embedded turbofan engines & podded configuration & $\begin{array}{c}\text { power balance method; experiments varying the } \\
\text { input mechanical flow power }\end{array}$ & $\begin{array}{l}\text { benefit affected by ingested dissipation, propulsor jet } \\
\text { velocity, and BLI installation }\end{array}$ \\
\hline & [77] & two embedded turbofan engines & podded configuration & $\begin{array}{l}\text { 3.5\% fan efficiency penalty; aerodynamic } \\
\text { performance and weight } \\
\text { estimation from empirical correlations }\end{array}$ & $2.8 \%$ decrease in fuel burn \\
\hline & [79] & two embedded turbofan engines & Boeing 737-800 & MDO framework; 3D CFD models & identified areas for redesign; $25 \%$ block fuel reduction \\
\hline & {$[80,81]$} & two embedded turbofan engines & podded configuration & ANOPP-Research noise estimation tool & $\begin{array}{l}15 \text { EPNdB noise penalty on } \\
\text { cumulative certification noise }\end{array}$ \\
\hline \multirow{2}{*}{ NOVA } & {$[85,91]$} & 2 embedded turbofan engines & $\begin{array}{c}\text { podded and } \\
\text { semi-buried engines }\end{array}$ & $\begin{array}{l}\text { 3D CFD studies with actuator disk; } \\
\text { exergy-based calculation }\end{array}$ & lower aircraft wake; PSC of $5 \%$ in cruise \\
\hline & {$[94,95]$} & two embedded turbofan engines & $\begin{array}{l}\text { configuration with underwing } \\
\text { mounted engines }\end{array}$ & CFD/CAA simulations & $\begin{array}{l}\text { highlight the ingestion of } \\
\text { turbulence and distorted inflow }\end{array}$ \\
\hline DRAGON & [86] & $\begin{array}{l}\text { two rear-mounted turbofan } \\
\text { engines; wing-mounted BLI fans }\end{array}$ & $\begin{array}{l}\text { conventional aircraft with same } \\
\text { technological assumptions }\end{array}$ & MDO framework & $7 \%$ fuel burn reduction \\
\hline \multirow{5}{*}{$\begin{array}{l}\text { Other } \\
\text { studies }\end{array}$} & [96] & two wake ingesting engines & podded configuration & 2D CFD axisymmetric studies & lower propulsive power requirements \\
\hline & [97] & embedded engines & uniform inflow baseline fan & $\begin{array}{l}\text { in-house SLC approach; 3D CFD simulations with } \\
\text { fully turbulent flat-plate BL profile }\end{array}$ & $\begin{array}{l}\text { existence of different optimal } \\
\text { points inside the design space }\end{array}$ \\
\hline & [100] & two embedded turbofan engines & A320neo aircraft with EIS 2035 & empirical models; 3D CFD studies from [97] & $1.1 \%$ block fuel reduction \\
\hline & [101] & embedded turbofan engine & uniform inflow baseline fan & 3D studies; predesign with SLC approach & design aspects that affect fan efficiency \\
\hline & {$[103,104]$} & two embedded turbofan engines & current Boeing 737-8 & $\begin{array}{l}\text { power balance method; } \\
\text { surrogate models from CFD simulations }\end{array}$ & $\begin{array}{l}\text { comparison of decoupled and coupled approach; } \\
1-6 \% \text { reduction in block fuel for couple approach }\end{array}$ \\
\hline
\end{tabular}


Table 3. Summary of reviewed publications focusing on propulsive fuselage concepts-Part I.

\begin{tabular}{|c|c|c|c|c|c|}
\hline Concept & Refs. & Propulsion Architecture & Baseline Aircraft & Modeling Approach & Main Conclusions \\
\hline \multirow[b]{2}{*}{ DISPURSAL } & [107] & aft-mounted engine & podded configuration & modified system efficiencies; CFD data from [106] & $11.7 \%$ ESAR improvement; significant power savings \\
\hline & [108-110] & aft-mounted engine & podded configuration & work based on [142]; aircraft sizing model & $\begin{array}{l}\text { highlighted main design drivers; importance of fan } \\
\text { efficiency and weight; } 12.1 \% \text { block fuel reduction }\end{array}$ \\
\hline \multirow{9}{*}{ STARC-ABL } & {$[39,114]$} & partial turbo-electric & podded configuration & 2D CFD model coupled with 1D propulsion model & highlight importance of coupled simulations \\
\hline & [117] & partial turbo-electric & podded configuration & $\begin{array}{l}\text { 2D CFD model coupled with 1D propulsion model; } \\
\text { optimization to minimize shaft power }\end{array}$ & $\begin{array}{l}\text { potential 20.2\% PSC; importance of including } \\
\text { underwing engines in the assessment }\end{array}$ \\
\hline & [118] & partial turbo-electric & clean inflow fan & 3D RANS solver for turbo-machinery & $\begin{array}{l}13 \% \text { of fuel burn savings; importance of wing } \\
\text { and tail geometry to inflow distortion }\end{array}$ \\
\hline & [119] & partial turbo-electric & no & $\begin{array}{l}\text { shape optimization study; case with body-duct and } \\
\text { one case with wing-body-duct; } \\
\text { minimize ARP1420 distortion metric }\end{array}$ & $\begin{array}{l}\text { several differences in wing, body and duct case; } \\
\text { full aircraft geometry is necessary }\end{array}$ \\
\hline & [38] & partial turbo-electric & no & $\begin{array}{l}\text { optimization CFD studies to minimize required shaft } \\
\text { power; detailed aircraft geometry; } \\
\text { 1D propulsion model }\end{array}$ & $\begin{array}{l}\text { careful force treatment required; potential } \\
\text { one-per-revolution excitation }\end{array}$ \\
\hline & [124] & partial turbo-electric & no & $\begin{array}{l}\text { optimization CFD studies to minimize required shaft } \\
\text { power for different values of } C_{F} \text { and FPR }\end{array}$ & lower FPR is favorable \\
\hline & [125] & partial turbo-electric & no & $\begin{array}{l}\text { optimization CFD studies; minimize required shaft } \\
\text { power; different levels of } C_{F} \text { and FPR; } \\
\text { distortion metric as constraint }\end{array}$ & $\begin{array}{l}\text { highlight importance of flow distortion; } \\
\text { reduced effectiveness of BLI fan }\end{array}$ \\
\hline & [126] & partial turbo-electric & podded configuration & $\begin{array}{l}\text { geometry optimization studies; } \\
\text { investigate different mission points }\end{array}$ & $\begin{array}{l}\text { highlighted the effect of Mach number, } \\
\text { AoA and altitude }\end{array}$ \\
\hline & [127] & partial turbo-electric & $\begin{array}{l}\text { conventional tube-and-wing } \\
\text { aircraft }\end{array}$ & signomial programming optimization framework & $\begin{array}{l}0.5 \% \text { increase in fuel burn; } \\
\text { importance of modular framework }\end{array}$ \\
\hline \multirow{6}{*}{ CENTRELINE } & [131] & partial turbo-electric & conventional 2035 aircraft & $\begin{array}{l}\text { parametric studies of main engines and aft-BLI fan; } \\
\text { data from previous investigations }\end{array}$ & $\begin{array}{c}\text { true impact of BLI concept can be investigated with } \\
\text { integrated assessments }\end{array}$ \\
\hline & [22] & partial turbo-electric & conventional aircraft (EIS 2035) & $\begin{array}{l}\text { development of a consistent } \\
\text { forces bookkeeping scheme }\end{array}$ & $\begin{array}{l}\text { importance of integrating tools based on different } \\
\text { levels of fidelity }\end{array}$ \\
\hline & [23] & partial turbo-electric & uniform inflow fan design & experimental testing; redesign of BLI fan blades & $0.5-1 \%$ fan efficiency penatly \\
\hline & [132] & partial turbo-electric & conventional aircraft (EIS 2035) & MDO framework; integrate different tools & block-fuel, OEW and MTOW trade-offs \\
\hline & [35] & partial turbo-electric & conventional aircraft (EIS 2035) & 2D axisymmetric simulations & identify power split as key parameter; \\
\hline & [133] & partial turbo-electric & baseline PFC geometry & $\begin{array}{c}\text { parametric 2D CFD studies; } \\
\text { development of surrogate models }\end{array}$ & $\begin{array}{l}\text { design guidelines for PFC geometry; need for 3D } \\
\text { geometry and shape optimization }\end{array}$ \\
\hline
\end{tabular}


Table 4. Summary of reviewed publications focusing on propulsive fuselage concepts-Part II.

\begin{tabular}{|c|c|c|c|c|c|}
\hline Concept & Refs. & Propulsion Architecture & Baseline Aircraft & Modeling Approach & Main Conclusions \\
\hline \multirow{3}{*}{ CENTRELINE } & [134] & partial turbo-electric & $\begin{array}{l}\text { conventional aircraft (EIS } \\
\text { 2035) }\end{array}$ & $\begin{array}{l}\text { system-level performance at cruise point; } \\
\text { semi-empirical aerodynamic calculations }\end{array}$ & $3.6 \%$ reduced fuel burn for $57 \%$ captured BL \\
\hline & [135] & partial turbo-electric & axisymmetric PFC geometry & $\begin{array}{l}\text { investigation of fuselage } \\
\text { upsweep with 3D CFD studies }\end{array}$ & $\begin{array}{l}\text { increasing upsweep angle leads to lower BLI } \\
\text { performance; importance of other operating } \\
\text { points }\end{array}$ \\
\hline & [136] & aft-BLI fan & bare fuselage geometry & $\begin{array}{l}\text { experimental studies (PIV); power balance } \\
\text { method }\end{array}$ & $\begin{array}{l}\text { significant effect of BLI fan to the upstream and } \\
\text { downstream flow-field }\end{array}$ \\
\hline \multirow{10}{*}{ Other studies } & {$[31]$} & propeller in body's wake & uniform flow propeller & $\begin{array}{l}\text { propulsive efficiency analysis; } \\
\text { Brèguet-Coffin equation }\end{array}$ & $\begin{array}{l}\text { higher potential range; lower available kinetic } \\
\text { energy }\end{array}$ \\
\hline & [146] & full-electric & turboprop aircraft & analytical calculations & $25 \%$ benefit in energy efficiency \\
\hline & [147] & aft-mounted BLI propulsor & Boeing 737-800 & 2D axisymmetric CFD studies & power savings of $81-85 \%$ can be achieved \\
\hline & [149] & $\begin{array}{l}\text { propulsor in the body's } \\
\text { wake }\end{array}$ & no & experimental and 3D CFD studies & reduced required power for same net axial force \\
\hline & {$[150]$} & thin haul PFC aircraft & no & mathematical analysis using an actuator model & $\begin{array}{l}\text { importance of velocity deficit parameter and } \\
\text { overall energy efficiency }\end{array}$ \\
\hline & [151] & propeller in body's wake & $\begin{array}{l}\text { twin-turbo propeller aircraft } \\
\text { (EIS 2035) }\end{array}$ & $\begin{array}{l}\text { BL profile from } 1 / 7 \text { th power law; investigated } \\
\text { thrust split and BLI propeller loading }\end{array}$ & BLI presented negligible benefits \\
\hline & [152] & $\begin{array}{l}\text { hybrid-electric aircraft; } \\
\text { aft-BLI propeller }\end{array}$ & ATR 42-500 aircraft & FLOPS-based method; different tools integrated & importance of synergistic benefits \\
\hline & [153] & aft-mounted BLI fan & baseline BLI geometry & $\begin{array}{l}\text { optimization to minimize the distortion on the } \\
\text { fan }\end{array}$ & vertical tail-plane increases distortion levels \\
\hline & {$[154,155]$} & all-electric & podded configuration & RANS CFD studies & $\begin{array}{l}\text { power savings ranged between } 3.4 \text { to } 4.9 \% \text {; } \\
\qquad 20 \mathrm{~dB} \text { noise reduction }\end{array}$ \\
\hline & [156] & partial turbo-electric & $\begin{array}{l}\text { conventional } \\
\text { aircraft with two engines }\end{array}$ & $\begin{array}{l}\text { three levels of BLI thrust; CFD simulations; } \\
\text { main engine redesign }\end{array}$ & $\begin{array}{l}2.8 \% \text { fuel burn increase; } 1.7 \% \text { fuel } \\
\text { burn increase after optimization }\end{array}$ \\
\hline
\end{tabular}


Table 4. Cont.

\begin{tabular}{|c|c|c|c|c|c|}
\hline Concept & Refs. & Propulsion Architecture & Baseline Aircraft & Modeling Approach & Main Conclusions \\
\hline \multirow{6}{*}{ Other studies } & [42] & partial turbo-electric & conventional aircraft & analytic calculations; in-house models & $\begin{array}{l}\text { promising concepts are regional jet and short to } \\
\text { medium-range aircraft }\end{array}$ \\
\hline & {$[41]$} & partial turbo-electric & baseline aircraft (EIS 2035) & $\begin{array}{l}\text { flat plate BL profile; engine cycle performance; } \\
\text { SLC approach }\end{array}$ & $\begin{array}{l}\text { design guidelines for BLI fans; } 2.2 \% \text { block fuel } \\
\text { benefit }\end{array}$ \\
\hline & {$[160,161]$} & partial turbo-electric & Embraer E175 aircraft & $\begin{array}{l}\text { empirical correlations for BL profile; } \\
\text { integrated framework }\end{array}$ & specific air range improvement of $4-7 \%$ \\
\hline & {$[162]$} & partial turbo-electric & Boeing 737-8 & power balance method; 3D CFD models & design guidelines for BLI concept \\
\hline & $\begin{array}{l}{[163]} \\
{[164]}\end{array}$ & $\begin{array}{l}\text { partial turbo-electric } \\
\text { aft-mounted BLI fan }\end{array}$ & $\begin{array}{l}\text { clean inflow fan } \\
\text { no }\end{array}$ & $\begin{array}{l}\text { 3D transient CFD simulations } \\
\text { power balance method; 2D CFD models }\end{array}$ & $\begin{array}{l}\text { low FPR favorable; importance of thrust split } \\
\text { low FPR favorable; importance of thrust split }\end{array}$ \\
\hline & [36] & partial turbo-electric & clean inflow propeller & $\begin{array}{l}\text { blade element theory; } \\
\text { potential and } 1 / 7 \text { power law BL }\end{array}$ & use of system level PSC; 1.5 to $5 \%$ power saving \\
\hline
\end{tabular}


A chronological order illustration showing the start and finish publication dates of the most intensively boundary layer ingestion concepts studied in the open literature is presented in Figure 11. An interesting aspect emerging from this timeline illustration is that initial research efforts focused on radically changed aircraft concepts, moving away from the traditional tube-and-wing aircraft geometry. However, as the assessment studies progressed over the years, the focus was shifted towards retrofitting the technology and, in parallel, alternative powertrain architectures in existing or mildly re-designed aircraft geometries.

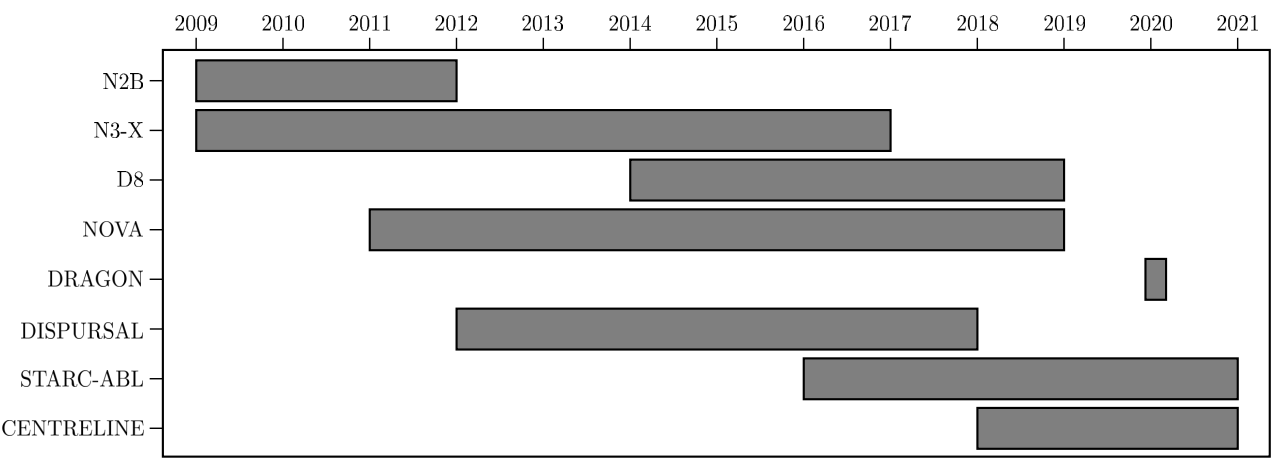

Figure 11. Timeline of most intensively studied boundary layer ingestion concepts.

The research community recognizes the need to investigate the airframe/propulsor integrated performance. Therefore, the uninstalled performance of boundary layer ingestion propulsion systems cannot give comprehensive conclusions. The recent advances in computational methods led to the current research efforts to focus on:

- $\quad$ more complex computational models focusing on aerodynamic simulations

- development of computational matching schemes to consider the airframe/engine interaction

- due to the increased computational cost, the majority of approaches are focused on showcasing the theoretical benefits of this technology and were not extensively used for design space exploration studies.

However, it is observed that each modeling approach is tailored to the focus of each research group. Most of the existing schemes are applicable to a limited range of configurations while considering simplifying assumptions. Benefit estimations are application-specific and are affected by the chosen level of fidelity. These elements must be carefully considered when interpreting the results.

An important trade-off is identified between the aero-propulsive benefit and the detrimental effect of inlet distortion and low momentum on propulsor efficiency. Therefore, in the recent years, the development of aeromechanical models to investigate the structural integrity of distortion tolerant propulsors is highlighted. The structural models for the additional components required for the realization of such applications will shed light on the potential cabin vibration issues that could be caused by the location of the boundary layer ingestion propulsor, especially for the rear engine(s) mounted and propulsive fuselage concepts.

A classification of the most intensively studied boundary layer ingestion concepts is given in Figure 12 based on the aircraft size, level of integration and powertrain architecture. This classification is based on the gathered information from the reviewed publications shown in Tables 1-4. An observation derived from the reviewed publications is that the majority of the boundary layer ingestion concepts investigated in the open-literature propose either embedded turbofan engines or the turbo-electric powertrain architecture. In the latter architecture, all available power is provided by the thermal engines. Another observation is that current research efforts focus on medium-to-long haul aircraft. The selection of the turbo-electric powertrain architecture could be related to the fact that the utilization of 
a battery component with the current technology assumptions in medium-to-long haul aircraft families leads to considerable additional weight.

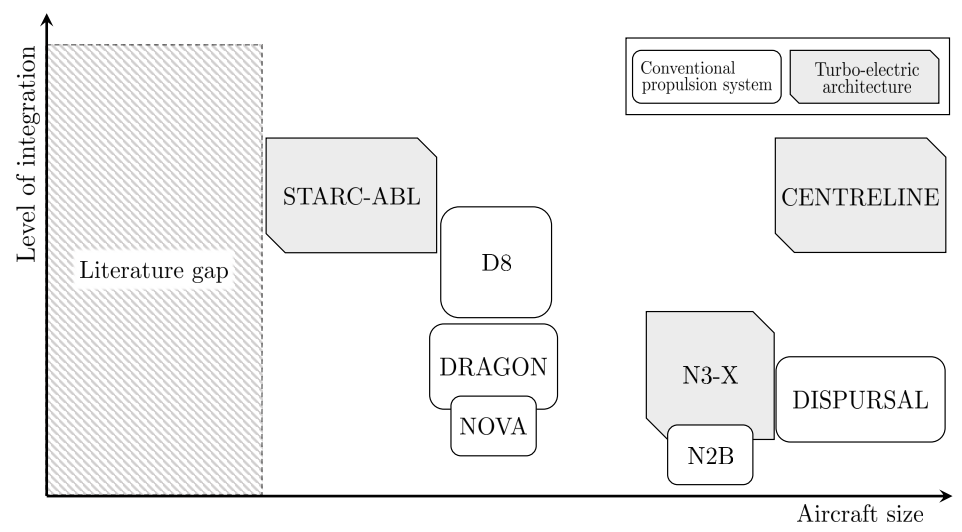

Figure 12. Classification of most intensively studied boundary layer ingestion concepts.

Additionally, most studies consider a single design point, typically the cruise condition. Until now, the research focus was to prove that in cruise condition, boundary layer ingestion technologies will lead to a benefit in terms of required power and fuel consumption. The majority of publications present comparisons between conventional (podded) and boundary layer ingestion propulsors operating in the same ambient conditions. This aspect is also related to the current focus on medium-to-long haul aircraft families, as the cruise portion is the longest mission phase. Therefore, potential performance benefits in the cruise operating point could be directly translated to mission fuel burned.

\subsection{Projected Vision}

From the aforementioned research, it was identified that the investigation of alternative propulsion architectures is an active research topic. These architectures give the possibility to introduce more than one energy sources in the system. The separation of energy sources and propulsive units provides the opportunity to investigate alternative placement positions of the powertrain system components. The placement of propulsors in different locations on the aircraft body falls into the "distributed propulsion concept" category and opens up possibilities in the aircraft control capabilities. Specifically, distributed propulsion concepts present potential when unbalanced thrust forces are caused by engine failure scenarios.

However, it was identified that there is limited research focused on the hybridelectric powertrain architecture. This architecture presents an additional energy storage component-electrical battery-compared to that of the turbo-electric architecture. The electrical battery opens up the design possibilities as it can solely provide electrical energy to the boundary layer ingestion propulsor, and it can also be charged by or boost the main engines when it is beneficial for their performance. Furthermore, the investigation of hybrid electric architectures in short-haul aircraft is an area that has a lot of potential while there are few research studies. The realization of such technologies into short-haul aircraft can unravel new trade-offs and provide more information about the physical phenomena and interactions that occur in such concepts.

To fully assess the boundary layer ingestion technology and provide meaningful insights, the proof-of-concept must be presented at the mission level. By investigating the cruise operating point in isolation, the impact of the boundary layer ingestion technology at other operating points such as the high angle of attack take-off, climb and landing will be ignored. The aircraft and propulsion system conceptual design phase is a procedure that tries to find the best and most balanced design considering performance requirements across the whole flight envelope. For the propulsive fuselage concept, the main underwing mounted gas turbine engines are aerodynamically designed for top of climb usually, which is selected due to the highest propulsor mass flow requirements in that condition. To draw 
meaningful conclusions regarding the potential technology benefits and fuel burn levels, design considerations at the mission level for the main engines need to be considered to avoid suboptimal performance. Furthermore, when assessing electrified aircraft concepts, the estimation of the energy consumption from different power sources is of major importance.

A consistent model that utilizes aircraft aerodynamic calculations while considering aspects from the propulsor and propulsion performance is important when employing boundary layer ingestion concepts. The use of higher-fidelity tools, such as computational fluid dynamics simulations is nonetheless essential. The effect of different parameters such as flight speed, altitude, angle of attack etc. shall be investigated using parametric studies of the concept under investigation as a first step. Conceptual design is an early phase of the design process and includes both design space exploration and evaluation of different design alternatives. This phase requires tools that are fast but accurate enough to evaluate different design alternatives and provide some initial estimations of system performance. Detailed 3D computational fluid dynamics analysis for each design alternative is therefore not feasible, since it is computationally demanding. The implementation of machine learning techniques such as surrogate models in a integrated framework is important to minimize the computational cost and complexity.

Moreover, the aircraft design including the effect of weight penalty due to the additional components as well as the effect of the stability margin arising from the location of different propulsors on the aircraft must be investigated and accounted apart from the aircraft performance and mission analysis. The snowball effects on the fuel burn and maximum take-off weight emerging from the boundary layer ingestion propulsors must be taken into account in a consistent manner. By employing aircraft rubberized models, it is possible to capture the snowball effects between the fuel burn and additional component weight. Investigation of fuel burn gives insights in the potential $\mathrm{CO}_{2}$ emissions reduction. However, the effect on other pollutants- $\mathrm{NO}_{X}$, soot and particulate matter - when realizing this technology is of major importance. Design space exploration and finally optimization studies using these objectives will shed light on the technology's potentials.

Finally, the introduction of additional components as well as energy sources due to the selected propulsion system architecture could affect the reliability of the system. In particular, boundary layer ingestion propulsors are exposed to unsteady and nonuniform inflow conditions. Therefore, an uncertainty analysis of the operating conditions effects to the propulsor performance is crucial for the proof of concept. Furthermore, the use of techno-economic assessments to analyze the economic performance of this technology as well as life cycle analysis to assess the environmental impact during all stages of the aircraft life cycle are of major importance for future research studies. The investigation of different aircraft families and mission ranges will also give insights on how this technology benefits are affected by the aircraft size and how the system sensitivities change.

Author Contributions: D.E.D. and K.G.K. conceptualized; D.E.D. outlined the methodology, performed the survey, analyzed the results, and wrote the paper; M.L.H. and K.G.K. reviewed the paper and supervised the work. All authors have read and agree to the published version of the manuscript.

Funding: This research was funded by European Commission under Horizon 2020 program within HECARRUS project (https:/ / hecarrus.eu/, accessed on 31 January 2022), grant number 865089.

Institutional Review Board Statement: Not applicable.

Informed Consent Statement: Not applicable.

Conflicts of Interest: The authors declare no conflict of interest. 


\section{Nomenclature}

\begin{tabular}{|c|c|}
\hline Abbreviations & \\
\hline 1D & One-Dimensional \\
\hline $2 \mathrm{D}$ & Two-Dimensional \\
\hline $3 \mathrm{D}$ & Three-Dimensional \\
\hline ACARE & Advisory Council for Aeronautics Research in Europe \\
\hline ANOPP & Aircraft NOise Prediction Program \\
\hline AoA & Angle of Attack \\
\hline ARF & Absolute Reference Frame \\
\hline BL & Boundary Layer \\
\hline BLI & Boundary Layer Ingestion \\
\hline BWB & Blended Wing Body \\
\hline CAA & Computational Aero-Acoustics \\
\hline CENTRELINE & ConcEpt validatioN sTudy foR fusElage wake-filLIng propulsioN intEgration \\
\hline CFD & Computational Fluid Dynamics \\
\hline $\mathrm{COC}$ & Cash Operating Cost \\
\hline DISPURSAL & Distributed Propulsion and Ultra-high By-Pass Rotor Study at Aircraft Level \\
\hline DMC & Direct Maintenance Cost \\
\hline DRAGON & Distributed fans and Research Aircraft with electric Generators \\
\hline DREAM & valiDation of Radical Engine Architecture systeMs \\
\hline EIS & Entry Into Service \\
\hline EPNdB & Effective Perceived Noise in deciBels \\
\hline EU & European Union \\
\hline FF & Fuselage Fan \\
\hline FFD & Free-Form Deformation \\
\hline FLOPS & Flight Optimization System \\
\hline FPR & Fan Pressure Ratio \\
\hline HP & High Pressure \\
\hline HWB & Hybrid Wing Body \\
\hline ICAO & International Civil Aviation Organization \\
\hline LP & Low Pressure \\
\hline LTO & Landing and Take-off cycle \\
\hline MDO & Multi-Disciplinary Optimization \\
\hline MFR & Mass Flow Ratio \\
\hline MIDAP & Ministry-Industry Drag Analysis Panel \\
\hline MIT & Massachusetts Institute of Technology \\
\hline MTOW & Maximum Take-off Weight \\
\hline NASA & National Aeronautics and Space Administration \\
\hline NEWAC & NEW Aero Engine Core concepts \\
\hline NOVA & Nextgen Onera Versatile Aircraft \\
\hline NPF & Net Propulsive Force \\
\hline NPSS & Numerical Propulsion System Simulation \\
\hline OEI & One Engine Inoperative \\
\hline OEW & Operating Empty Weight \\
\hline OGV & Outlet Guide Vanes \\
\hline ONERA & Office National d'Etudes et de Recherches Aerospatiales \\
\hline PAX & Passengers \\
\hline PFC & Propulsive Fuselage Concept \\
\hline PIV & Particle Image Velocimetry \\
\hline PROOSIS & Propulsion Object Oriented Simulation Software \\
\hline PSC & Power Saving Coefficient \\
\hline PSFC & Power Specific Fuel Consumption \\
\hline RANS & Reynolds-Averaged Navier Stokes \\
\hline RRF & Relative Reference Frame \\
\hline SAX & Silent Aircraft eXperimental \\
\hline
\end{tabular}




\begin{tabular}{|c|c|}
\hline SFC & Specific Fuel Consumption \\
\hline SLC & StreamLine Curvature \\
\hline STARC-ABL & Single-aisle Turboelectric Aircraft with Aft Boundary Layer propulsion \\
\hline SUGAR & Subsonic ultra Green Aircraft Research \\
\hline TASOPT & Transport Aircraft System OPTimization \\
\hline TSFC & Thrust Specific Fuel Consumption \\
\hline VITAL & EnVIronmenTALly Friendly Aero Engine \\
\hline WATE & Weight Analysis of Gas Turbine Engines \\
\hline \multicolumn{2}{|l|}{ Symbols } \\
\hline$\triangle F B \%$ & Percentage fuel burned change \\
\hline$\Delta K E_{\text {in }}$ & Kinetic energy added by the propulsor \\
\hline$\Delta X_{i} \%$ & Percentage change of parameter $X_{i}$ \\
\hline$\dot{\mathcal{E}}$ & Total energy rate \\
\hline$\dot{m}_{\text {exit }}$ & Fan exit mass flow \\
\hline$\dot{m}_{f u e l}$ & Fuel mass flow \\
\hline$\dot{m}_{\text {inlet }}$ & Fan inlet mass flow \\
\hline$\eta_{f u e l}$ & Fuel efficiency \\
\hline$\eta_{o v}$ & Overall system efficiency \\
\hline$\eta_{\text {prop }}$ & Propulsive efficiency \\
\hline$\hat{n}$ & Normal vector \\
\hline$\vec{f}_{\text {visc }}$ & Local viscous force on a infinitesimal surface element \\
\hline$\partial F B_{X_{i}} / \partial X_{i}$ & Exchange rate for parameter $X_{i}$ \\
\hline$\Phi$ & Power lost due to viscous dissipation \\
\hline$\rho_{\infty}$ & Free-stream air density \\
\hline$C_{L}$ & Coefficient of lift \\
\hline$C_{P_{K}}$ & Power coefficient \\
\hline$F$ & Thrust output \\
\hline$F_{B L I}$ & BLI force contribution \\
\hline$f_{n, P F C, \text { bare }}$ & Bare propulsive efficiency factor \\
\hline$g$ & Gravitational acceleration \\
\hline$h$ & Fuel energy density \\
\hline$k$ & Number of parameters $X_{i}$ considered \\
\hline$L / D$ & Lift to drag ratio \\
\hline$P$ & Power output \\
\hline$P_{K}$ & Net propulsor mechanical energy flow \\
\hline$p_{\infty}$ & Free-stream dynamic pressure \\
\hline$P_{\text {disc }, F F}$ & Ideal power added by the fuselage fan \\
\hline$P_{\text {out }}$ & Useful thrust power \\
\hline$P_{\text {shaft }}{ }_{B L I}$ & Shaft power required from BLI fan \\
\hline$P_{\text {shaft }}$ & Shaft power required from non-BLI fan \\
\hline$P_{\text {supply }}$ & Electrical and chemical power provided \\
\hline$P_{S}$ & Net propulsor shaft power \\
\hline$P_{V}$ & Net pressure-volume power \\
\hline$q_{\infty}$ & Free-stream dynamic pressure \\
\hline$R$ & Range \\
\hline$S_{r e f}$ & Geometric reference area \\
\hline$V_{\infty}$ & Free-stream velocity \\
\hline$V_{\text {exit }}$ & Fan exit velocity \\
\hline$V_{\text {inlet }}$ & Fan inlet velocity \\
\hline$V_{w}$ & Inflow velocity of the slipstream \\
\hline$X_{i}$ & Parameter affecting the fuel burned levels \\
\hline
\end{tabular}

\section{References}

1. Krein, A.; Williams, G. Flightpath 2050: Europe's vision for aeronautics. In Proceedings of the Innovation for Sustainable Aviation in a Global Environment: Proceedings of the Sixth European Aeronautics Days, Madrid, Spain 30 March-1 April 2011; IOS Press: Amsterdam, The Netherlands, 2012; p. 63.

2. Advisory Council for Aeronautics Research in Europe (ACARE). Strategic Research and Innovation Agenda (SRIA); Advisory Council for Aeronautics Research in Europe (ACARE): Brussels, Belgium, 2012; Volume 1, pp. 132-137. 
3. European Union Aviation Safety Agency (EASA). European Aviation Environmental Report; European Union Aviation Safety Agency (EASA): Köln, Germany, 2016.

4. Suder, K. Overview of the NASA Environmentally Responsible Aviation Project's Propulsion Technology Portfolio. In Proceedings of the 48th AIAA/ASME/SAE/ ASEE Joint Propulsion Conference \& Exhibit, Atlanta, GA, USA, 30 July-1 August 2012. [CrossRef]

5. Aeronautics, N. Strategic Implementation Plan 2017 Update; NP-2017-01-2352-HQ; National Aeronautics and Space Administration: Washington, DC, USA, 2017. Available online: https://www.nasa.gov/sites/default/files/atoms/files/sip-2017-03-23-17-high. pdf (accessed on 5 December 2021).

6. Wilfert, G.; Sieber, J.; Rolt, A.; Baker, N.; Touyeras, A.; Colantuoni, S. New Environmental Friendly Aero Engine Core Concepts; ISABE2007-1120; International Society for Air breathing Engines (ISABE): Beijing, China, 2007.

7. Korsia, J.J.; Guy, S. VITAL-European RED Programme for Greener Aero-Engines; International Society for Air Breathing Engines (ISABE): Beijing, China, 2007.

8. Bone, D. DREAM validation of radical engine architecture systems. Eur. Aerodays Madr. 2011. Available online: https: //www.cdti.es/recursos/doc/eventosCDTI/Aerodays2011/5C3.pdf (accessed on 5 December 2021).

9. Pornet, C.; Isikveren, A. Conceptual design of hybrid-electric transport aircraft. Prog. Aerosp. Sci. 2015, 79, 114-135. [CrossRef]

10. Kim, H.D. Distributed propulsion vehicles. In Proceedings of the 27 th International Congress of the Aeronautical Sciences, Nice, France, 19-24 September 2010; p. 2010-1.

11. Isikveren, A.; Seitz, A.; Bijewitz, J.; Hornung, M.; Mirzoyan, A.; Isyanov, A.; Godard, J.; Stückl, S.; Van Toor, J. Recent advances in airframe-propulsion concepts with distributed propulsion. In Proceedings of the 29th Congrees of the International Council of the Aerautical Sciences (ICAS 2014), St. Peterburg, Russia, 7-12 September 2014.

12. Felder, J.L. NASA Electric Propulsion System Studies; Technical Report GRC-E-DAA-TN28410; National Aeronautics and Space Administration (NASA): Washington, DC, USA, July 2016.

13. Wislicenu, G.F. Hydrodynamics and Propulsion of Submerged Bodies. ARS J. 1960, 30, 1140-1148. [CrossRef]

14. Gearhart, W.S.; Henderson, R.E. Selection of a Propulsor for a Submersible System. J. Aircr. 1966, 3, 84-90. [CrossRef]

15. Betz, A. Introduction to the Theory of Flow Machines; Pergamon Press: Oxford, UK, 1966. [CrossRef]

16. Smith, A.M.O.; Roberts, H.E. The Jet Airplane Utilizing Boundary Layer Air for Propulsion. J. Aeronaut. Sci. 1947, 14, 97-109. [CrossRef]

17. Smith, L.H. Wake ingestion propulsion benefit. J. Propuls. Power 1993, 9, 74-82. [CrossRef]

18. Plas, A.; Crichton, D.; Sargeant, M.; Hynes, T.; Greitzer, E.; Hall, C.; Madani, V. Performance of a Boundary Layer Ingesting (BLI) Propulsion System. In Proceedings of the 45th AIAA Aerospace Sciences Meeting and Exhibit, Reno, NV, USA, 8-11 January 2007. [CrossRef]

19. Rolt, A.; Whurr, J. Optimizing Propulsive Efficiency in Aircraft with Boundary Layer Ingesting Distributed Propulsion; ISABE-2015-20201; International Society for Airbreathing Engines (ISABE): Phoenix, AZ, USA, 2015; pp. 25-30.

20. Advisory Group For Aerospace Research \& Development. Guide to In-Flight Thrust Measurement of Turbojets and Fan Engines; Defense Technical Information Center: Fort Belvoir, VA, USA, 1979.

21. Drela, M. Power Balance in Aerodynamic Flows. AIAA J. 2009, 47, 1761-1771. [CrossRef]

22. Habermann, A.L.; Bijewitz, J.; Seitz, A.; Hornung, M. Performance bookkeeping for aircraft configurations with fuselage wake-filling propulsion integration. CEAS Aeronaut. 2020, 11, 529-551. [CrossRef]

23. Castillo Pardo, A.; Hall, C.A. Aerodynamics of Boundary Layer Ingesting Fuselage Fans. J. Turbomach. 2021, $143,041007$. [CrossRef]

24. Clarivate. Web of Science Search Engine. Available online: https://www.webofscience.com (accessed on 24 November 2021).

25. Elsevier. Scopus Search Engine. Available online: https://www.scopus.com/ (accessed on 24 November 2021).

26. Ferrar, A.; O'Brien, W. Progress in Boundary Layer Ingesting Embedded Engine Research. In Proceedings of the 48th AIAA/ASME/SAE/ASEE Joint Propulsion Conference \& Exhibit, Atlanta, GA, USA, 30 July-1 August 2012. [CrossRef]

27. Hendricks, E.S. A Review of Boundary Layer Ingestion Modeling Approaches for Use in Conceptual Design; Technical Report NASA/TM2018-219926; National Aeronautics and Space Administration (NASA): Washington, DC, USA, July 2018.

28. Menegozzo, L.; Benini, E. Boundary Layer Ingestion Propulsion: A Review on Numerical Modeling. J. Eng. Gas Turbines Power 2020, 142, 120801. [CrossRef]

29. Saravanamuttoo, H.I.H.; Rogers, G.F.C.; Cohen, H.; Straznicky, P.V. Gas Turbine Theory, 6th ed.; Pearson Prentice Hall: Harlow, UK; New York, NY, USA, 2009.

30. Seitz, A.; Schmitz, O.; Isikveren, A.T.; Hornung, M. Electrically Powered Propulsion: Comparison and Contrast to Gas Turbines; German Aerospace Congress: Berlin, Germany, 2012; Document ID: 281358.

31. Bevilaqua, P.; Yam, C. Propulsive Efficiency of Wake Ingestion. J. Propuls. Power 2020, 36, 517-526. [CrossRef]

32. Bréguet, L. Calcul du Poids de Combustible Consummé par un Avionen Vol Ascendant; Comptes Rendus Hebdomadaires des Séances del'Académie des Sciences: Paris, France, 1923.

33. Coffin, J.G. A Study of Airplane Ranges and Useful Loads; Technical Report NACA-TR-69; National Aeronautics and Space Administration (NASA): Washington, DC, USA, January 1920.

34. Cavcar, M. Bréguet Range Equation? J. Aircr. 2006, 43, 1542-1544. [CrossRef]

35. Seitz, A.; Habermann, A.L.; van Sluis, M. Optimality considerations for propulsive fuselage power savings. Proc. Inst. Mech. Eng. Part G J. Aerosp. Eng. 2021, 235, 22-39. [CrossRef] 
36. Hiebl, D. Aerodynamic Modeling and Performance Analysis of Boundary Layer Ingestion Propellers. Master's Thesis, Mälardalen University, Västerås, Sweden, 2021.

37. Blumenthal, B.T.; Elmiligui, A.A.; Geiselhart, K.A.; Campbell, R.L.; Maughmer, M.D.; Schmitz, S. Computational Investigation of a Boundary-Layer-Ingestion Propulsion System. J. Aircr. 2018, 55, 1141-1153. [CrossRef]

38. Gray, J.S.; Kenway, G.K.; Mader, C.A.; Martins, J.R.R.A. Aero-propulsive Design Optimization of a Turboelectric Boundary Layer Ingestion Propulsion System. In Proceedings of the 2018 Aviation Technology, Integration, and Operations Conference, Atlanta, GA, USA, 25-29 June 2018. [CrossRef]

39. Gray, J.S.; Mader, C.A.; Kenway, G.K.; Martins, J.R.R.A. Approach to Modeling Boundary Layer Ingestion using a Fully Coupled Propulsion-RANS Model. In Proceedings of the 58th AIAA/ASCE/AHS/ASC Structures, Structural Dynamics, and Materials Conference, Grapevine, TX, USA, 9-13 January 2017. [CrossRef]

40. Hardin, L.; Tillman, G.; Sharma, O.; Berton, J.; Arend, D. Aircraft System Study of Boundary Layer Ingesting Propulsion In Proceedings of the 48th AIAA/ASME/SAE/ASEE Joint Propulsion Conference \& Exhibit, Atlanta, GA, USA, 30 July-1 August 2012. [CrossRef]

41. Schnell, R.; Zhao, X.; Rallis, E.; Kavvalos, M.; Sahoo, S.; Schnoes, M.; Kyprianidis, K. Assessment of a Turbo-Electric Aircraft Configuration with Aft-Propulsion Using Boundary Layer Ingestion. Aerospace 2019, 6, 134. [CrossRef]

42. Giannakakis, P.; Pornet, C.; Turnbull, A. Turbo-electric propulsive fuselage aircraft BLI benefits: A design space exploration using an analytical method. Aeronaut. J. 2020, 124, 1523-1544. [CrossRef]

43. Brown, A. Ultra-Efficient Engine Technology (UEET) Program; Technical Report 20050195882; National Aeronautics and Space Administration (NASA): Washington, DC, USA, September 2013.

44. de la Rosa Blanco, E.; Hall, C.; Crichton, D. Challenges in the Silent Aircraft Engine Design. In Proceedings of the 45th AIAA Aerospace Sciences Meeting and Exhibit, Reno, NV, USA, 8-11 January 2007. [CrossRef]

45. Hileman, J.I.; Spakovszky, Z.S.; Drela, M.; Sargeant, M.A.; Jones, A. Airframe Design for Silent Fuel-Efficient Aircraft. J. Aircr. 2010, 47, 956-969. [CrossRef]

46. Kawai, R.T.; Friedman, D.M.; Serrano, L. Blended Wing Body (BWB) Boundary Layer Ingestion (BLI) Inlet Configuration and System Studies; Technical Report NASA/CR-2006-214534; National Aeronautics and Space Administration (NASA): Washington, DC, USA, September 2013.

47. Kim, H.J.; Liou, M.S. Optimal Inlet Shape Design of N2B Hybrid Wing Body Configuration. In Proceedings of the 48th AIAA/ASME/SAE/ASEE Joint Propulsion Conference \& Exhibit, Atlanta, GA, USA, 30 July-1 August 2012. [CrossRef]

48. Tong, M.; Jones, S.M.; Haller, W.J.; Handschuh, R.F. Engine Conceptual Design Studies for a Hybrid Wing Body Aircraft; Technical Report NASA/TM-2009-215680; National Aeronautics and Space Administration (NASA): Washington, DC, USA, November 2009.

49. Lytle, J.K. The Numerical Propulsion System Simulation: An Overview; Technical Report NASA/TM-2000-209915; National Aeronautics and Space Administration (NASA): Washington, DC, USA, June 2000.

50. Tong, M.T.; Naylor, B.A. An Object-Oriented Computer Code for Aircraft Engine Weight Estimation. In Proceedings of the Turbo Expo: Power for Land, Sea, and Air, Berlin, Germany, 9-13 June 2008; pp. 1-7. [CrossRef]

51. Felder, J.; Kim, H.; Brown, G. Turboelectric Distributed Propulsion Engine Cycle Analysis for Hybrid-Wing-Body Aircraft. In Proceedings of the 47th AIAA Aerospace Sciences Meeting including The New Horizons Forum and Aerospace Exposition, Orlando, FL, USA, 5-8 January 2009. [CrossRef]

52. Felder, J. NASA N3-X with Turboelectric Distributed Propulsion; Technical Report GRC-E-DAA-TN19290; National Aeronautics and Space Administration (NASA): Washington, DC, USA, November 2014.

53. Felder, J.; Kim, H.; Brown, G.; Kummer, J. An Examination of the Effect of Boundary Layer Ingestion on Turboelectric Distributed Propulsion Systems. In Proceedings of the 49th AIAA Aerospace Sciences Meeting including the New Horizons Forum and Aerospace Exposition, Orlando, FL, USA, 4-7 January 2009. [CrossRef]

54. Gladin, J.; Sands, J.; Kestner, B.; Mavris, D. Effects of Boundary Layer Ingesting (BLI) Propulsion Systems on Engine Cycle Selection and HWB Vehicle Sizing. In Proceedings of the 50th AIAA Aerospace Sciences Meeting including the New Horizons Forum and Aerospace Exposition, Nashville, TN, USA, 9-12 January 2012. [CrossRef]

55. Liu, C.; Doulgeris, G.; Laskaridis, P.; Singh, R. Turboelectric Distributed Propulsion System Modeling for Hybrid-Wing-Body Aircraft. In Proceedings of the 48th AIAA/ASME/SAE/ASEE Joint Propulsion Conference \& Exhibit, Atlanta, GA, USA, 30 July-1 August 2012. [CrossRef]

56. Liu, C.; Ihiabe, D.; Laskaridis, P.; Singh, R. A preliminary method to estimate impacts of inlet flow distortion on boundary layer ingesting propulsion system design point performance. Proc. Inst. Mech. Eng. Part G J. Aerosp. Eng. 2014, 228, 1528-1539. [CrossRef]

57. Valencia, E.A.; Nalianda, D.; Laskaridis, P.; Singh, R. Methodology to assess the performance of an aircraft concept with distributed propulsion and boundary layer ingestion using a parametric approach. Proc. Inst. Mech. Eng. Part G J. Aerosp. Eng. 2015, 229, 682-693. [CrossRef]

58. Valencia, E.A.; Liu, C.; Panagiotis, L.; Singh, R.; Nalianda, D. Performance Analysis of a Distributed Propulsion System with Boundary Layer Ingestion. In Proceedings of the 51st AIAA/SAE/ASEE Joint Propulsion Conference, Orlando, FL, USA, 27-29 July 2015. [CrossRef]

59. Ochs, S.S.; Tillman, G.; Joo, J.; Voytovych, D. CFD-based Analysis of Boundary Layer Ingesting Propulsion. In Proceedings of the 51st AIAA/SAE/ASEE Joint Propulsion Conference, Orlando, FL, USA, 27-29 July 2015. [CrossRef] 
60. Uranga, A.; Drela, M.; Greitzer, E.; Titchener, N.; Lieu, M.; Siu, N.; Huang, A.; Gatlin, G.M.; Hannon, J. Preliminary Experimental Assessment of the Boundary Layer Ingestion Benefit for the D8 Aircraft. In Proceedings of the 52nd Aerospace Sciences Meeting, National Harbor, MD, USA, 13-17 January 2014. [CrossRef]

61. Cousins, W.T.; Voytovych, D.; Tillman, G.; Gray, E. Design of a Distortion-Tolerant Fan for a Boundary-Layer Ingesting Embedded Engine Application. In Proceedings of the 53rd AIAA/SAE/ASEE Joint Propulsion Conference, Atlanta, GA, USA, 10-12 July 2017. [CrossRef]

62. Florea, R.V.; Voytovych, D.; Tillman, G.; Stucky, M.; Shabbir, A.; Sharma, O.; Arend, D.J. Aerodynamic Analysis of a Boundary-LayerIngesting Distortion-Tolerant Fan; Volume 6B: Turbomachinery, Turbo Expo: Power for Land, Sea, and Air; American Society of Mechanical Engineers: San Antonio, TX, USA, 3-7 June 2013. [CrossRef]

63. Florea, R.V.; Matalanis, C.; Hardin, L.W.; Stucky, M.; Shabbir, A. Parametric Analysis and Design for Embedded Engine Inlets. J. Propuls. Power 2015, 31, 843-850. [CrossRef]

64. Hirt, S.M.; Arend, D.J.; Wolter, J.D.; Johnson, A.M. Development of a Flow Field for Testing a Boundary-Layer-Ingesting Propulsor. In Proceedings of the 53rd AIAA/SAE/ASEE Joint Propulsion Conference, Atlanta, GA, USA, 10-12 July 2017. [CrossRef]

65. Wolter, J.; Arend, D.; Hirt, S.; Gazzaniga, J. Development of a Rotating Rake Array for Boundary-Layer-Ingesting Fan-Stage Measurements; Technical Report NASA/TM-2017-219553; National Aeronautics and Space Administration (NASA): Washington, DC, USA, December 2017.

66. Arend, D.J.; Wolter, J.D.; Hirt, S.M.; Provenza, A.; Gazzaniga, J.A.; Cousins, W.T.; Hardin, L.W.; Sharma, O. Experimental Evaluation of an Embedded Boundary Layer Ingesting Propulsor for Highly Efficient Subsonic Cruise Aircraft. In Proceedings of the 53rd AIAA/SAE/ASEE Joint Propulsion Conference, Atlanta, GA, USA, 10-12 July 2017. [CrossRef]

67. Goldberg, C.; Nalianda, D.; MacManus, D.; Pilidis, P.; Felder, J. Method for simulating the performance of a boundary layer ingesting propulsion system at design and off-design. Aerosp. Sci. Technol. 2018, 78, 312-319. [CrossRef]

68. Mantič-Lugo, V.; Doulgeris, G.; Singh, R. Computational analysis of the effects of a boundary layer ingesting propulsion system in transonic flow. Proc. Inst. Mech. Eng. Part G J. Aerosp. Eng. 2013, 227, 1215-1232. [CrossRef]

69. Budziszewski, N.; Friedrichs, J. Modeling of A Boundary Layer Ingesting Propulsor. Energies 2018, 11, 708. [CrossRef]

70. Drela, M. XFOIL: An Analysis and Design System for Low Reynolds Number Airfoils. In Low ReynoldsNumber Aerodynamics. In Proceedings of the Conference Notre Dame, Indiana, USA, 5-7 June 1989; Mueller, T.J., Ed.; Springer: Berlin/Heidelberg, Germany, 1989; pp. 1-12.

71. Gao, Z.; Smith, H. Blended Wing Body with Boundary layer Ingestion Conceptual Design in a Multidisciplinary Design Analysis Optimization Environment. In Proceedings of the AIAA Scitech 2020 Forum, Orlando, FL, USA, 6-10 January 2020; p. 1955. [CrossRef]

72. Drela, M. Development of the D8 Transport Configuration. In Proceedings of the 29th AIAA Applied Aerodynamics Conference, Honolulu, HI, USA, 27 June-30 June 2011. [CrossRef]

73. Pandya, S.A.; Uranga, A.; Espitia, A.; Huang, A. Computational Assessment of the Boundary Layer Ingesting Nacelle Design of the D8 Aircraft. In Proceedings of the 52nd Aerospace Sciences Meeting, National Harbor, MD, USA, 13-17 January 2014. [CrossRef]

74. Uranga, A.; Drela, M.; Greitzer, E.M.; Hall, D.K.; Titchener, N.A.; Lieu, M.K.; Siu, N.M.; Casses, C.; Huang, A.C.; Gatlin, G.M.; et al. Boundary Layer Ingestion Benefit of the D8 Transport Aircraft. AIAA J. 2017, 55, 3693-3708. [CrossRef]

75. Hall, D.K.; Huang, A.C.; Uranga, A.; Greitzer, E.M.; Drela, M.; Sato, S. Boundary Layer Ingestion Propulsion Benefit for Transport Aircraft. J. Propuls. Power 2017, 33, 1118-1129. [CrossRef]

76. Uranga, A.; Drela, M.; Hall, D.K.; Greitzer, E.M. Analysis of the Aerodynamic Benefit from Boundary Layer Ingestion for Transport Aircraft. AIAA J. 2018, 56, 4271-4281. [CrossRef]

77. Marien, T.; Welstead, J.R.; Jones, S.M. Vehicle Level System Impact of Boundary Layer Ingestion for the NASA D8 Concept Aircraft. In Proceedings of the 2018 AIAA Aerospace Sciences Meeting, Kissimmee, FL, USA, 8-12 January 2018. [CrossRef]

78. McCullers, L. Aircraft Configuration Optimization including Optimized Flight Profiles; Technical Report ID: 19870002310; National Aeronautics and Space Administration (NASA): Washington, DC, USA, January 1984.

79. Yutko, B.M.; Titchener, N.; Courtin, C.; Lieu, M.; Wirsing, L.; Tylko, J.; Chambers, J.T.; Roberts, T.W.; Church, C.S. Conceptual Design of a D8 Commercial Aircraft. In Proceedings of the 17th AIAA Aviation Technology, Integration, and Operations Conference, Denver, CO, USA, 5-9 June 2017. [CrossRef]

80. Clark, I.; Thomas, R.H.; Guo, Y. Aircraft System Noise Assessment of the NASA D8 Subsonic Transport Concept. In Proceedings of the 2018 AIAA/CEAS Aeroacoustics Conference, Atlanta, GA, USA, 25-29 June 2018. [CrossRef]

81. Clark, I.; Thomas, R.H.; Guo, Y. Far Term Noise Reduction Roadmap for the NASA D8 and Single-Aisle Tube-and-Wing Aircraft Concepts. In Proceedings of the 25th AIAA/CEAS Aeroacoustics Conference, Delft, The Netherlands, 20-23 May 2019. [CrossRef]

82. Lopes, L.V.; Burley, C.L. ANOPP2 User's Manual: Version 1.2; Technical Report NASA/TM-2016-219342; National Aeronautics and Space Administration (NASA): Washington, DC, USA, October 2016.

83. Office National d'Etudes et de Recherches Aérospatiales (ONERA) NOVA (Nextgen Onera Versatile Aircraft) Concept. Available online: https:/ / www.onera.fr/en/news/nova-nextgen-onera-versatile-aircraft (accessed on 5 December 2021).

84. Office National d'Etudes et de Recherches Aérospatiales (ONERA) DRAGON (Distributed Fans and Re- search Aircraft with Electric Generators) Concept. Available online: https:/ /www.onera.fr/en/news/how-can-we-reduce-fuel-consumption\%3Fdragon (accessed on 5 December 2021). 
85. Wiart, L.; Atinault, O.; Grenon, R.; Paluch, B.; Hue, D. Development of NOVA Aircraft Configurations for Large Engine Integration Studies. In Proceedings of the 33rd AIAA Applied Aerodynamics Conference, Dallas, TX, USA, 22-26 June, 2015. [CrossRef]

86. Schmollgruber, P.; Donjat, D.; Ridel, M.; Cafarelli, I.; Atinault, O.; François, C.; Paluch, B. Multidisciplinary Design and performance of the ONERA Hybrid Electric Distributed Propulsion concept (DRAGON). In Proceedings of the AIAA Scitech 2020 Forum, Orlando, FL, USA, 6-10 January 2020. [CrossRef]

87. Arntz, A. Civil Aircraft Aero-Thermo-Propulsive Performance Assessment by an Exergy Analysis of High-Fidelity CFD-RANS Flow Solutions. Ph.D. Thesis, Université de Lille 1, Villeneuve-d'Ascq, France, 2014.

88. Arntz, A.; Atinault, O.; Merlen, A. Exergy-Based Formulation for Aircraft Aeropropulsive Performance Assessment: Theoretical Development. AIAA J. 2015, 53, 1627-1639. [CrossRef]

89. Arntz, A.; Atinault, O.; Destarac, D.; Merlen, A. Exergy-based Aircraft Aeropropulsive Performance Assessment: CFD Application to Boundary Layer Ingestion. In Proceedings of the 32nd AIAA Applied Aerodynamics Conference, Atlanta, GA, USA, 16-20 June 2014. [CrossRef]

90. Arntz, A.; Atinault, O.; Destarac, D. Numerical Airframe Aerodynamic Performance Prediction: An Exergy Point of View. In Proceedings of the 49th International Symposium of Applied Aerodynamics, Lille, France, 24-26 March 2014.

91. Wiart, L.; Atinault, O.; Boniface, J.C.; Barrier, R. Aeropropulsive performance analysis of the NOVA configurations. In Proceedings of the 30th Congress of the International Council of the Aeronautical Sciences, Daejeon, Korea, 25-30 September 2016.

92. Mincu, D.C.; Garrec, T.L.; Peron, S.; Terracol, M. Immersed boundary conditions for high order CAA solvers-Aeroacoustics installation effects assessment. In Proceedings of the 23rd AIAA/CEAS Aeroacoustics Conference, Denver, CO, USA, 5-9 June 2017. [CrossRef]

93. Lorteau, M.; Wiart, L.; Kopiev, V.; Denisov, S.L. Numerical study, with experimental validation, of fan noise installation effects in Over-Wing Nacelle configuration using the Immersed Boundary Method. In Proceedings of the 25th AIAA/CEAS Aeroacoustics Conference, Delft, The Netherlands, 20-23 May 2019. [CrossRef]

94. Romani, G.; Ye, Q.; Avallone, F.; Ragni, D.; Casalino, D. Fan Noise Boundary-Layer Ingestion Installation Effects for NOVA Aircraft Configuration. In Proceedings of the 25th AIAA/CEAS Aeroacoustics Conference, Delft, The Netherlands, 20-23 May 2019. [CrossRef]

95. Romani, G.; Ye, Q.; Avallone, F.; Ragni, D.; Casalino, D. Numerical analysis of fan noise for the NOVA boundary-layer ingestion configuration. Aerosp. Sci. Technol. 2020, 96, 105532. [CrossRef]

96. Wiart, L.; Negulescu, C. Exploration of the airbus "Nautilius" engine integration concept. In Proceedings of the 31st Congress of the International Council of the Aeronautical Sciences, Belo Horizonte, Brazil, 9-14 September 2018.

97. Conceptual Fan Design for Boundary Layer Ingestion. In Turbo Expo: Power for Land, Sea, and Air; American Society of Mechanical Engineers: New York, NY USA, 2019; Volume 58578, p. V02CT41A009. [CrossRef]

98. Schnoes, M.; Nicke, E. A Database of Optimal Airfoils for Axial Compressor Throughflow Design. J. Turbomach. 2017, 139, 051008. [CrossRef]

99. Schlichting, H.; Gersten, K. Grenzschicht-Theorie; Springer: Berlin/Heidelberg, Germany, 2006.

100. Silberhorn, D.; Hollmann, C.; Mennicken, M.; Wolters, F.; Eichner, F.; Staggat, M. Overall Design and Assessment of Aircraft Concepts with Boundary Layer Ingesting Engines. In Proceedings of the Deutscher Luft-und Raumfahrtkongress, Darmstadt, Germany, 30 September-2 October 2019.

101. Mennicken, M.; Schoenweitz, D.; Schnoes, M.; Schnell, R. Fan design assessment for BLI propulsion systems. CEAS Aeronaut. J. 2021. doi: $10.1007 / \mathrm{s} 13272-021-00532-8$. [CrossRef]

102. Seitz, A.; Hübner, A.; Risse, K. The DLR TuLam project: Design of a short and medium range transport aircraft with forward swept NLF wing. CEAS Aeronaut. J. 2020, 11, 449-459. [CrossRef]

103. Ahuja, J.; Mavris, D.N. A Method for Modeling the Aero-Propulsive Coupling Characteristics of BLI Aircraft in Conceptual Design. In Proceedings of the AIAA Scitech 2021 Forum, Online, 11-15 \& 19-21 January 2021. [CrossRef]

104. Ahuja, J. A Methodology for Capturing the Aero-Propulsive Coupling Characteristics of Boundary Layer Ingesting Aircraft in Conceptual Design. Ph.D. Thesis, Georgia Institute of Technology, Atlanta, GA, USA, 2020.

105. Ahuja, J.; Mavris, D.N. Assessment of Propulsor On-Design and Off-Design Impacts on BLI Effects. In Proceedings of the AIAA Scitech 2021 Forum, Online, 11-15 \& 19-21 January 2021. [CrossRef]

106. Steiner, H.J.; Seitz, A.; Wieczorek, K.; Plötner, K.; Isikveren, A.T.; Hornung, M. Multi-disciplinary design and feasibility study of distributed propulsion systems. In Proceedings of the 28th International Congress of the Aeronautical Sciences, Brisbane, Australia, 23-28 September 2012; pp. 23-28.

107. Seitz, A.; Gologan, C. Parametric design studies for propulsive fuselage aircraft concepts. CEAS Aeronaut. J. 2015, 6, 69-82. [CrossRef]

108. Bijewitz, J.; Seitz, A.; Isikveren, A.T.; Hornung, M. Multi-disciplinary design investigation of propulsive fuselage aircraft concepts. Aircr. Eng. Aerosp. Technol. Int. J. 2016, 88, 257-267. [CrossRef]

109. Bijewitz, J.; Seitz, A.; Hornung, M.; Isikveren, A.T. Progress in Optimizing the Propulsive Fuselage Aircraft Concept. J. Aircr. 2017, 54, 1979-1989. [CrossRef]

110. Bijewitz, J.; Seitz, A.; Hornung, M. Extended Design Studies for a Mechanically Driven Propulsive Fuselage Aircraft Concept. In Proceedings of the 2018 AIAA Aerospace Sciences Meeting, Kissimmee, FL, USA, 8-12 January 2018. [CrossRef] 
111. Welstead, J.; Felder, J.L. Conceptual Design of a Single-Aisle Turboelectric Commercial Transport with Fuselage Boundary Layer Ingestion. In Proceedings of the 54th AIAA Aerospace Sciences Meeting, San Diego, CA, USA, 4-8 January 2016. [CrossRef]

112. Bradley, M.K.; Droney, C.K. Subsonic Ultra Green Aircraft Research: Phase 2. Volume 2; Hybrid Electric Design Exploration; Technical Report NASA/CR-2015-218704/VOL2; National Aeronautics and Space Administration (NASA): Washington, DC, USA, September 2015.

113. Welstead, J.; Felder, J.; Guynn, M.; Haller, B.; Tong, M.; Jones, S.; Ordaz, I.; Quinlan, J.; Mason, B. Overview of the NASA STARC-ABL (Rev. B) Advanced Concept; Technical Report NF1676L-26767; National Aeronautics and Space Administration (NASA): Washington, DC, USA, Match 2017.

114. Gray, J.S.; Mader, C.A.; Kenway, G.K.W.; Martins, J.R.R.A. Modeling Boundary Layer Ingestion Using a Coupled Aeropropulsive Analysis. J. Aircr. 2018, 55, 1191-1199. [CrossRef]

115. Gray, J. Design Optimization of a Boundary Layer Ingestion Propulsor Using a Coupled Aeropropulsive Model. Ph.D. Thesis, University of Michigan, Ann Arbor, MI, USA, 2018.

116. Gray, J.S.; Hwang, J.T.; Martins, J.R.R.A.; Moore, K.T.; Naylor, B.A. OpenMDAO: An open-source framework for multidisciplinary design, analysis, and optimization. Struct. Multidiscip. Optim. 2019, 59, 1075-1104. [CrossRef]

117. Gray, J.S.; Martins, J.R.R.A. Coupled aeropropulsive design optimisation of a boundary-layer ingestion propulsor. Aeronaut. J. 2019, 123, 121-137. [CrossRef]

118. Lee, B.J.; Liou, M.F. Aerodynamic Design and Optimization of Fan Stage for Boundary Layer Ingestion Propulsion System. In Proceedings of the 10th International Conference on Computational Fluid Dynamics, Barcelona, Spain, 9-13 July 2018.

119. Kenway, G.K.; Kiris, C.C. Aerodynamic Shape Optimization of the STARC-ABL Concept for Minimal Inlet Distortion. In Proceedings of the 2018 AIAA/ASCE/AHS/ASC Structures, Structural Dynamics, and Materials Conference, Kissimmee, FL, USA, 8-12 January 2018. [CrossRef]

120. Society of Automotive Engineers (SAE). Gas Turbine Engine Inlet Flow Distortion Guidelines; Society of Automotive Engineers (SAE): Warrendale, PA, USA, 2017. [CrossRef]

121. Hall, D.K.; Greitzer, E.M.; Tan, C.S. Analysis of Fan Stage Conceptual Design Attributes for Boundary Layer Ingestion. J. Turbomach. 2017, 139, 071012. [CrossRef]

122. Gray, J.; Chin, J.; Hearn, T.; Hendricks, E.; Lavelle, T.; Martins, J.R.R.A. Chemical-Equilibrium Analysis with Adjoint Derivatives for Propulsion Cycle Analysis. J. Propuls. Power 2017, 33, 1041-1052. [CrossRef]

123. Jasa, J.P.; Gray, J.S.; Seidel, J.; Mader, C.A.; Martins, J.R.R.A. Multipoint Variable Cycle Engine Design Using Gradient-Based Optimization. In Proceedings of the AIAA Scitech 2019 Forum, San Diego, CA, USA, 7-11 January 2019. [CrossRef]

124. Yildirim, A.; Gray, J.S.; Mader, C.A.; Martins, J.R.R.A. Aeropropulsive Design Optimization of a Boundary Layer Ingestion System. In Proceedings of the AIAA Scitech 2019 Forum, San Diego, CA, USA, 7-11 January 2019. [CrossRef]

125. Gray, J.S.; Mader, C.A.; Kenway, G.K.W.; Martins, J.R.R.A. Coupled Aeropropulsive Optimization of a Three-Dimensional Boundary-Layer Ingestion Propulsor Considering Inlet Distortion. J. Aircr. 2020, 57, 1014-1025. [CrossRef]

126. Yildirim, A.; Gray, J.S.; Mader, C.A.; Martins, J.R.R.A. Performance Analysis of Optimized STARC-ABL Designs Across the Entire Mission Profile. In Proceedings of the AIAA Scitech 2021 Forum, Online, 11-15 \& 19-21 January 2021. [CrossRef]

127. Hall, D.K.; Dowdle, A.; Gonzalez, J.; Trollinger, L.; Thalheimer, W., Assessment of a Boundary Layer Ingesting Turboelectric Aircraft Configuration using Signomial Programming. In Proceedings of the 2018 Aviation Technology, Integration, and Operations Conference, Atlanta, GA, USA, 25-29 June 2018. [CrossRef]

128. CENTRELINE. Propulsive Fuselage Concept. Available online: https://www.centreline.eu/ (accessed on 1 December 2021).

129. Seitz, A.; Peter, F.; Bijewitz, J.; Habermann, A.; Goraj, Z.; Kowalski, M.; Castillo, A.; Meller, F.; Merkler, R.; Samuelsson, S.; et al.. Concept validation study for fuselage wake-filling propulsion integration. In Proceedings of the 31st Congress of the International Council of the Aeronautical Sciences, Belo Horizonte, Brazil, 9-14 September 2018; pp. 9-14.

130. Seitz, A.; Habermann, A.L.; Peter, F.; Troeltsch, F.; Castillo Pardo, A.; Della Corte, B.; van Sluis, M.; Goraj, Z.; Kowalski, M.; Zhao, X.; et al. Proof of Concept Study for Fuselage Boundary Layer Ingesting Propulsion. Aerospace 2021, 8, 16. [CrossRef]

131. Bijewitz, J.; Seitz, A.; Hornung, M. Power Plant Pre-Design Exploration for a Turbo-Electric Propulsive Fuselage Concept. In Proceedings of the 2018 Joint Propulsion Conference, Cincinnati, OH, USA, 9-11 July 2018. [CrossRef]

132. Troeltsch, F.; Bijewitz, J.; Seitz, A. Design Trade Studies for Turbo-electric Propulsive Fuselage Integration; ISABE-2019-24141; ISABE: Canberra, Australia, 2019.

133. Habermann, A.L.; Zahn, R.; Seitz, A.; Hornung, M. Multidimensional Parametric Study of a Propulsive Fuselage Concept Using OpenFOAM. In Proceedings of the AIAA Aviation 2020 Forum, Online, 15-19 June 2020. [CrossRef]

134. Performance analysis of turbo-electric propulsion system with fuselage boundary layer ingestion. Aerosp. Sci. Technol. 2021, 109, 106412. [CrossRef]

135. Habermann, A.L.; Gokhale, A.; Hornung, M. Numerical investigation of the effects of fuselage upsweep in a propulsive fuselage concept. CEAS Aeronaut. J. 2021, 12, 173-189. [CrossRef]

136. Della Corte, B.; van Sluis, M.; Veldhuis, L.L.M.; Gangoli Rao, A. Power Balance Analysis Experiments on an Axisymmetric Fuselage with an Integrated Boundary-Layer-Ingesting Fan. AIAA J. 2021, 59, 5211-5224. [CrossRef]

137. Della Corte, B.; Perpignan, A.A.; van Sluis, M.; Rao, A.G. Experimental and Computational Analysis of Model-Support Interference in Low-Speed Wind-Tunnel Testing of Fuselage-Boundary-Layer Ingestion. In MATEC Web of Conferences; EDP Sciences: Ulys, France, 2019; Volume 304, p. 02020. [CrossRef] 
138. Van Sluis, M.; Della Corte, B.; Rao, A. Aerodynamic Design Space Exploration of a Fuselage Boundary Layer Ingesting Aircraft Concept. Centreline Deliv. 2021, Manuscript in preparation.

139. Goraj, Z.; Kowalski, M.; Goliszek, B. Optimisation of the loading structure for Propulsive Fuselage Concept. In Proceedings of the 24th International Symposium on Air Breathing Engines (ISABE Conference), Canberra, Australia, 22-27 September 2019; ISABE-2019-24193; International Society for Air Breathing Engines: Canberra, Australia, 2019; pp. $22-27$.

140. Kowalski, M.; Goraj, Z.J.; Goliszek, B. The use of FEA and semi-empirical equations for weight estimation of a passenger aircraft. Aircr. Eng. Aerosp. Technol. 2021, 93, 1412-1420. [CrossRef]

141. CS-25 European Union Aviation Safety Agency (EASA). Certification Specifications and Acceptable Means of Compliance for Large Aeroplanes; EASA: Köln, Germany, 2017.

142. Seitz, A. Advanced Methods for Propulsion System Integration in Aircraft Conceptual Design. Ph.D. Thesis, Technische Universität München, München, Germany, 2012.

143. Grönstedt, T.; Au, D.; Kyprianidis, K.; Ogaji, S. Low-Pressure System Component Advancements and Its Influence on Future Turbofan Engine Emissions. In Proceedings of the ASME Turbo Expo Turbo Expo: Power for Land, Sea, and Air, Orlando, FL, USA, 8-12 June 2009; Volume 4, pp. 505-516. [CrossRef]

144. Plötner, K.O. Operating Cost Estimation for Electric-Powered Transport Aircraft. In Proceedings of the 2013 Aviation Technology, Integration, and Operations Conference, Los Angeles, CA, USA, 12-14 August 2013. [CrossRef]

145. Plötner, K.; Wesseler, P.; Phleps, P. Identification of key aircraft and operational parameters affecting airport charges. Int. J. Aviat. Manag. 2013, 2, 91-115. [CrossRef]

146. Stückl, S.; van Toor, J.; Lobentanzer, H. VOLTAIR-the all electric propulsion concept platform-A vision for atmospheric friendly flight. In Proceedings of the 28th International Congress of the Aeronautical Sciences (ICAS), Brisbane, Australia, 23-28 September 2012.

147. Elmiligui, A.A.; Fredericks, W.J.; Guynn, M.D.; Campbell, R.L. Numerical Investigation of Fuselage Boundary Ingestion Propulsion Techniques. In Proceedings of the 2013 Aviation Technology, Integration, and Operations Conference, Los Angeles, CA, USA, 12-14 August 2013. [CrossRef]

148. Goldschmied, F.R. On the aerodynamic optimization of mini-RPV and small GA aircraft. In Proceedings of the 2nd Applied Aerodynamics Conference, Seattle, WA, USA, 21-23 August 1984. [CrossRef]

149. Carrier, G.; Atinault, O.; Grenon, R.; Verbecke, C. Numerical and Experimental Aerodynamic Investigations of Boundary Layer Ingestion for Improving Propulsion Efficiency of Future Air Transport. In Proceedings of the 31st AIAA Applied Aerodynamics Conference, San Diego, CA, USA, 24-27 June 2013. [CrossRef]

150. Mikic, G.V.; Stoll, A.M.; Bevirt, J.; Grah, R.; Moore, M.D. Fuselage Boundary Layer Ingestion Propulsion Applied to a Thin Haul Commuter Aircraft for Optimal Efficiency. In Proceedings of the 16th AIAA Aviation Technology, Integration, and Operations Conference, Washington, DC, USA, 13-17 June 2016. [CrossRef]

151. Thauvin, J.; Barraud, G.; Budinger, M.; Leray, D.; Roboam, X.; Sareni, B. Hybrid Regional Aircraft: A Comparative Review of New Potentials Enabled by Electric Power. In Proceedings of the 52nd AIAA/SAE/ASEE Joint Propulsion Conference, Salt Lake City, UT, USA, 25-27 July 2016; pp. 1-15.

152. Antcliff, K.R.; Capristan, F.M. Conceptual Design of the Parallel Electric-Gas Architecture with Synergistic Utilization Scheme (PEGASUS) Concept. In Proceedings of the 18th AIAA/ISSMO Multidisciplinary Analysis and Optimization Conference, Denver, CO, USA, 5-9 June 2017. [CrossRef]

153. Ordaz, I.; Rallabhandi, S.K.; Nielsen, E.J.; Diskin, B. Mitigation of Engine Inlet Distortion through Adjoint-Based Design. In Proceedings of the 35th AIAA Applied Aerodynamics Conference, Denver, CO, USA, 5-9 June 2017. [CrossRef]

154. Brown, K.A.; Fleming, J.L.; Langford, M.; Ng, W.; Schwartz, K.; Combs, C., Development of a Ducted Propulsor for BLI Electric Regional Aircraft-Part I: Aerodynamic Design and Analysis. In Proceedings of the AIAA Propulsion and Energy 2019 Forum, Indianapolis, IN, USA, 19-22 August 2019. [CrossRef]

155. Schwartz, K.; Burdisso, R.; Witcher, B.; Brown, K.A.; Fleming, J.L.; Combs, C., Development of a Ducted Propulsor for BLI Electric Regional Aircraft-Part II: Aeroacoustic Analysis. In Proceedings of the AIAA Propulsion and Energy 2019 Forum, Indianapolis, IN, USA, 19-22 August 2019. [CrossRef]

156. Giannakakis, P.; Maldonado, Y.B.; Tantot, N.; Frantz, C.; Belleville, M. Fuel burn evaluation of a turbo-electric propulsive fuselage aircraft. In Proceedings of the AIAA Propulsion and Energy 2019 Forum, Indianapolis, IN, USA, 19-22 August 2019 ; p. 4181. [CrossRef]

157. Bala, A.; Sethi, V.; Gatto, E.L.; Pachidis, V.; Pilidis, P. PROOSIS-A collaborative venture for gas turbine performance simulation using an object oriented programming schema. In Proceedings of the 18th ISABE Conference, Beijing, China, 2-7 September 2007; ISABE-2007-1357.

158. Isikveren, A.T.; Seitz, A.; Bijewitz, J.; Mirzoyan, A.; Isyanov, A.; Grenon, R.; Atinault, O.; Godard, J.L.; Stückl, S. Distributed propulsion and ultra-high by-pass rotor study at aircraft level. Aeronaut. J. 2015, 119, 1327-1376. [CrossRef]

159. Fefermann, Y.; Maury, C.; Level, C.; Zarati, K.; Salanne, J.P.; Pornet, C.; Thoraval, B.; Isikveren, A.T. Hybrid-Electric motive power systems for commuter transport applications. In Proceedings of the 30th Congress of the International Council of the Aeronautical Sciences, Daejeon, Korea, 25-30 September 2016; pp. 25-30.

160. Secchi, M.; Lacava, P.; Trapp, G.; Ribeiro, R.F. Evaluation of a Regional Aircraft with Fuselage Boundary Layer Ingestion. In Proceedings of the AIAA Propulsion and Energy 2019 Forum, Indianapolis, IN, USA, 19-22 August 2019. [CrossRef] 
161. Secchi, M.; Lacava, P.T.; Trapp, L.G.; Gama Ribeiro, R.F. Evaluation of a Regional Aircraft with Boundary Layer Ingestion and Electric-Fan Propulsor. J. Aircr. 2021, 58, 1204-1215. [CrossRef]

162. Ahuja, J.; Mavris, D.N. Sensitivity of Boundary Layer Ingestion Effects to Tube and Wing Airframe Design Features. In Proceedings of the AIAA Scitech 2020 Forum, Orlando, FL, USA, 6-10 January 2020. [CrossRef]

163. Martínez Fernández, A.; Smith, H. Effect of a fuselage boundary layer ingesting propulsor on airframe forces and moments. Aerosp. Sci. Technol. 2020, 100, 105808. [CrossRef]

164. Sanders, D.S.; Laskaridis, P. Full-Aircraft Energy-Based Force Decomposition Applied to Boundary-Layer Ingestion. AIAA J. 2020, 58, 4357-4373. [CrossRef] 